University of South Carolina

Scholar Commons

Theses and Dissertations

$12-16-2013$

\title{
Modified Sodium Diuranate Process For the Recovery of Uranium From Uranium Hexafluoride Transport Cylinder Wash Solution
}

Austin Dean Meredith

University of South Carolina - Columbia

Follow this and additional works at: https://scholarcommons.sc.edu/etd

Part of the Nuclear Engineering Commons

\section{Recommended Citation}

Meredith, A. D.(2013). Modified Sodium Diuranate Process For the Recovery of Uranium From Uranium Hexafluoride Transport Cylinder Wash Solution. (Doctoral dissertation). Retrieved from https://scholarcommons.sc.edu/etd/2466

This Open Access Dissertation is brought to you by Scholar Commons. It has been accepted for inclusion in Theses and Dissertations by an authorized administrator of Scholar Commons. For more information, please contact digres@mailbox.sc.edu. 
Modified Sodium Diuranate Process for the Recovery of Uranium from Uranium Hexafluoride Transport Cylinder Wash Solution

by

Austin Dean Meredith

Bachelor of Science

University of South Carolina, 2013

Submitted in Partial Fulfillment of the Requirements

For the Degree of Master of Science in

Nuclear Engineering

College of Engineering and Computing

University of South Carolina

2013

Accepted by:

Travis W. Knight, Director of Thesis

Thad Adams, Reader

Lacy Ford, Vice Provost and Dean of Graduate Studies 
(C) Copyright by Austin Dean Meredith, 2013 All Rights Reserved. 


\section{ACKNOWLEDGEMENTS}

Special thanks to Ron Noe for his help with this project and his invaluable expertise in the fields of nuclear chemistry and chemical engineering.

Thanks to Dr. Elizabeth Bair and the Center for Elemental Mass Spectrometry at the University of South Carolina for analyzing the product and filtrate samples.

Thanks to Seung Min Lee for his assistance with the Netzsch TG 409 CD thermobalance.

Thanks to Dr. Travis W. Knight and Dr. Thad Adams for their assistance with this thesis, in time commitments, direction, scope, and feedback.

Special thanks also to my parents, Craig and Rachelle Meredith, my sister, Heather Meredith, and my wife, Meagan Meredith, without whom I would not be the man I am today.

Without any of these, this project would not have been a success. 


\begin{abstract}
Uranium hexafluoride $\left(\mathrm{UF}_{6}\right)$ containment cylinders must be emptied and washed every five years in order to undergo recertification, according to ANSI standards. During the emptying of the $\mathrm{UF}_{6}$ from the cylinders, a thin residue, or heel, of $\mathrm{UF}_{6}$ is left behind. This heel must be removed in order for recertification to take place.
\end{abstract}

To remove it, the inside of the containment cylinder is washed with acid and the resulting solution generally contains three or four kilograms of uranium. Thus, before the liquid solution can be disposed of, the uranium must be separated. A modified sodium diuranate (SDU) uranium recovery process was studied to support development of a commercial process. This process was sought to ensure complete uranium recovery, at high purity, in order that it might be reused in the nuclear fuel cycle. An experimental procedure was designed and carried out in order to verify the effectiveness of the commercial process in a laboratory setting.

The experiments involved a small quantity of dried $\mathrm{UO}_{2} \mathrm{~F}_{2}$ powder that was dosed with $3 \mathrm{wt} \% \mathrm{FeF}_{3}$ and was dissolved in water to simulate the cylinder wash solution. Each experiment series started with a measured amount of this powder mixture which was dissolved in enough water to make a solution containing about 120 gmU/liter.

The experiments involved validating the modified SDU extraction process. A potassium diuranate (KDU) process was also attempted. Very little information exists regarding such a process, so the task was undertaken to evaluate its efficacy and determine whether a potassium process yields any significant differences or advantages 
as compared to a sodium process. However, the KDU process ultimately proved ineffective and was abandoned.

Each of the experiments was organized into a series of procedures that started with the $\mathrm{UO}_{2} \mathrm{~F}_{2}$ powder being dissolved in water, and proceeded through the steps needed to first convert the uranium to a diuranate precipitate, then to a carbonate complex solution, and finally to a uranyl peroxide $\left(\mathrm{UO}_{4}\right)$ precipitate product. Evaluation of operating technique, uranium recovery efficiency, and final product purity were part of each experiment. Evaluation of a technique for removing fluoride from the diuranate precipitation byproduct filtrate using granular calcite was also included at the end of the uranium recovery testing.

It was observed that precipitation of sodium diuranate (SDU) was very nearly complete at a $\mathrm{pH}$ of $11-12$, using room temperature conditions. Uranium residuals in the filtrate ranged from 3.6 - $19.6 \mathrm{ppm}$, meaning almost complete precipitation as SDU. It was postulated and then verified that a tailing reaction occurs in the SDU precipitation, which necessitates a digestion period of about 2 hours to complete the precipitation. Further, it was shown, during this phase of the process, that a partial precipitation step at $\mathrm{pH} 5.5$ did not adequately separate iron contamination due to an overlap of uranium and iron precipitations at that condition.

Carbonate extraction of the SDU required an extended (3-4 hours) digestion at $40^{\circ} \mathrm{C}$ and $\mathrm{pH}$ 7-8 to complete, with sodium bicarbonate found to be the preferred extractant. The carbonate extraction was also proven to successfully separate the iron contamination from the uranium. 
Potassium-based chemistry did produce a potassium diuranate (KDU) analogue of SDU, but the subsequent carbonate extraction using either potassium bicarbonate or potassium carbonate proved to be too difficult and was incomplete. The potassium testing was terminated at this step.

The uranyl peroxide precipitation was found to operate best at $\mathrm{pH} 3.5-4.0$, at room temperature, and required an expected, extended digestion period of $8-10$ hours. The reaction was nearly complete at those conditions, with a filtrate residual ranging from 2.4 to $36.8 \mathrm{ppmU}$. The uranyl peroxide itself was very pure, with impurity averages at a very low $0.8 \mathrm{ppmNa}$ and $0.004 \mathrm{ppmFe}$. ASTM maximum levels are $20 \mathrm{ppmNa}$ and 150 ppmFe.

Fluoride removal from the SDU precipitation filtrate required multiple passes of the solution through a calcite bed with acid additions to adjust the $\mathrm{pH}$ back down to below 6 before each pass to allow the removal reaction to proceed. This result was a modification of the single pass technique that was planned due to the apparent shutdown of the $\mathrm{NaF} /$ calcite reaction at $\mathrm{pH}$ above about 10 .

Conclusions drawn from the testing were that the results demonstrated a workable and effective series of processing steps. Techniques developed from the tests will make uranium recovery viable when transferred to the commercial process design. 


\section{TABLE OF CONTENTS}

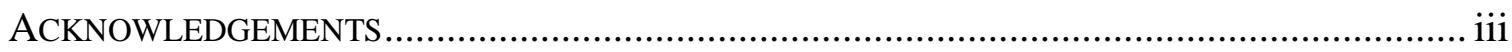

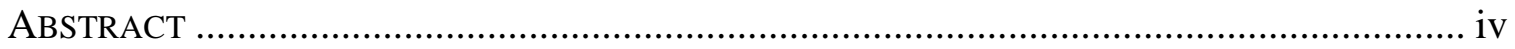

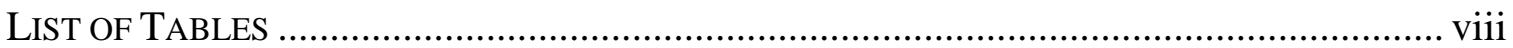

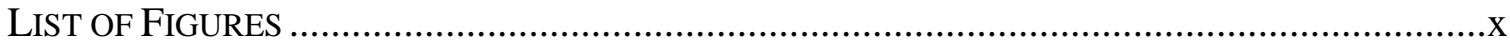

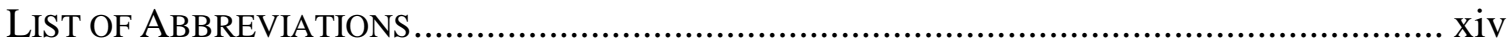

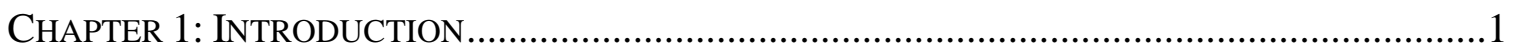

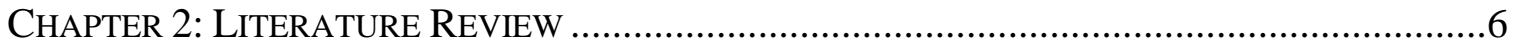

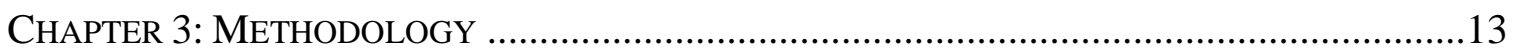

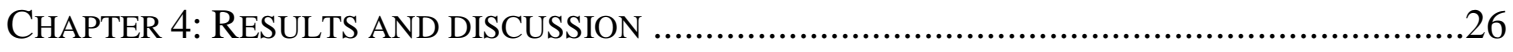

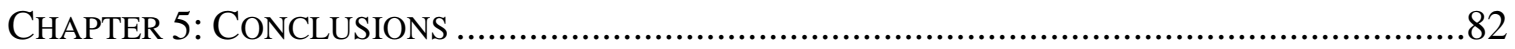

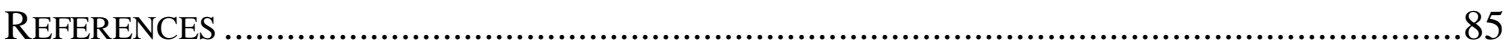




\section{LIST OF TABLES}

Table 2.1 Maximum Heel Allowed by Cylinder Type …………………………................

Table 2.2 Impurity Elements and Maximum Concentration Limits .................................10

Table 4.1 First Test Series, SDU Precipitation ..........................................................26

Table 4.2 Second Test Series, Partial Precipitation of Iron Sediment Settling...................30

Table 4.3 Second Test Series, SDU Precipitation............................................................32

Table 4.4 Second Test Series, SDU Settling, No Digestion Period.....................................33

Table 4.5 Second Test Series, SDU Settling, With Digestion Period....................................35

Table 4.6 Second Test Series, First Half, $\mathrm{UO}_{4}$ Settling Test .............................................42

Table 4.7 Second Test Series, Second Half, $\mathrm{UO}_{4}$ Settling Test.........................................44

Table 4.8 First Test Series, Auxiliary Testing, $\mathrm{UO}_{4}$ Settling...........................................46

Table 4.9 Third Test Series, KDU Precipitation...............................................................49

Table 4.10 Third Test Series, KDU Settling ..................................................................50

Table 4.11 Third Test Series, Additional KDU Settling.................................................52

Table 4.12 Third Test Series, First Uranyl Carbonate Extraction Titration .......................54

Table 4.13 Fourth Test Series, KDU Precipitation ……………………….....................59

Table 4.14 Fifth Test Series, SDU Precipitation.................................................................60

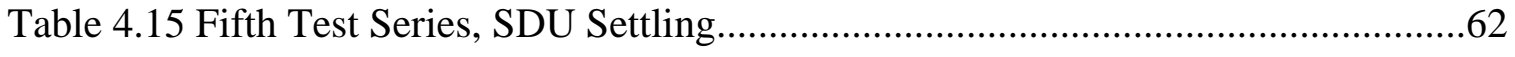

Table 4.16 Fifth Test Series, Batch 1, $\mathrm{UO}_{4}$ Precipitation ...............................................67

Table 4.17 Fifth Test Series, Batch 1, $\mathrm{UO}_{4}$ Settling .......................................................68

Table 4.18 Fifth Test Series, Batch 2, $\mathrm{UO}_{4}$ Precipitation ................................................70 
Table 4.19 Fifth Test Series, Batch 2, $\mathrm{UO}_{4}$ Settling ................................................. 70

Table 4.20 Fifth Test Series, Batch 3, $\mathrm{UO}_{4}$ Precipitation ............................................72

Table 4.21 Fifth Test Series, Batch 3, $\mathrm{UO}_{4}$ Settling ................................................. 72

Table 4.22 pH Change with Each Pass through Calcite Column ...................................75

Table 4.23 Mass $\mathrm{UO}_{4} \cdot \mathrm{nH}_{2} \mathrm{O}$ from Each Series ........................................................ 77

Table 4.24 Mass of Uranium before Recovery Process..............................................77

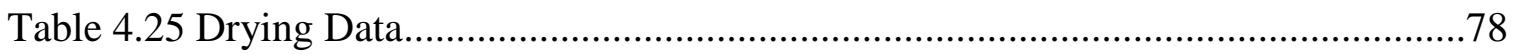

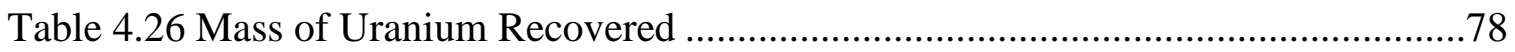

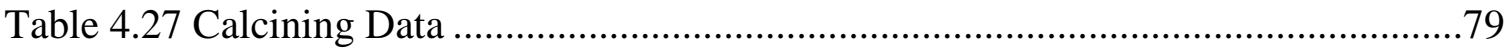

Table 4.28 Mass of Uranium Recovered through Calcination .....................................79

Table 4.29 Residual Uranium Content in $\mathrm{SDU}$ and $\mathrm{UO}_{4}$ Filtrates .................................80

Table 4.30 Sodium and Iron Contaminant Concentrations in $\mathrm{UO}_{4}$ Product .....................81 


\section{LIST OF FIGURES}

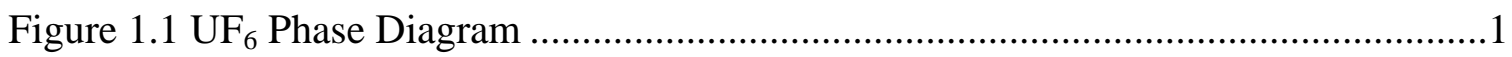

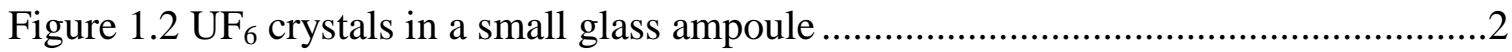

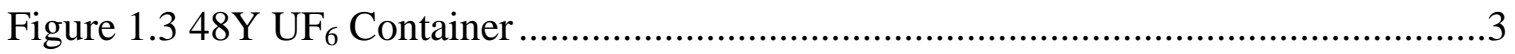

Figure 3.1 SDU Process for recovering uranium from $\mathrm{UF}_{6}$ containment

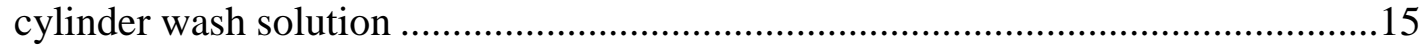

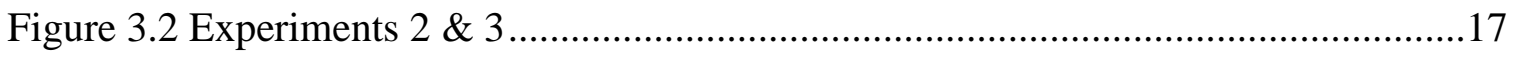

Figure 3.3 Vacuum apparatus system ............................................................... 18

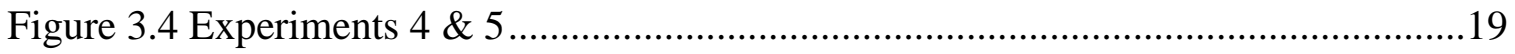

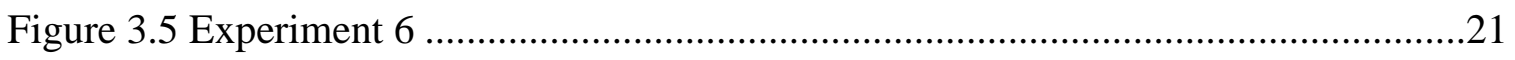

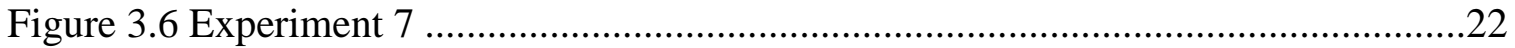

Figure 3.7 Modified Recovery Process....................................................................24

Figure 4.1 Graph of First Test Series, SDU Precipitation pH Curve,

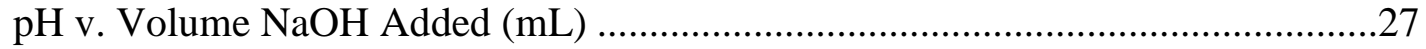

Figure 4.2 Powdered $\mathrm{UO}_{2} \mathrm{~F}_{2}$ dosed with $3 \mathrm{wt} \% \mathrm{FeF}_{3}$, and the powder

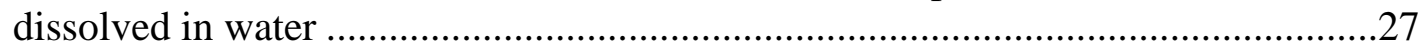

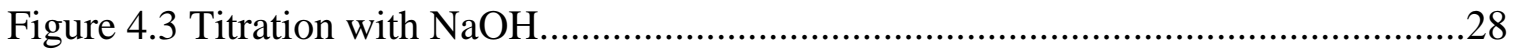

Figure 4.4 First Test Series SDU after overnight settling.......................................29

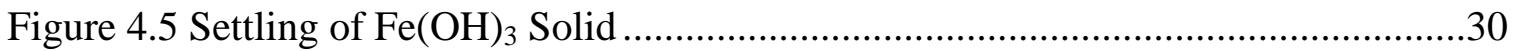

Figure 4.6 Siphoning off supernate liquid before filtering out $\mathrm{Fe}(\mathrm{OH})_{3}$ solids ................31

Figure 4.7 Graph of Second Test Series, SDU Precipitation pH Curve,

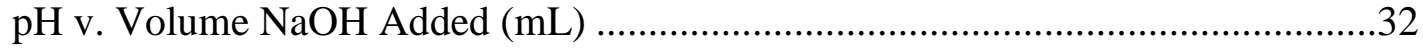


Figure 4.8 Titration set-up

Figure 4.9 SDU settling, no digestion period

Figure 4.10 Graph of the Estimated Supernate Volume (\%) over Time (min)

for Second Test Series, SDU Settling, Without a Digestion Period....

Figure 4.11 Graph of the Supernate Volume (mL) over Time (min)

for Second Test Series, SDU Settling, With 2 hour Digestion Period.......................36

Figure 4.12 Second Test Series, SDU settling after 2 hour digestion.............................36

Figure 4.13 Filtration set-up, SDU Filter Cake, SDU filtrate (NaF Solution) ...................37

Figure 4.14 SDU Filter Cake in Beaker, Sodium Carbonate/Bicarbonate mixture ( $\mathrm{pH}=10)$, Slurry of SDU and $300 \mathrm{~mL}$ of $10 \% \mathrm{Na}_{2} \mathrm{CO}_{3}$ solution .................38

Figure 4.15 Uranyl Carbonate Solution after overnight settling ..................................38

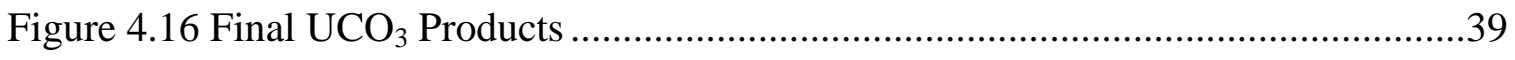

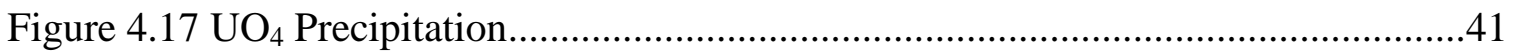

Figure 4.18 Graph of Supernate Volume (mL) over Time (min)

for Second Test Series, First Half, $\mathrm{UO}_{4}$ Settling ...............................................42

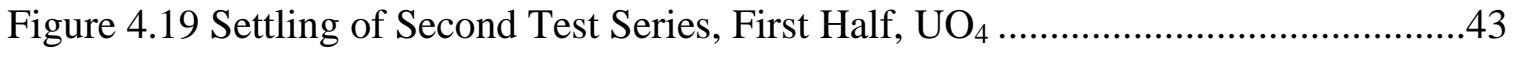

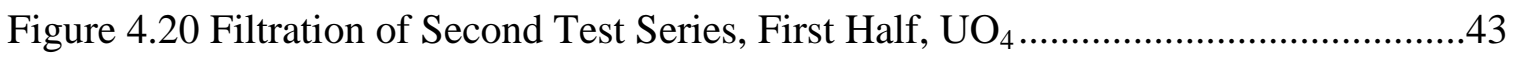

Figure 4.21 Uranyl Carbonate Solution prepared from First Test Series SDU ................46

Figure 4.22 Graph of Supernate Volume (mL) over Time (min)

for First Test Series, Auxiliary Testing, $\mathrm{UO}_{4}$ Settling ........................................47

Figure 4.23 First Test Series, Auxiliary Testing, $\mathrm{UO}_{4}$ Settling ...................................47

Figure 4.24 First Test Series, Auxiliary Testing, $\mathrm{UO}_{4}$ and filtrate ...............................48

Figure 4.25 Graph of $\mathrm{pH}$ v. Time (min) for Third Test Series, KDU Precipitation ..........50

Figure 4.26 Graph of Supernate Volume (mL) over Time (min)

for Third Test Series, KDU Precipitate Settling ................................................51

Figure 4.27 Graph of Supernate Volume (mL) over Time (min)

for Third Test Series, Additional KDU Settling ..................................................52 
Figure 4.28 Third Test Series KDU Extraction after settling.

Figure 4.29 Third Test Series, First Carbonate Extraction ..... 55

Figure 4.30 Re-slurried solids from Third Test Series, first carbonate extraction .56

Figure 4.31 Third Test Series, second carbonate extraction filtrate and Solids from second carbonate extraction, re-slurried in water. 56

Figure 4.32 Attempted third carbonate extraction 57

Figure 4.33 Third Test Series, Third Carbonate Extraction filtration 58

Figure 4.34 Graph of Fifth Test Series, SDU Precipitation pH Curve, $\mathrm{pH}$ v. Volume $\mathrm{NaOH}$ Added (mL)

Figure 4.35 Fifth Test Series SDU Precipitation .61

Figure 4.36 Graph of Volume Supernate Liquid (mL) over Time (min)

for Fifth Test Series, SDU Settling.... .62

Figure 4.37 Fifth Test Series SDU Settling.... .63

Figure 4.38 Fifth Test Series SDU Carbonate Extraction 1 .65

Figure 4.39 Fifth Test Series SDU Carbonate Extraction 2...... .65

Figure 4.40 Fifth Test Series SDU Carbonate Extraction 3.......................................66

Figure 4.41 Fifth Test Series, Batch 1, $\mathrm{UO}_{4}$ precipitation.

Figure 4.42 Graph of Volume Supernate Liquid (mL) over Time (min) for Fifth Test Series, Batch 1, $\mathrm{UO}_{4}$ Settling. .68

Figure 4.43 Fifth Test Series, Batch $1, \mathrm{UO}_{4}$ settling .69

Figure 4.44 Fifth Test Series, Batch 1, $\mathrm{UO}_{4}$ filter cake and filtrate.....

Figure 4.45 Graph of Volume of Supernate Liquid (mL) over Time (min)

for Fifth Test Series, Batch 2, $\mathrm{UO}_{4}$ Settling. .71

Figure 4.46 Fifth Test Series, Batch 2, $\mathrm{UO}_{4}$ filter cake and filtrate.

Figure 4.47 Graph of Volume of Supernate Liquid (mL) over Time (min)

for Fifth Test Series, Batch 3, $\mathrm{UO}_{4}$ Settling .73 
Figure 4.48 Fifth Test Series, Batch 3, $\mathrm{UO}_{4}$ filter cake and filtrate...............................73

Figure 4.49 Calcite column apparatus ............................................................... 74

Figure 4.50 Graph of $\mathrm{pH}$ In and $\mathrm{pH}$ Out for each pass through the calcite column ..........76 


\section{LIST OF ABBREVIATIONS}

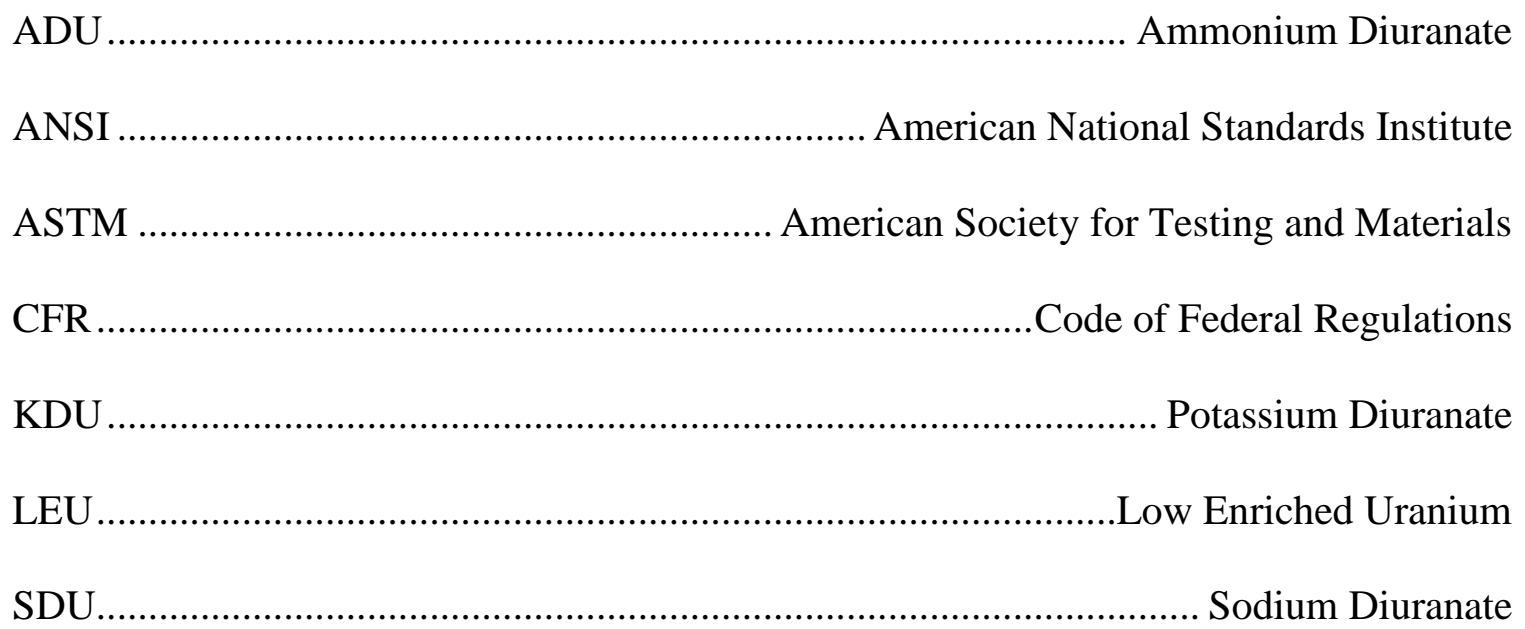




\section{CHAPTER 1: INTRODUCTION}

Uranium hexafluoride $\left(\mathrm{UF}_{6}\right)$, known in the nuclear industry as "hex," is a chemical compound used in the conversion, enrichment, transportation, and storage of uranium. It is an incredibly useful compound because it has a unique triple point, which makes it perfectly suited for most applications. The triple point of $\mathrm{UF}_{6}$ lies at a mere $64.05^{\circ} \mathrm{C}\left(147^{\circ} \mathrm{F}\right)$ and just above standard atmospheric pressure—at about 20 psia (1). Thus, it can readily be converted between its solid, liquid, and gas phases, making it easy to handle, transport, enrich, and store.

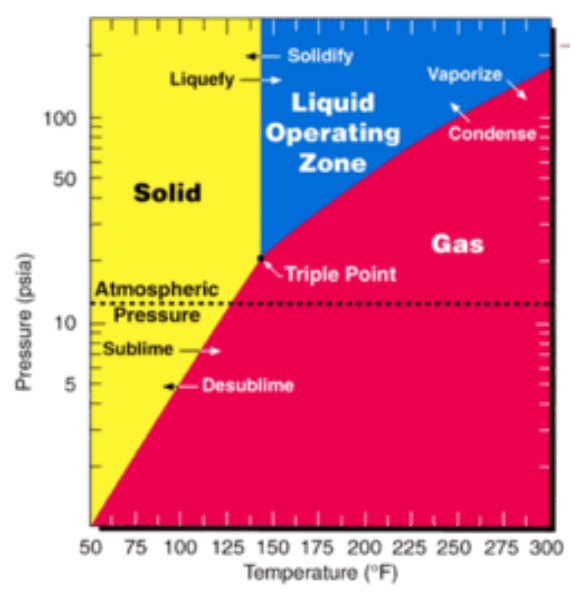

Figure 1.1 - $\mathrm{UF}_{6}$ Phase Diagram (2) 
$\mathrm{UF}_{6}$ is usually transported as a solid and then quickly converted to liquid or gas for removal from its transport container. It can then be easily put to use, most often for enrichment at gaseous diffusion or centrifuge enrichment facilities (3). Also, because there are not many uses for the large amounts of depleted uranium generated at this time, $\mathrm{UF}_{6}$ is used as a chemical means to store it long-term.

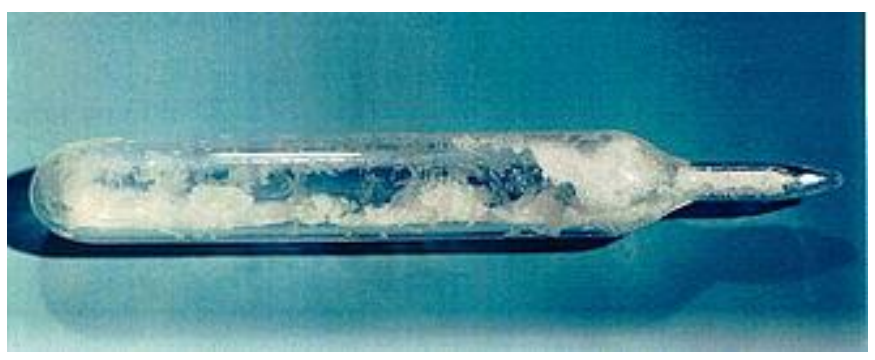

Figure $1.2-\mathrm{UF}_{6}$ crystals in a small glass ampoule (4)

As a solid, $\mathrm{UF}_{6}$ is a white, crystalline material. It is inert in dry air and will not react with oxygen, nitrogen, or carbon dioxide. However, it is highly corrosive and exceptionally reactive with water-the humidity in the air being enough for it to react. As $\mathrm{UF}_{6}$ reacts with water, it is quickly converted to uranyl fluoride $\left(\mathrm{UO}_{2} \mathrm{~F}_{2}\right)$ and hydrogen fluoride (HF). In aqueous solution, whether in water or even humid air, hydrogen fluoride forms hydrofluoric acid, which is incredibly toxic and extremely corrosive, even in low concentrations. This means that stringent measures must be taken when transporting $\mathrm{UF}_{6}$, not only to protect the public from the radiation and toxicity hazards inherent with uranium, but also from the health hazards of HF. (5)

To mitigate these risks and make the transport of $\mathrm{UF}_{6}$ safe, easy, and costeffective, special containment vessels have been designed for its shipment. These containers come in a variety of sizes depending on the enrichment of the $\mathrm{UF}_{6}$ being 
transported and the needs leading to its use. The smallest certified containers are only 1.5 inches in diameter, hold a maximum of $11 \mathrm{~b}$ of $\mathrm{UF}_{6}$, and are made of nickel or nickelcopper alloy. The largest containers are 48 inches in diameter, can hold upward of 14 metric tons of $\mathrm{UF}_{6}$, and are made of stainless steel (6). The two basic sizes that have been developed over the years to transport commercial quantities of $\mathrm{UF}_{6}$ are a 30 inch diameter cylinder that holds about 2.25 metric tons of solid $\mathrm{UF}_{6}$ (30B container), and a 48 inch diameter cylinder that holds either 10 metric tons (48X container) or 14 metric tons (48Y container) of $\mathrm{UF}_{6}$, depending on its length. The current predominant designs are the $30 \mathrm{~B}$ and $48 \mathrm{Y}$ containers.

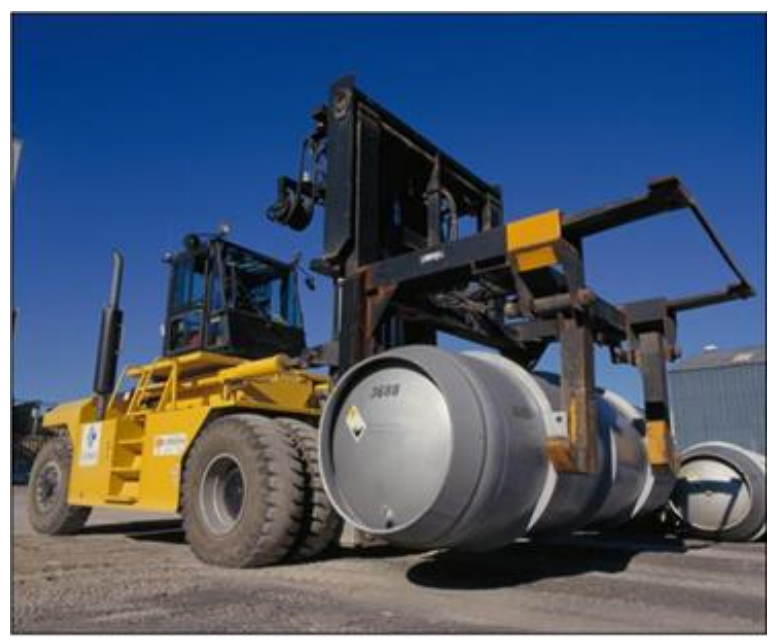

Figure $1.3-48 \mathrm{Y} \mathrm{UF}_{6}$ Container (7)

No matter the size, each of the container designs is a metal cylinder, with rounded ends, specially designed to hold solid $\mathrm{UF}_{6}$ for decades. They are designed to meet or exceed very strict ANSI regulations, and during transportation they are fitted with overpacks to help protect them in case of fire (8). 
The expected, worldwide uranium requirements for "commercial nuclear generating capacity and reactor-related uranium requirements" for 2011 were 65,180 metric tons of natural uranium, and that number is expected to increase to somewhere between 69,000 and 76,000 metric tons by 2015 (9). All of this uranium must be converted, enriched, and fabricated into fuel before it can be used, and the only way to transport it currently is in the described containment cylinders. Thousands of metric tons of $\mathrm{UF}_{6}$ are handled and transported on a yearly basis (3).

About 6,600, 30B cylinders, containing low enriched uranium (LEU, <5 wt $\%$ $235 \mathrm{U})$, are transported each year, moving $\mathrm{UF}_{6}$ from enrichment plants to fuel fabrication plants, where the $\mathrm{UF}_{6}$ is converted into $\mathrm{UO}_{2}$ for power reactor fuel. About 9,100, 48X and $48 \mathrm{Y}$ cylinders each year are used each year to transport natural $\mathrm{UF}_{6}$ from $\mathrm{UF}_{6}$ conversion plants to enrichment plants (10). About 90,000 48X, 48Y and 48G (a thinnerwalled version of the 48Y) cylinders are used for long-term storage of depleted UF6 tailings from enrichment plants. Many of this last group of cylinders have long exceeded their transport certification limit and cannot be moved out of their storage sites without special dispensation by government authorities or recertification.

The $\mathrm{UF}_{6}$ being transported is highly corrosive and poses serious health risks should it be released to the environment. So, the transport cylinders must be inspected regularly — at "intervals not to exceed 5 years" - to ensure that there are no "leaks, corrosion, cracks, bulges, dents, gouges, defective valves, damaged stiffening rings or skirts, or other conditions that, in the opinion of the qualified inspector, render it unsafe or unserviceable in its existing condition" (11). Thus, in order to maintain the credentials required for continued use as a transportation container, each of these cylinders must be 
recertified every five years, using a series of physical tests designed to demonstrate the integrity of the cylinder. Successful completion of the physical testing recertifies the cylinder for five additional years of service.

When the time comes for a container's recertification, it is first heated in order to vaporize the $\mathrm{UF}_{6}$ within so that it can be extracted from the container. Empty cylinders contain a small residue of $\mathrm{UF}_{6}$, called a "heel," which must be washed from the cylinder before testing can begin. This heel is usually $3-4 \mathrm{~kg}$ - though regulations allow for up to 22.7 $\mathrm{kg}$ - of solid $\mathrm{UF}_{6}$ that has adhered to the cylinder walls due to corrosion. Many different techniques, operating procedures, additives, and approaches to cylinder washing have been developed and are in use throughout the world, with varying degrees of efficacy. Most of these approaches involve the use of a caustic chemical wash that pulls the uranium off of the inside of the container. The wash solution must then be stripped of uranium so that it can meet disposal standards.

This study was conducted to evaluate the efficacy of a sodium diuranate process that was designed to completely remove the uranium from a cylinder wash solution, and recover it as highly pure, solid uranyl peroxide, which can be put back into the nuclear fuel cycle. 


\section{CHAPTER 2: LITERATURE REVIEW}

Title 49 of the Code of Federal Regulations, Part 173.420 (49CFR173.420) establishes the guidelines for the transportation of $\mathrm{UF}_{6}$ in the United States. This section requires that packages for the transport of $\mathrm{UF}_{6}$ must conform to American National Standard N14.1 (ANSI N14.1) (12), which sets standards for all aspects of $\mathrm{UF}_{6}$ transportation cylinders, covering everything from cylinder design and materials, to testing, certification, and transportation.

ANSI N14.1, Section 6.3.2 requires that "all cylinders shall be periodically inspected and tested throughout their service life at intervals not to exceed 5 years" and that "cylinders shall not be refilled [after each five-year interval] until they are properly reinspected, retested, and restamped." This required, periodic inspection includes internal and external examinations of the cylinder, hydrostatic strength testing, and air leak testing. Should anything about a cylinder be "found to..., in the opinion of [a] qualified inspector, render it unsafe or unserviceable," it must be removed from service for repair or replacement. (11)

Section 8.1.2 of ANSI N14.1 allows for the transport of empty $\mathrm{UF}_{6}$ cylinders that contain less than a specified weight of $\mathrm{UF}_{6}$ residue, or heel. This allowed weight varies according to container size and percent enrichment, but does not exceed a heel of $50 \mathrm{lbs}$ at $4.5 \mathrm{wt} \% \mathrm{U} 235$ - the weight allowed to be transported in $48 \mathrm{X}$ and $48 \mathrm{Y}$ containers (13). This information is given in Table 2.1. 
Table 2.1 - Maximum Heel Allowed by Cylinder Type

\begin{tabular}{|c|c|c|c|}
\hline Cylinder Model Number & Heel (lb) & Heel (kg) & Max U235, wt\% \\
\hline 5A or 5B & 0.1 & 0.045 & 100 \\
\hline 8A & 0.5 & 0.227 & 12.5 \\
\hline 12A or 12B & 1 & 0.454 & 5 \\
\hline 30B & 25 & 11.3 & 5 \\
\hline 48X & 50 & 22.7 & 4.5 \\
\hline 48Y & 50 & 22.7 & 4.5 \\
\hline 48G, 48H, 48O, 48OM & 50 & 22.7 & 1 \\
\hline Allied or 48T & 50 & 22.7 & 1 \\
\hline
\end{tabular}

However, when the time comes for recertification, the inside of the container must be thoroughly cleaned and the heel must be removed, so that the cylinder can be fully, properly, and safely inspected. The uranium heel is removed with an acidic solution, which must then be processed to recover the uranium, which can afterward be processed into a form and purity that will allow it to be reused in the nuclear fuel cycle.

Many milling processes use an acidic solution to leach uranium from its ores so that it can be processed into yellow cake. The acidic solution is treated with an alkaline solution to strip the uranium and convert it into an alkali form, which is then processed with more acid and precipitated with hydrogen peroxide into a uranium oxide yellow cake (14).

A similar process is used to convert the uranium oxide to $\mathrm{UF}_{6}$. To produce $\mathrm{UF}_{6}$, the yellow cake is dissolved in nitric acid, forming a uranyl nitrate solution. A selective solvent extraction is used to remove impurities, and the resulting, purified uranyl nitrate can then be precipitated with an alkaline solution (ammonium hydroxide, sodium 
hydroxide, potassium hydroxide, etc.) to form an alkali diuranate. This substance is then calcined, reduced, hydrofluorinated, and fluorinated in order to produce $\mathrm{UF}_{6}$. (15) The process to recover uranium from $\mathrm{AF}_{6}$ solution as a usable uranium oxide works much like the conversion process in reverse, and uses similar techniques to the milling process. A liquid, acidic $\mathrm{UF}_{6}$ solution is treated with an alkali solution to form an alkali diuranate solid. This diuranate goes through a carbonate solvent extraction, wherein the diuranate solid is mixed with a carbonate solution, to strip the uranium from any present impurities. The resulting uranyl carbonate complex can then be precipitated with hydrogen peroxide as uranyl peroxide (16), which can be calcined into usable yellow cake.

There are many processes available to convert uranium into an alkali form, but according to Murty, et al., the ammonium diuranate (ADU) process "has been the most intensively followed and investigated" (17). Sodium diuranate (SDU) processes have also been widely used, but have generally been discarded because of the potential for sodium contamination. Murty, et al., and Manna, Roy and Joshi, point out that the properties of the diuranate precursor, which are gained from the processes that make it, are passed on to the final uranium dioxide product $(17,18)$.

Since SDU and ADU are chemically analogous, it is of great benefit to understand the importance of ADU in the nuclear fuel cycle. ADU is an intermediate compound in the milling and conversion of uranium. It is generally produced by either a uranyl nitrate or a uranyl fluoride process, where the uranyl compound is reacted with a gaseous ammonia or an aqueous ammonium hydroxide. The ADU solid formed can then be filtered, dried, and calcined in air to form $\mathrm{UO}_{3}$ or $\mathrm{U}_{3} \mathrm{O}_{8}$ (18), which can then be more 
readily converted into $\mathrm{UF}_{6}$ for storage and transport or reduced to $\mathrm{UO}_{2}$ for fuel fabrication. The only thing necessary to produce SDU instead of ADU, is the use of sodium compounds as opposed to ammonium compounds (i.e. $\mathrm{NaOH}$ instead of $\left.\mathrm{NH}_{4} \mathrm{OH}\right)$.

The Triple Altura Laboratory (LTA) in Argentina uses a sodium diuranate process to recover uranium from scrap that has been generated by the manufacture of uranium/aluminum alloy fuel elements. In order to recover the nuclear material from the scrap, LTA uses a three-step process. First, the material from which the uranium is to be recovered is dissolved using $\mathrm{NaNO}_{3}$ and $\mathrm{NaOH}$ solutions. This alkaline dissolution converts the aluminum to soluble sodium aluminate and the uranium to insoluble sodium diuranate $\left(\mathrm{Na}_{2} \mathrm{U}_{2} \mathrm{O}_{7}\right)$. The second step is to separate the sodium diuranate from the liquid via filtration, and then eliminate any excess aluminum with a wash each of $\mathrm{NaOH}$ and deionized water. The solid is then, finally, dissolved with $\mathrm{HNO}_{3}$ to form an aluminumfree, uranyl nitrate solution. The process researched follows steps very similar to those used by LTA, in that an alkaline dissolution would be used to separate the impurities and uranium from the initial solution, and then a carbonate (rather than nitrate) extraction dissolution would be used to recover the uranium from the SDU. (19)

In order for uranium oxides to be used for direct hydrogen reduction to nuclear grade uranium dioxide, they must conform to the standards set forth in ASTM C1348. Table 1 of ASTM C1348 gives a list of impurity elements and their maximum allowable concentrations in the uranium if it is to be used for eventual fuel fabrication (20). This list is shown in Table 2.2. 
Table 2.2 - Impurity Elements and Maximum Concentration Limits

\begin{tabular}{|c|c|}
\hline Element & $\begin{array}{c}\text { Maximum Concentration Limit of } \\
\text { Uranium, } \mu \mathrm{g} / \mathrm{gU}\end{array}$ \\
\hline Aluminum & 50 \\
\hline Barium & 5 \\
\hline Beryllium & 100 \\
\hline Bismuth & 3 \\
\hline Calcium + Magnesium & 100 \\
\hline Carbon & 100 \\
\hline Chlorine & 100 \\
\hline Chromium & 100 \\
\hline Cobalt & 80 \\
\hline Copper & 100 \\
\hline Fluorine & 100 \\
\hline Iron & 150 \\
\hline Lead & 40 \\
\hline Manganese & 50 \\
\hline Molybdenum & 200 \\
\hline Nickel & 80 \\
\hline Phosphorus & 100 \\
\hline Silicon & 200 \\
\hline Sodium & 20 \\
\hline Tantalum & 200 \\
\hline Thorium & 10 \\
\hline Tin & 50 \\
\hline Titanium & 50 \\
\hline Tungsten & 100 \\
\hline Vanadium & 10 \\
\hline Zinc & 20 \\
\hline
\end{tabular}

The limit for sodium contaminants is $20 \mu \mathrm{g} / \mathrm{gU}$, and must be held below this level because sodium contamination can cause cracking in reactor fuel. As SDU processes use large amounts of sodium, they typically have to be carried out more slowly and have to be more carefully monitored than ADU processes in order to ensure an acceptable final product. Thus, most of the current processes use ammonia to form ADU. Since fuel conversion and fabrication facilities generally shoulder the burden of washing $\mathrm{UF}_{6}$ 
cylinders and use ammonia in their processes, an ADU process is also used to recover uranium from the $\mathrm{UF}_{6}$ cylinder wash solution.

An SDU process was designed that would recover all of the uranium from the cylinder wash solution, separate all of the iron contamination from the recovered uranium, and allow ensure sodium content less than $20 \mu \mathrm{g} / \mathrm{gU}$ in the final uranium oxide, meeting the requirements of ASTM C1348. In this process, a cylinder wash solution would be titrated with sodium hydroxide $(\mathrm{NaOH})$ to a $\mathrm{pH}$ of $4.5-5.5$, in order to remove iron contaminants. The iron would precipitate out of solution as solid ferric hydroxide $\left(\mathrm{Fe}(\mathrm{OH})_{3}\right)$, which usually precipitates at about $\mathrm{pH} 3.5(21)$. Literature indicates that the uranium should not fully precipitate as $\mathrm{SDU}\left(\mathrm{Na}_{2} \mathrm{U}_{2} \mathrm{O}_{7}\right)$ until around pH $12.0(22,23)$, allowing for full removal of the iron and subsequent precipitation of the SDU with the addition of more $\mathrm{NaOH}$. This SDU would undergo a carbonate solvent extraction with a sodium carbonate/sodium bicarbonate solution, in order to strip the uranium from any sodium impurities, as a uranyl carbonate complex solution (24). The uranium would then be precipitated out of the solution as uranyl peroxide solid $\left(\mathrm{UO}_{4} \cdot \mathrm{nH}_{2} \mathrm{O}\right)$, by titrating it with hydrogen peroxide $\left(\mathrm{H}_{2} \mathrm{O}_{2}\right)$ and nitric acid $\left(\mathrm{HNO}_{3}\right)$, which is used to keep the $\mathrm{pH}$ in the range of 2.5-5.5, which the literature suggests is the optimal range for the reaction $(16,25)$.

Since the uranyl peroxide from this process is precipitated as a hydrate, water trapped in the final solid could result in an incorrect calculation of recovered uranium if a simple mass balance is used. Thus, measures other than simply weighing, or air drying and then weighing, would have to be taken to verify complete uranium recovery, either by baking the solid product or converting it into a different, non-hydrated uranium oxide. 
Both measures were used in order to determine the mass of uranium recovered. While a temperature of 400-450C was chosen to dry the uranyl peroxide, work by Morais, et al., and Bonini, et al., showed that a temperature of at least $800^{\circ} \mathrm{C}$ was necessary to fully calcine the $\mathrm{UO}_{4} \cdot \mathrm{nH}_{2} \mathrm{O}$ and convert it to $\mathrm{U}_{3} \mathrm{O}_{8}(19,25)$. Thus it was calcined at $1000^{\circ} \mathrm{C}$ for 6 hours. 


\section{CHAPTER 3: METHODOLOGY}

A modified sodium diuranate (SDU) process was designed to extract the uranium from $\mathrm{UF}_{6}$ cylinder wash solution, carry it through a purification and conversion process, and then recover it as uranyl peroxide $\left(\mathrm{UO}_{4}\right)$ solid. An experimental procedure was developed and carried out in order to study the process and evaluate its efficacy in a laboratory setting.

The process was designed to first use sodium hydroxide to precipitate any iron contamination from the wash solution, according to Eqn. 3.1, which iron would then be filtered from the solution.

$$
\mathrm{FeF}_{3}+3 \mathrm{NaOH} \rightarrow \mathrm{Fe}(\mathrm{OH})_{3}(\mathrm{~s})+3 \mathrm{NaF}
$$

Then more sodium hydroxide would be used to precipitate the uranium out of the solution as solid SDU, following the reaction given in Eqn. 3.2.

$$
2 \mathrm{UO}_{2} \mathrm{~F}_{2}+6 \mathrm{NaOH} \rightarrow \mathrm{Na}_{2} \mathrm{U}_{2} \mathrm{O}_{7}(\mathrm{~s})+4 \mathrm{NaF}+3 \mathrm{H} 2 \mathrm{O}
$$

The intermediary precipitation of the iron was thought to be possible because the iron should react and precipitate at a much lower $\mathrm{pH}$ than the uranium. The SDU would go on to be mixed with a sodium carbonate/bicarbonate solution to extract the uranium as a uranyl carbonate complex solution ("uranyl carbonate" and " $\mathrm{UCO}_{3}$ " are used as 
shorthand notations for "uranyl carbonate complex solution throughout the study), as shown below in Eqn. 3.3.

$$
\mathrm{Na}_{2} \mathrm{U}_{2} \mathrm{O}_{7}+6 \mathrm{Na}_{2} \mathrm{CO}_{3}+3 \mathrm{H}_{2} \mathrm{O} \rightarrow 2 \mathrm{Na}_{4} \mathrm{UO}_{2}\left(\mathrm{CO}_{3}\right)_{3}+6 \mathrm{NaOH}
$$

The uranium would then be precipitated out of the carbonate solution with nitric acid and hydrogen peroxide, as solid $\mathrm{UO}_{4}$.

$$
\begin{aligned}
& \mathrm{Na}_{4} \mathrm{UO}_{2}\left(\mathrm{CO}_{3}\right)_{3}+6 \mathrm{HNO}_{3} \rightarrow \mathrm{UO}_{2}\left(\mathrm{NO}_{3}\right)_{2}+3 \mathrm{CO}_{2}+3 \mathrm{H}_{2} \mathrm{O}+4 \mathrm{NaNO}_{3} \\
& \mathrm{UO}_{2}\left(\mathrm{NO}_{3}\right)_{2}+\mathrm{H}_{2} \mathrm{O}_{2}+n \mathrm{H}_{2} \mathrm{O} \rightarrow \mathrm{UO}_{4} \cdot n \mathrm{H}_{2} \mathrm{O}(\mathrm{s})+2 \mathrm{HNO}_{3}
\end{aligned}
$$

The process was developed to extract all of the uranium from the wash solution and carry it through to the production of $\mathrm{UO}_{4}$, and the $\mathrm{UO}_{4}$ should be devoid of any iron or sodium contamination. Figure 3.1 outlines this process. 


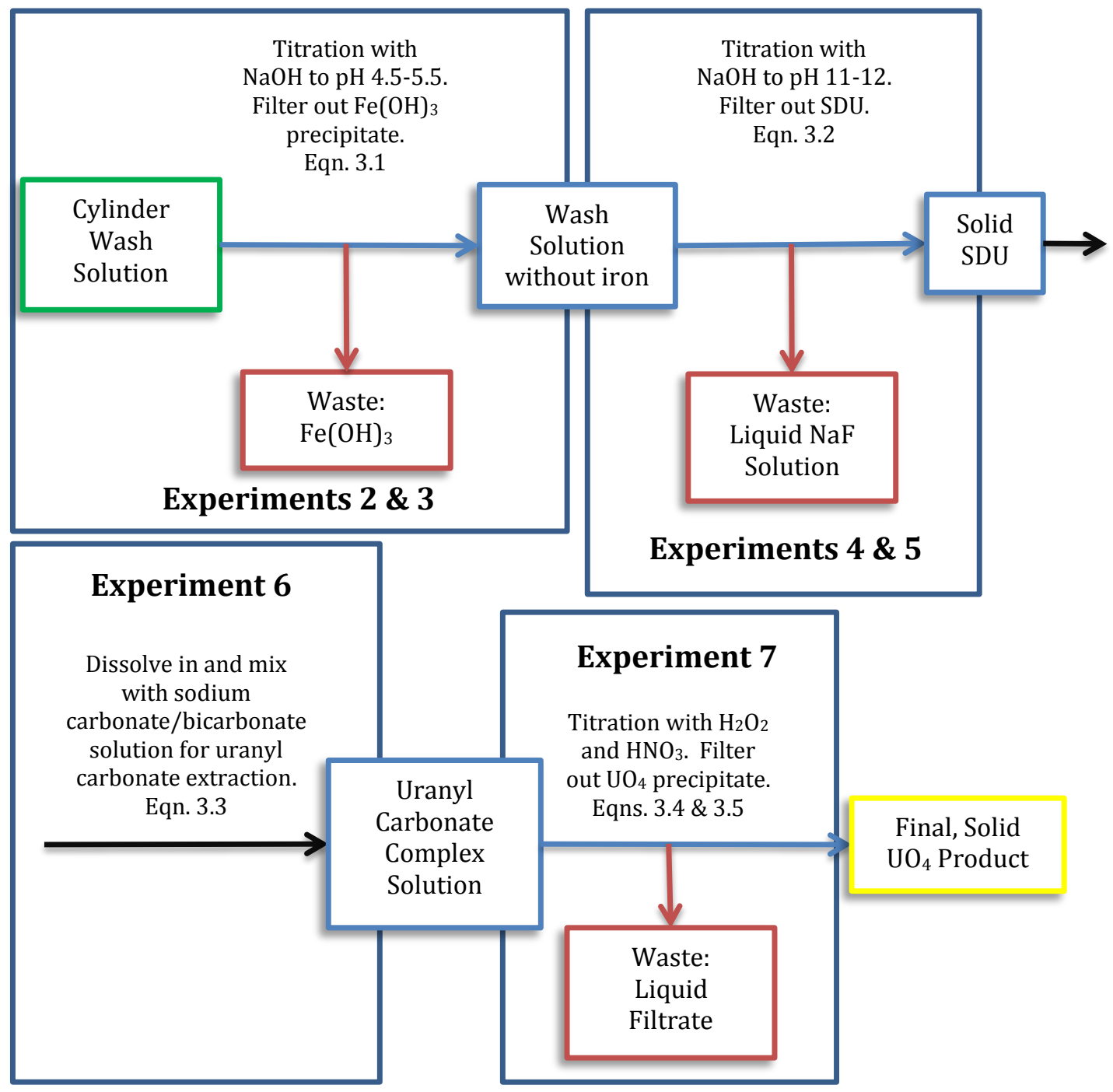

Figure 3.1 - SDU Process for recovering uranium from $\mathrm{UF}_{6}$ containment cylinder wash solution

A similar, potassium diuranate (KDU) process was also investigated, using potassium hydroxide instead of sodium hydroxide to form KDU instead of SDU, and using potassium carbonate/bicarbonate to extract the uranium as uranyl carbonate. Experimentation was carried out to see if this would make a viable recovery process.

Nine experiments were developed to evaluate these processes and gauge key information, such as precipitate settling rates and titration curves. Each experiment involved an initial quantity of dried $\mathrm{UO}_{2} \mathrm{~F}_{2}$ powder that was dosed with $3 \mathrm{wt} \% \mathrm{FeF}_{3}$ and 
was dissolved in water to simulate the cylinder wash solution. Each experimental series started with a measured amount of this powder mixture which was dissolved in enough water to make a solution containing about $120 \mathrm{~g}$ uranium per liter of solution.

All of the experiments proceeded from the preparation of simulated cylinder wash solution through the steps needed to first convert the uranium to a diuranate precipitate, then to a carbonate complex solution, and finally to a $\mathrm{UO}_{4}$ precipitate product. Evaluation of operating technique, uranium recovery efficiency, and final product purity were part of each experiment. Evaluation of a technique for removing fluoride from the diuranate precipitation byproduct filtrate using granular calcite was also included at the end of the uranium recovery testing. The nine experiments are described thusly:

\section{Experiment One}

The first experiment was to be used to develop a titration curve for the SDU precipitation reaction, and to exercise the laboratory setup and equipment for the first time. The simulated wash solution would be prepared and placed in a magneticallystirred polyethylene beaker. The solution would then be slowly titrated with $24 \% \mathrm{NaOH}$ solution, dispensed as droplets from a $100 \mathrm{~mL}$ burette that was positioned over the beaker. The $\mathrm{pH}$ of the mixture would be periodically measured with $\mathrm{p}$-Hydrion paper strips as the titration progressed, at room temperature, and it would be titrated with $\mathrm{NaOH}$ from a $\mathrm{pH}$ of about 1 to a $\mathrm{pH}$ of 11-12. The data would be collected, and a curve prepared. 


\section{Experiment Two}

The second experiment was designed to begin a run-through of the full recovery process, by first titrating the simulated wash solution to a $\mathrm{pH}$ of 4.5 . This was to be done to evaluate a partial precipitation technique for separating the iron from the uranium in the mixture. In theory, the $\mathrm{FeF}_{3}$ solid and any dissolved iron would be immediately converted to $\mathrm{Fe}(\mathrm{OH})_{3}$ solid at the first addition of $\mathrm{NaOH}$ and would remain insoluble at a $\mathrm{pH}$ lower than that at which the uranium would begin to precipitate as SDU, and this separation of the iron from the uranium was thought to be possible at a $\mathrm{pH}$ of about 4.5 . A new batch of simulated wash solution would be prepared, and the same set-up was to be used as that for the first experiment, except an $8 \% \mathrm{NaOH}$ solution was used for titration, to allow for a slower approach toward the $\mathrm{pH}$ of 4.5 . After the target $\mathrm{pH}$ of 4.5 was reached, the third experiment was to begin.

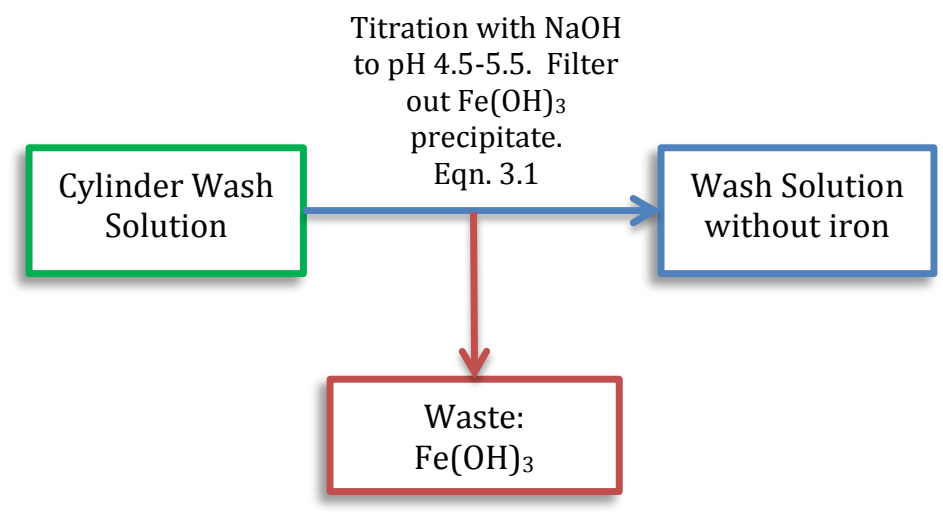

Figure 3.2 - Experiments $2 \& 3$

\section{Experiment Three}

The third experiment was a settling test to determine the volume of $\mathrm{Fe}(\mathrm{OH})_{3}$ precipitate generated in Experiment Two, and the time it takes to settle out of solution. Thus, the solution from the second experiment would be poured into a graduated cylinder 
and allowed to settle for two hours. During these two hours, the demarcation level between the sediment and the clear, supernate liquid above it would be recorded at specific time intervals. The solution would then be allowed to sit overnight, and the final demarcation would be recorded.

\section{Experiment Four}

The fourth experiment was to precipitate the uranium out of the remainder of the wash solution (now devoid of iron) as solid SDU precipitate. First, a vacuum transfer apparatus would be assembled by connecting a vacuum pump to a polypropylene Erlenmeyer flask with a bit of tubing. The first flask would serve as an overflow flask to protect the vacuum pump, and it would be connected to a second, capture flask by more tubing. The second flask would be attached to a dipping tube, which would be dipped into the clear supernate solution to draw it into the flask. This set up is shown in Figure 3.3 .

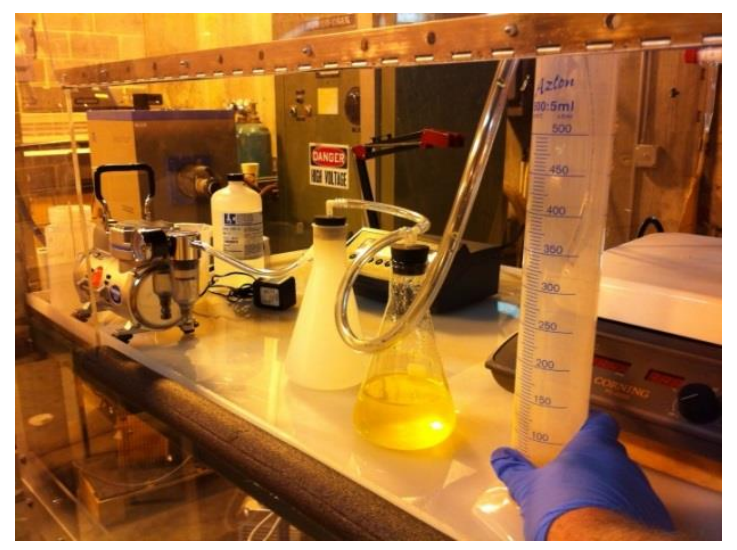

Figure 3.3 - Vacuum apparatus system 
This vacuum apparatus would be used to remove the clear supernate liquid from the top of the Experiment Three settling test, and, afterward, the solid precipitate would be filtered from the dregs, leaving a brilliant yellow, partially titrated wash solution, now containing no iron. This solution would be put in a new beaker and further titrated with $8 \% \mathrm{NaOH}$, to a $\mathrm{pH}$ of $11-12$, to form the solid SDU precipitate. An electronic $\mathrm{pH}$ sensor was to be used to record the $\mathrm{pH}$ during this titration, and a reading would be taken at regular intervals to form a titration curve. After the $\mathrm{pH}$ reached about 12 , the magnetic stirrer would be stopped and initial settling observations would be made. After these observations had been made, the stirrer would be started again, a temperature sensor would be lowered into the solution, and the hot plate would be turned on. The solution was then to be heated to $35-40^{\circ} \mathrm{C}$, and allowed to stir slowly for two hours, to see if heat and a digestion period increase particle size and speed precipitate settling. After the two hour digestion time passed, the hot plate and stirrer would be turned off and Experiment Five would immediately begin.

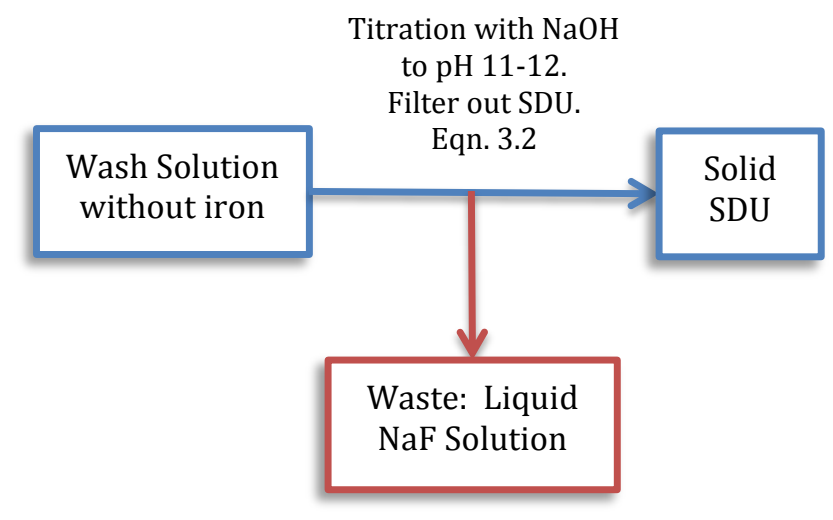

Figure 3.4 - Experiments 4 \& 5 


\section{Experiment Five}

The fifth experiment was to be used to observe the settling behavior of the SDU precipitate formed in Experiment Four. The final solution from the fourth experiment would be poured into a graduated cylinder and the demarcation between the supernate liquid and solid precipitate was to be recorded, at regular intervals, as in Experiment Three.

\section{Experiment Six}

Once full separation between the SDU precipitate and the liquid waste had been achieved, Experiment Six would begin. This experiment would be used to extract the uranium from the SDU precipitate in the form of a carbonate complex solution. This would start with a filtering of the solution to separate out the SDU. The liquid filtrate would be set aside for further testing to measure residual uranium content. The SDU filter cake and filter paper would be removed from the vacuum filtration system and the SDU scraped into a beaker. A sodium carbonate/sodium bicarbonate solution would be made by mixing together $240 \mathrm{~mL}$ of saturated $\mathrm{NaHCO}_{3}$ solution and $60 \mathrm{~mL}$ of $10 \%$ $\mathrm{Na}_{2} \mathrm{CO}_{3}$ solution. The filter paper would be washed into the SDU beaker with a bit of this solution and the rest would be poured into the beaker as well. The magnetic stir bar would then be added and the stirrer turned on to thoroughly mix the SDU and carbonate solution, forming a bright yellow/orange uranyl carbonate solution. 


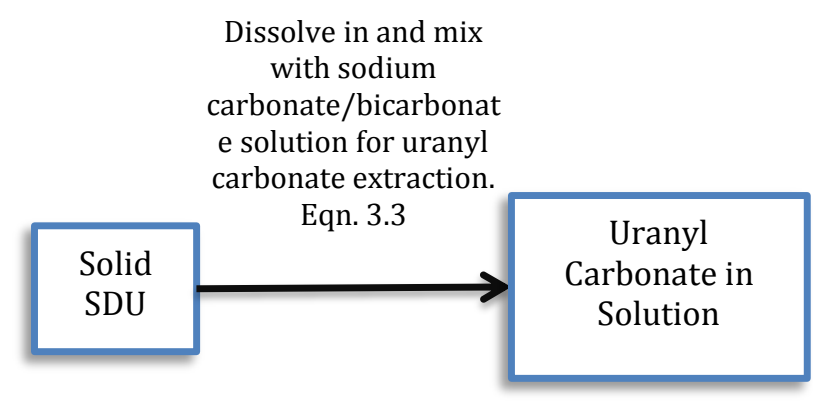

Figure 3.5 - Experiment 6

\section{Experiment Seven}

Experiment Seven was designed to precipitate the uranium out of the carbonate solution and into a $\mathrm{UO}_{4}$ solid. A $50 \mathrm{~mL}$ portion of the $\mathrm{UCO}_{3}$ solution would be poured into a beaker with the stir rod. Two $100 \mathrm{~mL}$ burettes would be mounted and positioned above the beaker, one filled with $100 \mathrm{~mL}$ of additional $\mathrm{UCO}_{3}$ solution, and the other filled with $100 \mathrm{~mL}$ of $35 \% \mathrm{H}_{2} \mathrm{O}_{2}$. A small squeeze bottle would be filled with $20 \%$ $\mathrm{HNO}_{3}$, to be used throughout the experiment. The temperature and $\mathrm{pH}$ sensors would be extended into the beaker and preliminary measurements made. Enough $\mathrm{HNO}_{3}$ would be gradually added to the uranyl carbonate solution in the beaker until the $\mathrm{pH}$ dropped to 3 , and then titration would begin. A slow drip of $\mathrm{H}_{2} \mathrm{O}_{2}$ would be started, and when yellow $\mathrm{UO}_{4}$ crystals began to form in the solution, a slow drip of $\mathrm{UCO}_{3}$ would be started as well. The $\mathrm{pH}$ meter reading would be closely monitored at this point, and the flow rates would be adjusted, and $\mathrm{HNO}_{3}$ would be added, a little at a time, to hold the $\mathrm{pH}$ of the solution at 4. The precipitation would be continued until all of the $\mathrm{UCO}_{3}$ had been used, pausing to refill burettes as needed. Once all of the $\mathrm{UCO}_{3}$ had been added the burettes would be removed and the final $\mathrm{pH}$ and volumes recorded. The mixture would stir slowly overnight, to allow for a complete reaction and crystal growth. 


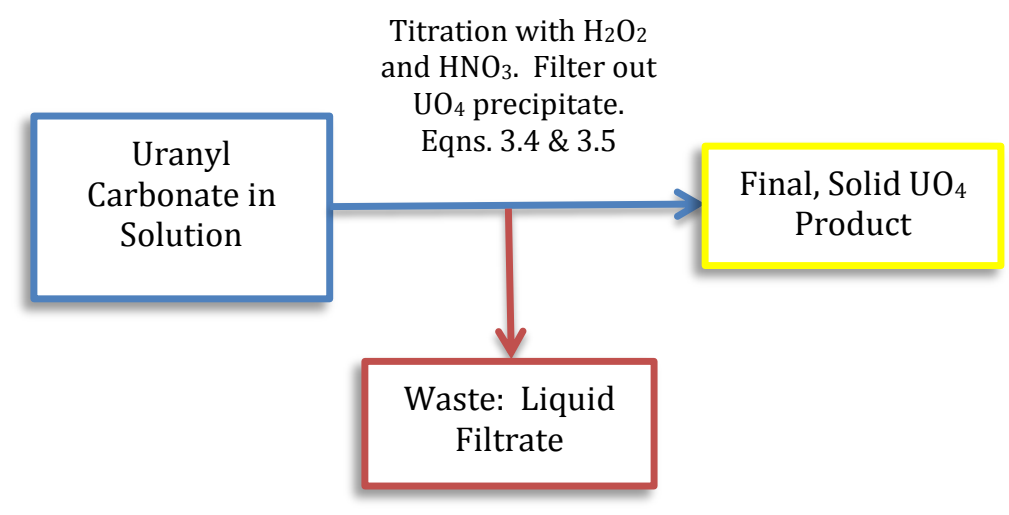

Figure 3.6 - Experiment 7

\section{Experiment Eight}

Experiment Eight was a settling test for the $\mathrm{UO}_{4}$ precipitate produced in Experiment Seven. After being allowed to stir all night, the mixture from the seventh experiment would be poured into a graduated cylinder and observed as in the third and fifth experiments. After full settling had taken place, the solution would be filtered, separating the $\mathrm{UO}_{4}$ precipitate from the $\mathrm{NaNO}_{3}$ solution filtrate. The liquid filtrate was stored for further analysis and the solids were set aside for drying and subsequent analysis.

Both the liquid and solids were analyzed by on a Thermo Scientific Element II high -resolution inductively coupled plasma mass spectrometer (ICP-MS). The liquids were analyzed for uranium content in parts per million ( $\mathrm{ppm}$ ) and the solids were analyzed for $\mathrm{Na}$ and Fe contamination in ppm. Each liquid sample was collected and diluted by a factor of 100, and each solid sample was made by dissolving about $1 \mathrm{mg}$ of solid $\mathrm{UO}_{4}$ in $100 \mathrm{~mL}$ of $5 \% \mathrm{HNO}_{3}$ solution. The ICP-MS was calibrated by analyzing a blank rinse of $2 \%$ distilled nitric acid five times, then, each sample was run through the machine and the data was collected. The concentrations of the contaminants in question 
were calculated based on a linear regression. Special thanks must be given to Elizabeth Bair and the Center for Elemental Mass Spectrometry at the University of South Carolina for running these tests and analyzing the data.

\section{Experiment Nine}

The ninth and final experiment was designed to evaluate a process for the removal of fluoride from the $\mathrm{NaF}$ solution generated in Experiment Four and filtered in Experiment Five. This was to be accomplished by filling a Sentry RC-100 column with calcite granules and capping it. The bottom end would be attached to the vacuum apparatus and the top connected to a length of tubing which was to be used to draw the $\mathrm{NaF}$ solution into the column.

The NaF solution would be poured in a glass beaker, placed on the hot plate, and heated to about $70^{\circ} \mathrm{C}$, then enough $20 \% \mathrm{HNO}_{3}$ would be added to drop the $\mathrm{pH}$ to about 5 . This heated, $\mathrm{pH}$-modified solution would be drawn out of the beaker and run through the column slowly—in increments of about $5 \mathrm{~mL}$ each —until it had all passed through the column. The NaF solution, at a $\mathrm{pH}$ of about 5 , reacts with the calcite to form sodium carbonate and calcium fluoride according to the reaction noted in Equation 3.6.

$$
2 \mathrm{NaF}+\mathrm{CaCO}_{3} \rightarrow \mathrm{CaF}_{2}+\mathrm{Na}_{2} \mathrm{CO}_{3}
$$

Should multiple passes be required, the solution exiting the column would be collected and have its $\mathrm{pH}$ checked and modified as necessary. It would then be heated and run through the column again.

These nine experiments came together into five test series. The first test series dealt only with experiment one. The second test series followed the complete sodium 
process from experiment two through experiment eight. The results of the second test series led to the development of modifications to the process, which had to be tested, and an auxiliary test was devised to do this using the combination $\mathrm{SDU} / \mathrm{Fe}(\mathrm{OH})_{3}$ precipitate in $\mathrm{NaF}$ solution that was the product of the first test series. This modified process was altered to forego the partial precipitation step in experiments two and three, and separated the iron from the wash solution during the carbonate extraction in experiment six, also changing the carbonate extraction process to use only water and $\mathrm{NaHCO}_{3}$. This test series was named "Auxiliary Tests on First Test Series SDU." The modified process is shown in Figure 3.3.

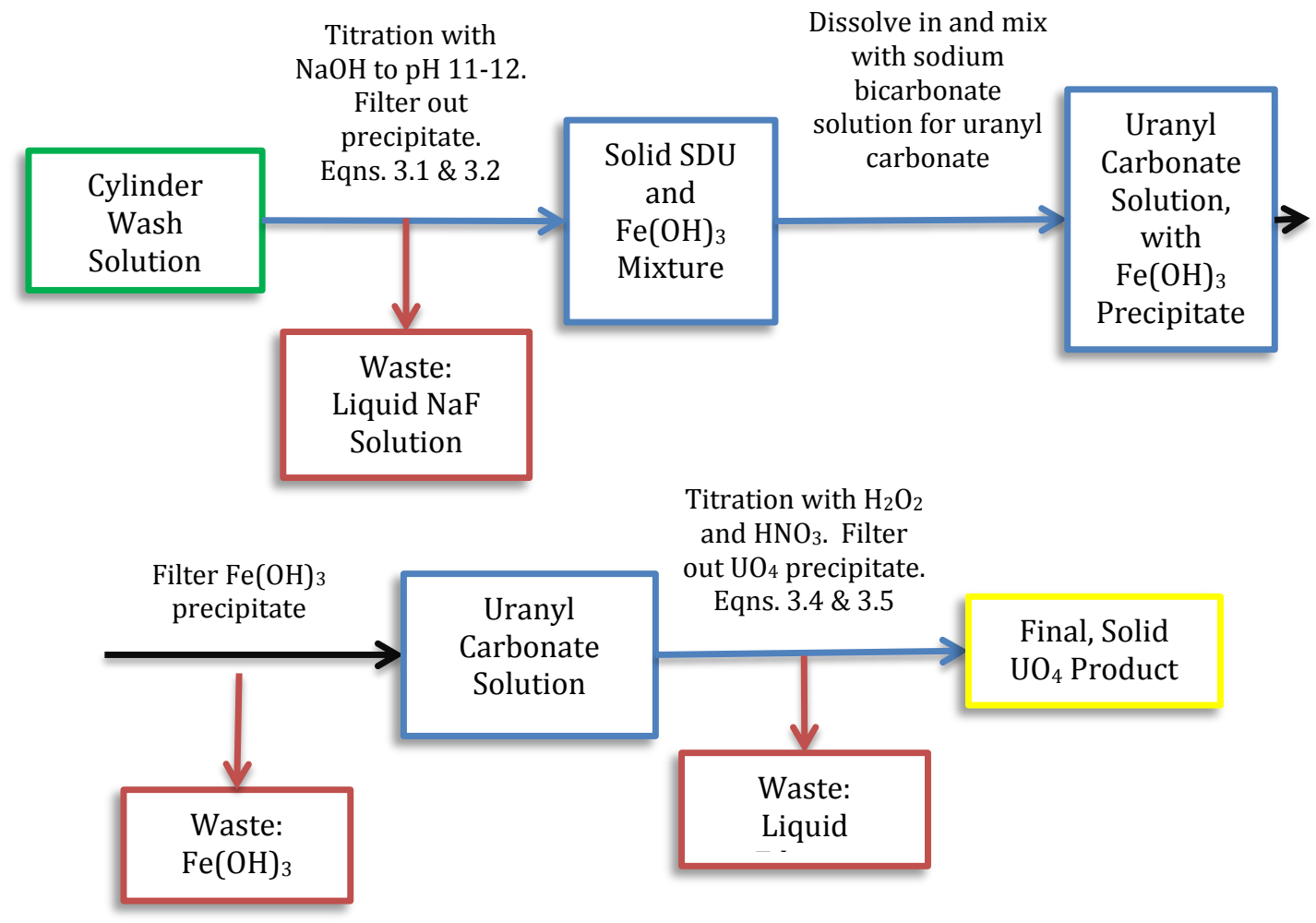

Figure 3.7 - Modified Recovery Process 
The third and fourth test series ran through the potassium-analogous process, going from experiments two through eight, as modified in Figure 3.3, using $\mathrm{KOH}$ in place of $\mathrm{NaOH}, \mathrm{KHCO}_{3}$ in place of $\mathrm{NaHCO}_{3}$, and $\mathrm{K}_{2} \mathrm{CO}_{3}$ in place of $\mathrm{Na}_{2} \mathrm{CO}_{3}$. The fifth and final test series was used as a verification run for the modified recovery process, going through the entire procedure from the second to ninth experiments, again, as modified. 


\section{CHAPTER 4: RESUlTS AND DisCUSSION}

\section{First Test Series}

The first test series was used to develop a precipitation curve for the initial reagents. A $\mathrm{UO}_{2} \mathrm{~F}_{2}$ solution was prepared by dissolving $16 \mathrm{~g}$ of the $\mathrm{UO}_{2} \mathrm{~F}_{2}$ powder mix into $100 \mathrm{~mL}$ of water, and this mixture was titrated with $24 \mathrm{wt} \% \mathrm{NaOH}$ solution. A magnetically stirred polyethylene beaker was the reaction container and the $\mathrm{NaOH}$ solution was dispensed as droplets from a $100 \mathrm{~mL}$ burette positioned over the beaker. The $\mathrm{pH}$ of the mixture was periodically measured with $\mathrm{p}$-Hydrion paper strips as the titration progressed, at room temperature. Table 4.1 following depicts the results of the titration.

Table 4.1 - First Test Series, SDU Precipitation

\begin{tabular}{|c|c|l|}
\hline $\mathrm{NaOH}$ added (total $\mathrm{mL})$ & $\mathrm{pH}$ & \multicolumn{1}{|c|}{ Comments } \\
\hline 0 & 1.0 & Solution light green color \\
\hline 1.8 & 3.0 & Local precipitation, re-dissolved \\
\hline 2.6 & 3.5 & \\
\hline 4.6 & 5.5 & Precipitation persisting more \\
\hline 5.6 & 5.5 & Tan/yellow precipitate forming \\
\hline 7.5 & 6.5 & Precipitating heavily \\
\hline 9.2 & 7.0 & \\
\hline 12.6 & 8.0 & \\
\hline 17.8 & 10.0 & Precipitation complete \\
\hline 20.6 & 12.0 & \\
\hline
\end{tabular}


The data are displayed graphically in Figure 4.1 below. Test photos are also shown in Figure 4.2 and 4.3.

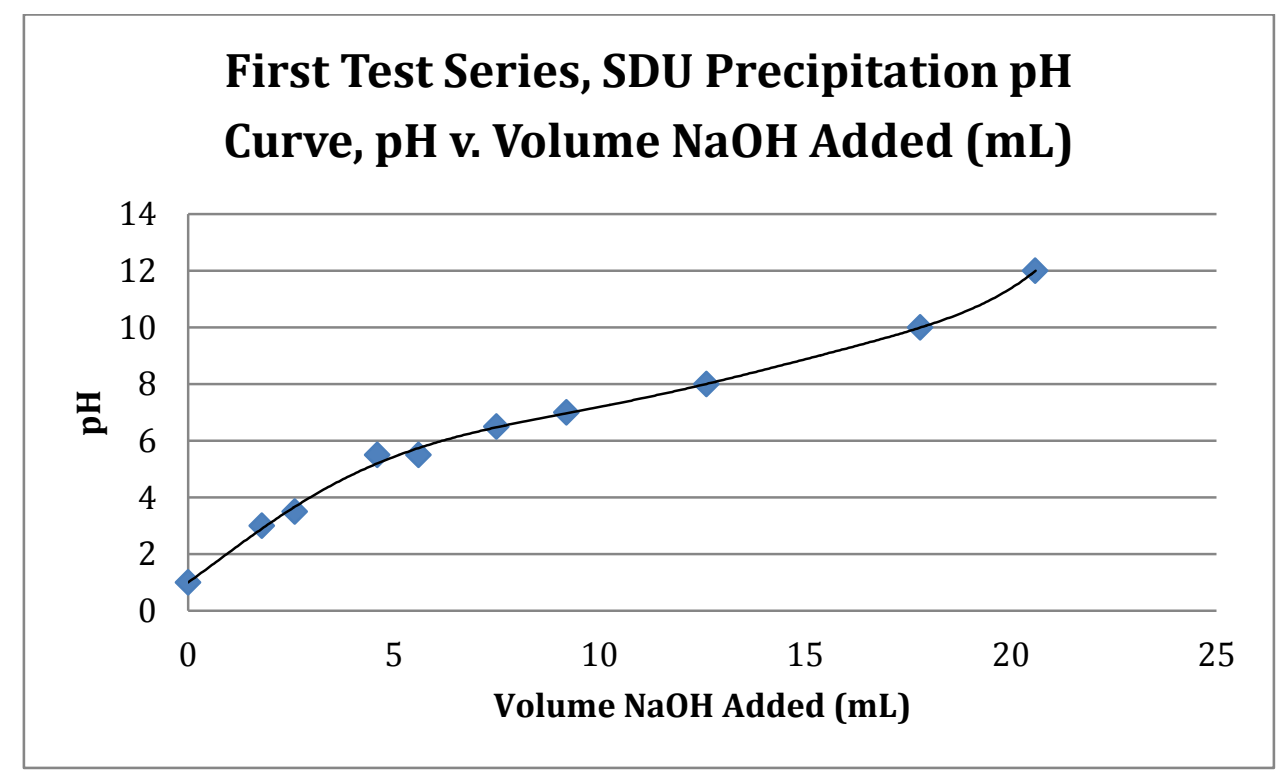

Figure 4.1 - Graph of First Test Series, SDU Precipitation pH Curve, pH v. Volume $\mathrm{NaOH}$ Added $(\mathrm{mL})$

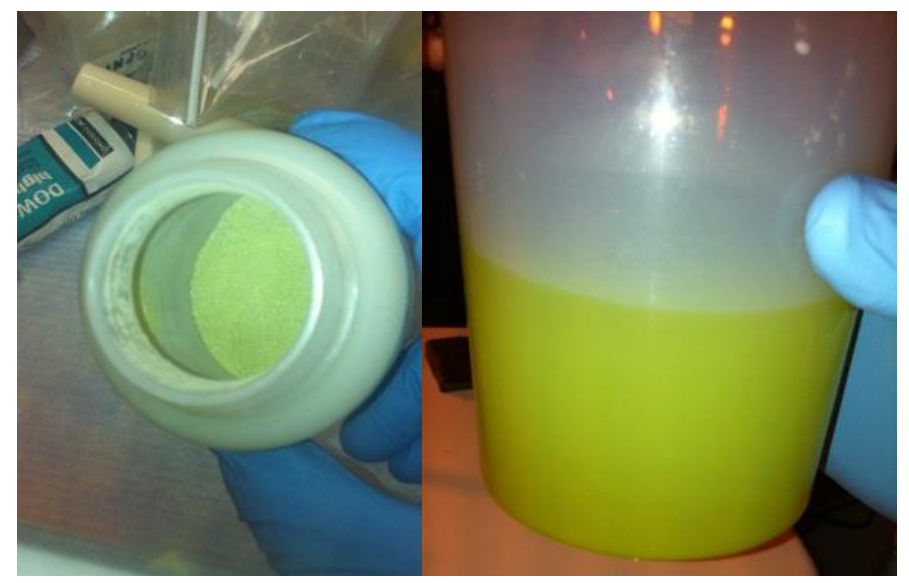

Figure 4.2 - Powdered $\mathrm{UO}_{2} \mathrm{~F}_{2}$ dosed with $3 \mathrm{wt} \% \mathrm{FeF}_{3}$, and the powder dissolved in water 


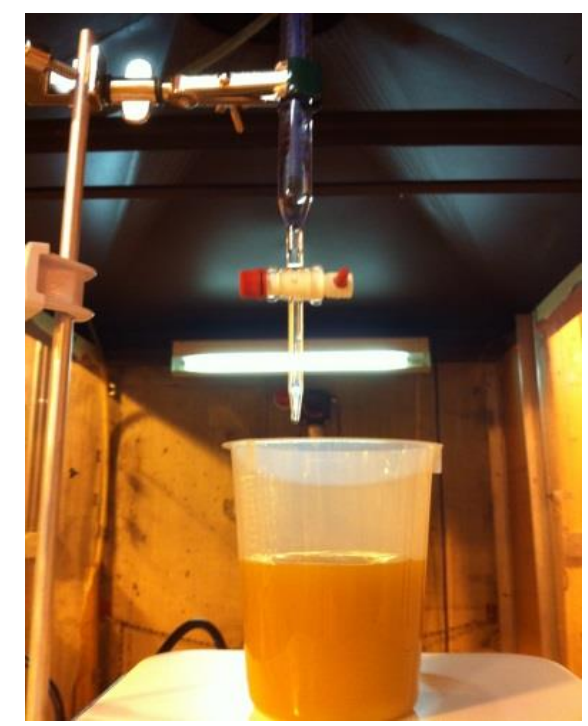

Figure 4.3 - Titration with $\mathrm{NaOH}$

One item of test observation was that the magnetic mixing system was having difficulty dispersing first additions of $\mathrm{NaOH}$ with the result that localized precipitation formations took several seconds to re-dissolve and stabilize in the solution. As a result, a decision was made to dilute the $\mathrm{NaOH}$ solution with water from $24 \%$ to $8 \%$ on subsequent test series, in order to better control the uniformity of the precipitations.

After the $\mathrm{pH}$ of the slurry of precipitated $\mathrm{SDU} / \mathrm{Fe}(\mathrm{OH})_{3}$ reached 12.0, it was transferred to a storage bottle and left overnight to settle. The next morning the solids had settled to one-third of the original slurry volume, with the remaining two-thirds of the volume consisting of a clear supernate liquid. The settled mixture was held for additional testing, described later in this chapter, in the section "Auxiliary Tests on First Test Series SDU”. 


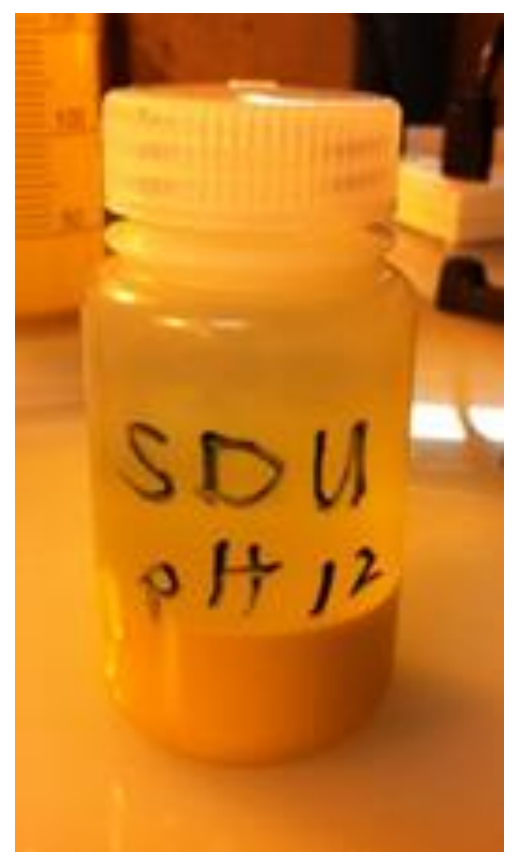

Figure 4.4 - First Test Series SDU after overnight settling

\section{Second Test Series}

The second test series started with $50 \mathrm{~g}$ of the $\mathrm{UO}_{2} \mathrm{~F}_{2}$ powder dissolved in $300 \mathrm{~mL}$ of water. The precipitation setup was the same as it was for the first test series, except $8 \% \mathrm{NaOH}$ solution was loaded into the titration burette. The purpose of the first step of this series was to evaluate a partial precipitation technique for separating the iron from the uranium in the mixture. In theory, the $\mathrm{FeF}_{3}$ solid and any dissolved $\mathrm{Fe}$ would be immediately converted to $\mathrm{Fe}(\mathrm{OH})_{3}$ solid at the first addition of $\mathrm{NaOH}$ and would remain insoluble at a pH lower than where the uranium would begin to precipitate as SDU. A physical separation of the iron from the uranium at $\mathrm{pH}$ of about 4.5 was thought to be possible. As the titration began, a rust colored precipitate soon formed, so it looked as if the reaction was following the prediction. As the titration reaction progressed, however, some yellowing occurred in the precipitate. After a slow addition of $17.6 \mathrm{~mL}$ of $\mathrm{NaOH}$, 
the $\mathrm{pH}$ measured 4.5. The titration was stopped and the mixture was transferred to a graduated cylinder for a settling test.

The settling test data are shown in Table 4.2 following. The starting volume of the mixture was $315 \mathrm{~mL}$ on the graduated cylinder.

Table 4.2 - Second Test Series, Partial Precipitation of Iron Sediment Settling

\begin{tabular}{|c|c|c|l|}
\hline Settling Time (min) & $\begin{array}{c}\text { Volume of } \\
\text { Supernate Liquid } \\
(\mathrm{mL})\end{array}$ & $\begin{array}{c}\text { Volume of Slurry } \\
(\mathrm{mL})\end{array}$ & Comments \\
\hline 10 & 305 & 10 & Murky supernate \\
\hline 20 & 307.5 & 7.5 & Some clearing \\
\hline 30 & 307.5 & 7.5 & Clear \\
\hline 40 & 307.5 & 7.5 & \\
\hline 50 & 307.5 & 7.5 & \\
\hline 60 & 307.5 & 7.5 & \\
\hline 80 & 307.5 & 7.5 & \\
\hline 100 & 307.5 & 7.5 & Clear* \\
\hline 120 & 307.5 & 7.5 & \\
\hline Overnight & 307.5 & & \\
\hline
\end{tabular}

*Had a slight haze to about $15 \mathrm{~mL}$ above slurry

The result of the settling was a very rapid separation to a fixed fraction of solids and liquid that did not change even with extended settling. A yellowish caste remained in the precipitate indicating some SDU had precipitated with the iron.

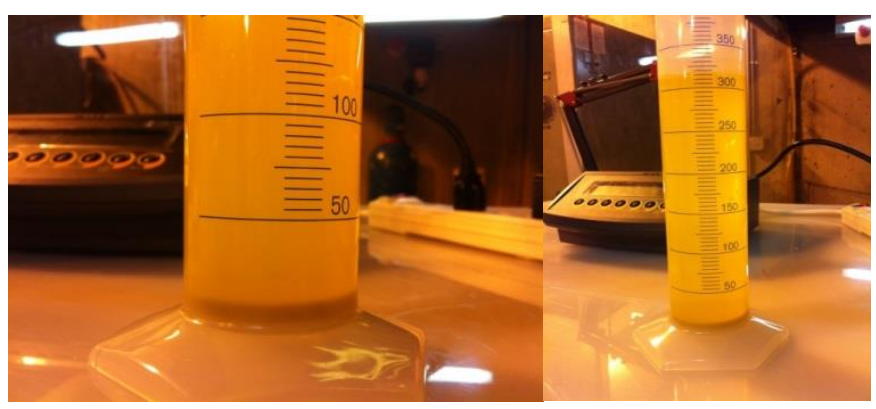

Figure 4.5 - Settling of $\mathrm{Fe}(\mathrm{OH})_{3}$ Solid 
The purpose of the next steps of this series was to filter the mixture to separate the iron precipitate and then set up the filtrate to complete the precipitation of SDU.

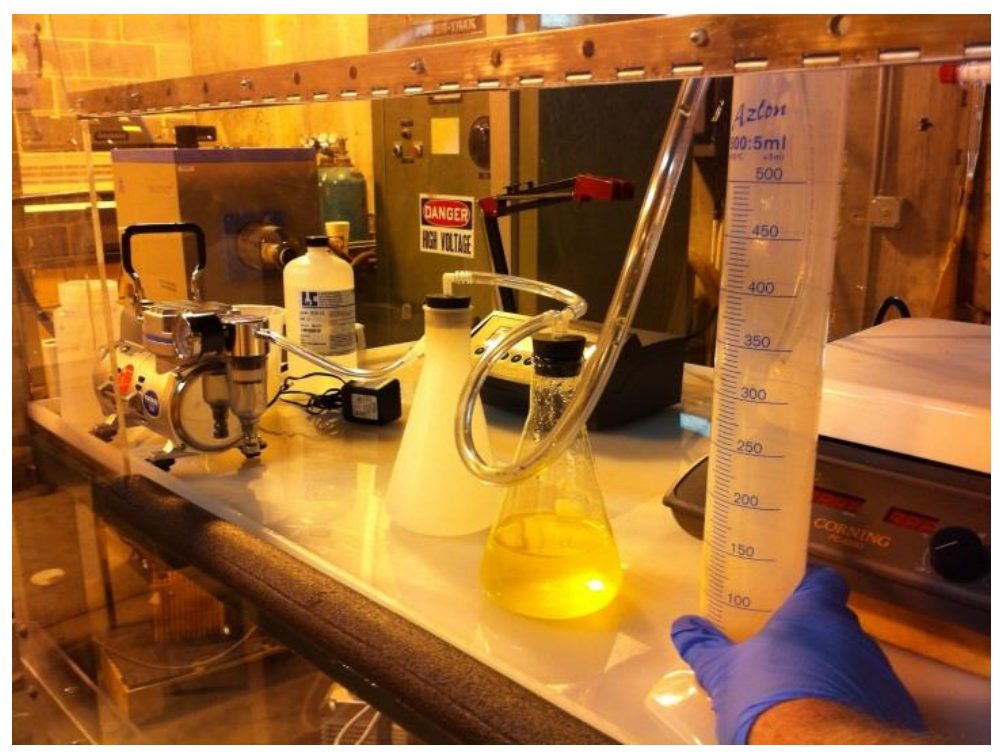

Figure 4.6 - Siphoning off supernate liquid before filtering out $\mathrm{Fe}(\mathrm{OH})_{3}$ solids

The filtration yielded $265 \mathrm{~mL}$ of filtrate which was put into a beaker for titration with additional $8 \% \mathrm{NaOH}$ solution. The filtrate volume had been reduced by the solids removal and some evaporation losses during the previous overnight settling test. The Hanna electrical $\mathrm{pH}$ meter was set up for the first time and its probe was submerged in the beaker of filtrate before the titration began. It took about 20 minutes for the $\mathrm{pH}$ meter to stabilize at a starting reading of 5.05 (versus $\mathrm{pH} 4.50$ by $\mathrm{p}$-Hydrion paper measurement at the end of the previous day). Table 4.3 and Figure 4.7 show the SDU precipitation data and the $\mathrm{pH}$ readings on the Hanna instrument. 
Table 4.3 - Second Test Series, SDU Precipitation

\begin{tabular}{|c|c|c|l|}
\hline Time & $\mathrm{mL} \mathrm{NaOH}$ Added & $\mathrm{pH}$ Meter Reading & \multicolumn{1}{|c|}{ Comments } \\
\hline $9: 30$ & 0 & 5.05 & \\
\hline $9: 45$ & 6.5 & 5.34 & Precipitation starting \\
\hline $10: 00$ & 17.2 & 5.58 & Additional precipitate \\
\hline $10: 10$ & 24.2 & 5.81 & \\
\hline $10: 22$ & 36.0 & 6.38 & \\
\hline $10: 30$ & 43.4 & 6.91 & \\
\hline $10: 40$ & 50.0 & 7.37 & Heavy precipitation \\
\hline $10: 50$ & 60.0 & 7.87 & \\
\hline $11: 00$ & 74.0 & 8.38 & \\
\hline $11: 10$ & 86.0 & 8.74 & Precipitation about done \\
\hline $11: 20$ & 98.5 & 9.19 & \\
\hline $11: 25$ & 100.0 & 9.22 & Stop and reload burette \\
\hline $11: 35$ & 107.5 & 9.50 & Precipitation done \\
\hline $11: 45$ & 114.0 & 10.08 & \\
\hline $11: 55$ & 121.2 & 10.90 & \\
\hline $12: 05$ & 128.8 & 11.63 & \\
\hline $12: 07$ & 129.5 & 11.62 & Stopped titration \\
\hline
\end{tabular}

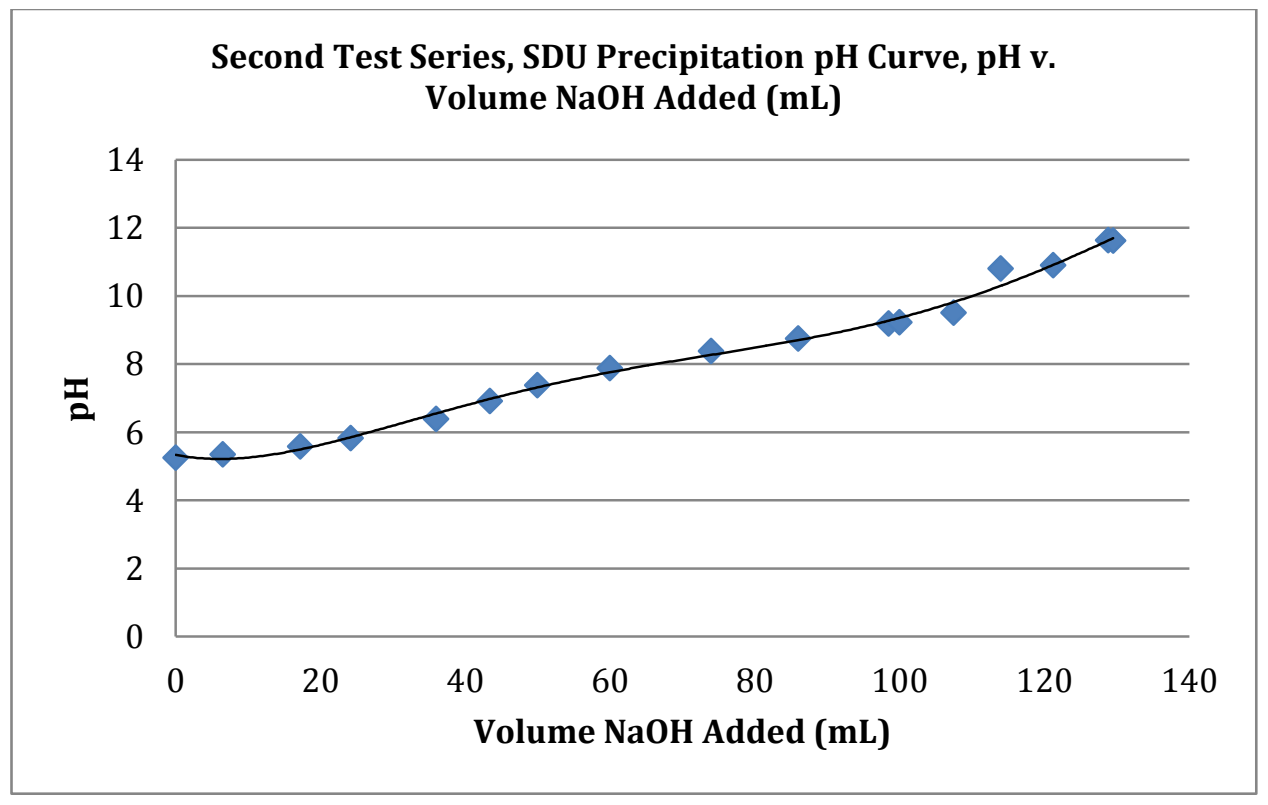

Figure 4.7 - Graph of Second Test Series, SDU Precipitation pH Curve, pH v. Volume $\mathrm{NaOH}$ Added (mL) 


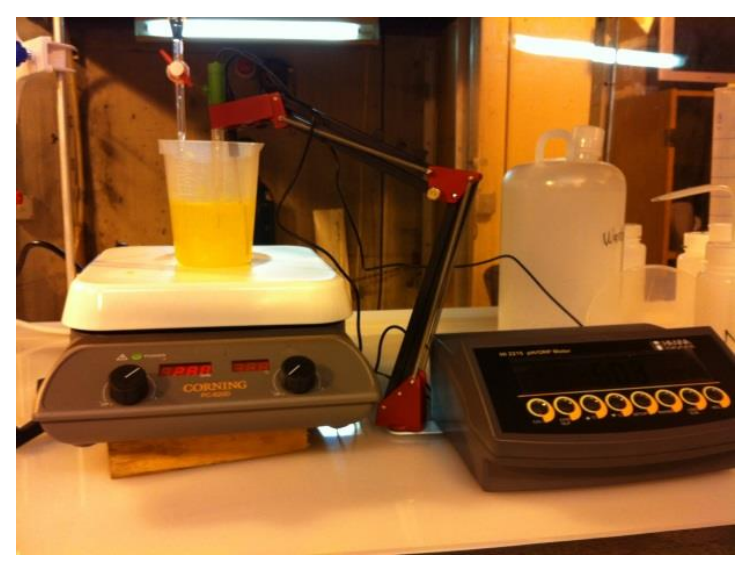

Figure 4.8 - Titration set-up

The magnetic stirring was stopped to install the temperature probe into the beaker.

Just after the stirring stopped, preliminary observations of the settling characteristics were noted. The estimated supernate volume in the beaker for each time period is shown in Table 4.4 below, as a prior-to-digestion settling data set.

Table 4.4 - Second Test Series, SDU Settling, No Digestion Period

\begin{tabular}{|c|c|}
\hline Time & Estimated Supernate Volume (\% of total volume) \\
\hline $12: 11$ & 0 \\
\hline $12: 16$ & 50 \\
\hline $12: 21$ & 70 \\
\hline $12: 31$ & 73 \\
\hline $13: 35$ & 73 \\
\hline
\end{tabular}

These data indicated that even without a heated digestion period to promote particle size growth, the solids settled into the bottom $27 \%$ of the beaker within 20 minutes. 


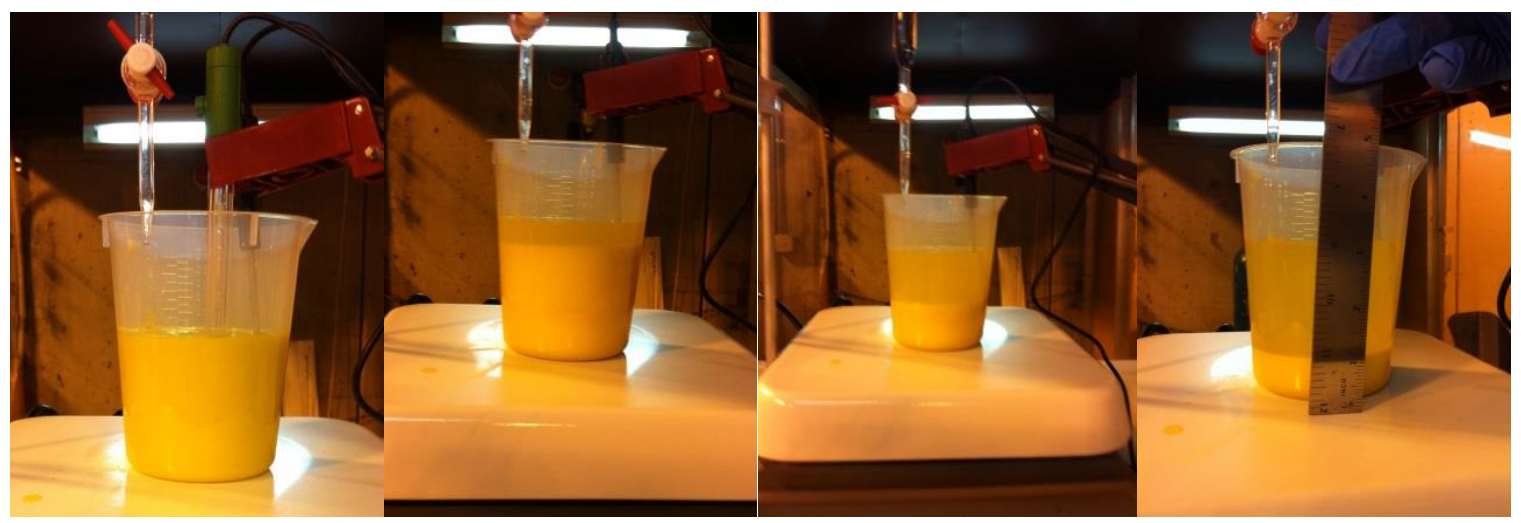

Figure 4.9 - SDU settling, no digestion period

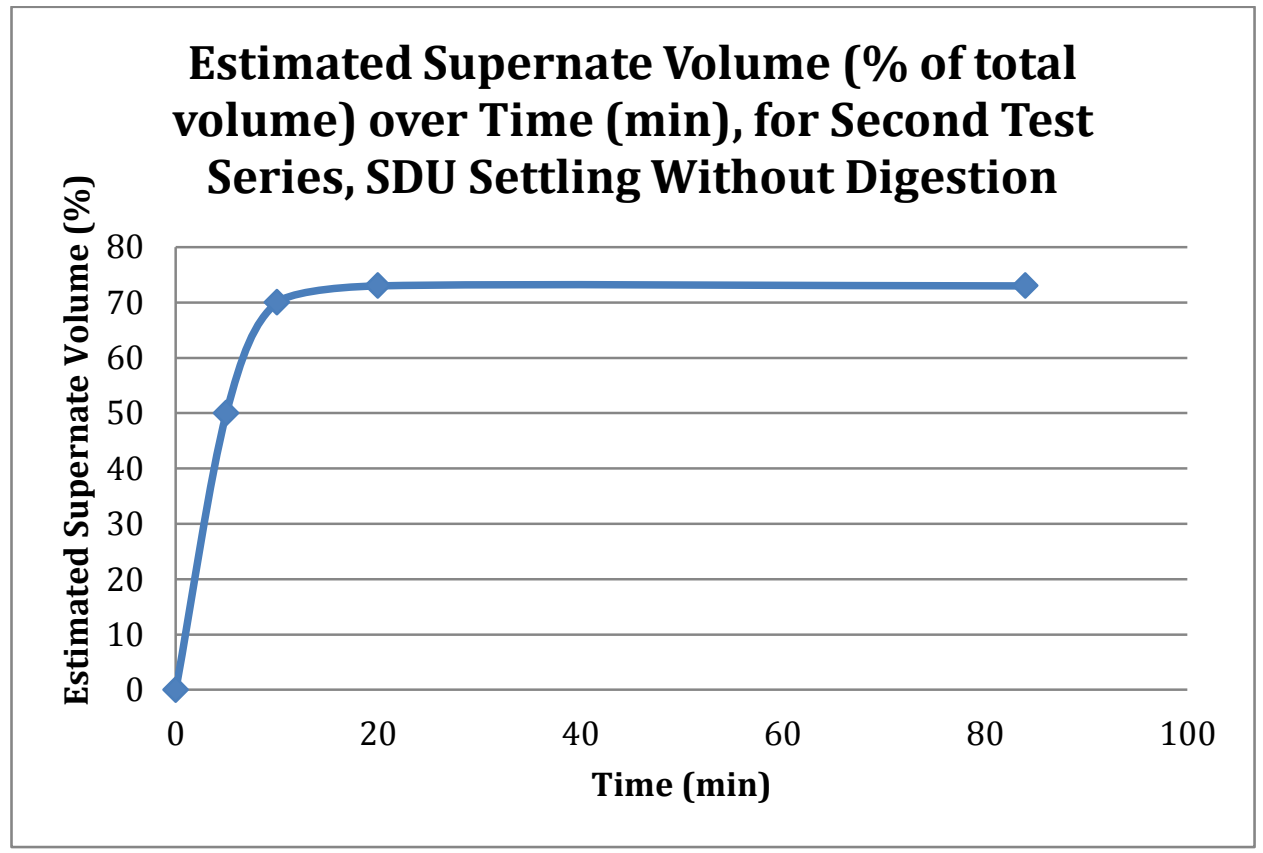

Figure 4.10 - Graph of the Estimated Supernate Volume (\%) over Time (min) for Second Test Series, SDU Settling, Without a Digestion Period

At 13:40 the magnetic stirrer was re-started and the heating plate under the beaker was turned on. The temperature of the slurry was elevated to $35-40^{\circ} \mathrm{C}$ and held there for about 2 hours to give the mixture a digestion period. Next, the mixture was poured into a graduated cylinder along with about $5 \mathrm{~mL}$ of water used to rinse out the beaker. The settling test data for the $400 \mathrm{~mL}$ of digested slurry follows in Table 4.5. 
Table 4.5 - Second Test Series, SDU Settling, With Digestion Period

\begin{tabular}{|c|c|c|}
\hline Time & Supernate Volume $(\mathrm{mL})$ & Slurry Volume $(\mathrm{mL})$ \\
\hline $15: 45$ & 0 & 400 \\
\hline $15: 50$ & 160 & 240 \\
\hline $15: 55$ & 240 & 160 \\
\hline $16: 00$ & 275 & 125 \\
\hline $16: 05$ & 290 & 110 \\
\hline $16: 10$ & 300 & 100 \\
\hline $16: 15$ & 310 & 90 \\
\hline $16: 20$ & 315 & 85 \\
\hline $16: 25$ & 315 & 85 \\
\hline $16: 30$ & 315 & 85 \\
\hline Overnight & 317.5 & 82.5 \\
\hline
\end{tabular}

An interesting observation of the data in Table 4.4 and Table 4.5 shows that a twenty minute settling gives almost exactly the same sediment volume fraction (about $27 \%$ ), indicating that heated digestion at about $40^{\circ} \mathrm{C}$ does not improve settling rates of the slurry sediment - at least not in the early stages of the settling. A graph display of the data and photos follow. 


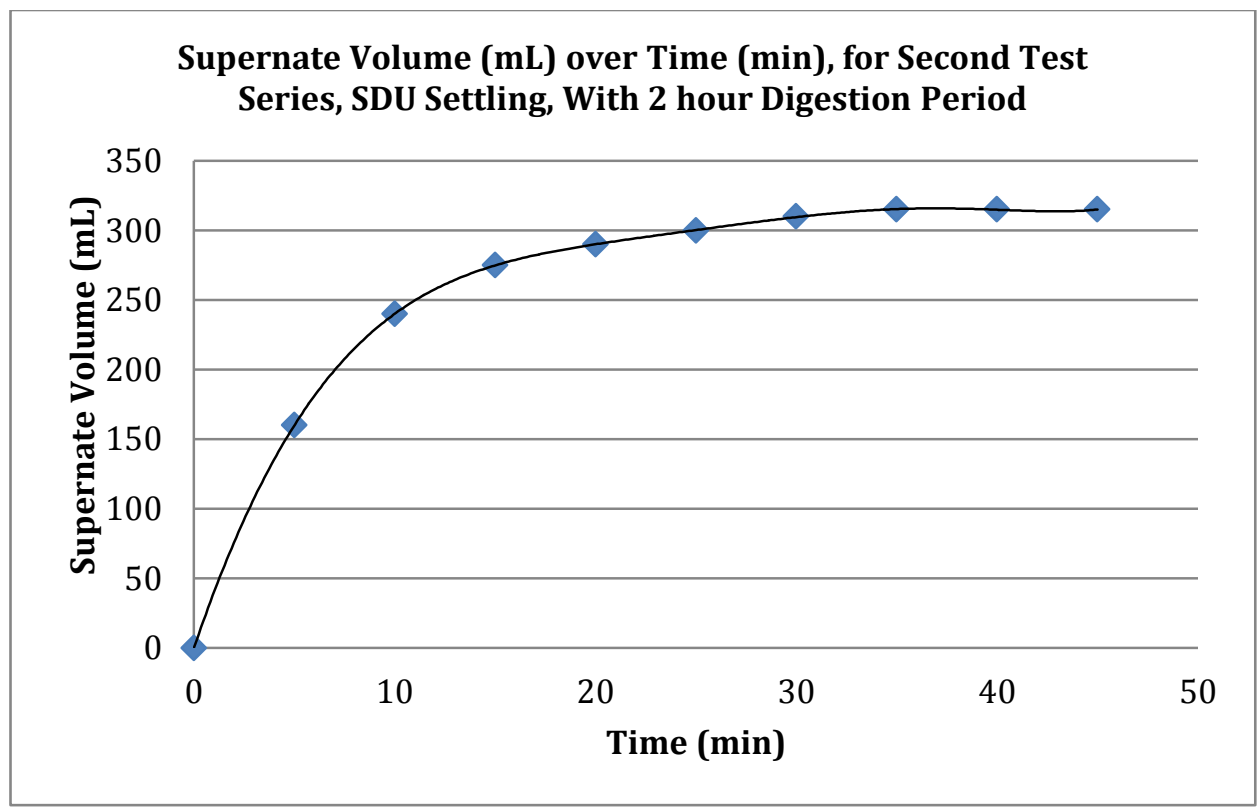

Figure 4.11 - Graph of the Supernate Volume (mL) over Time (min) for Second Test Series, SDU Settling, With 2 hour Digestion Period

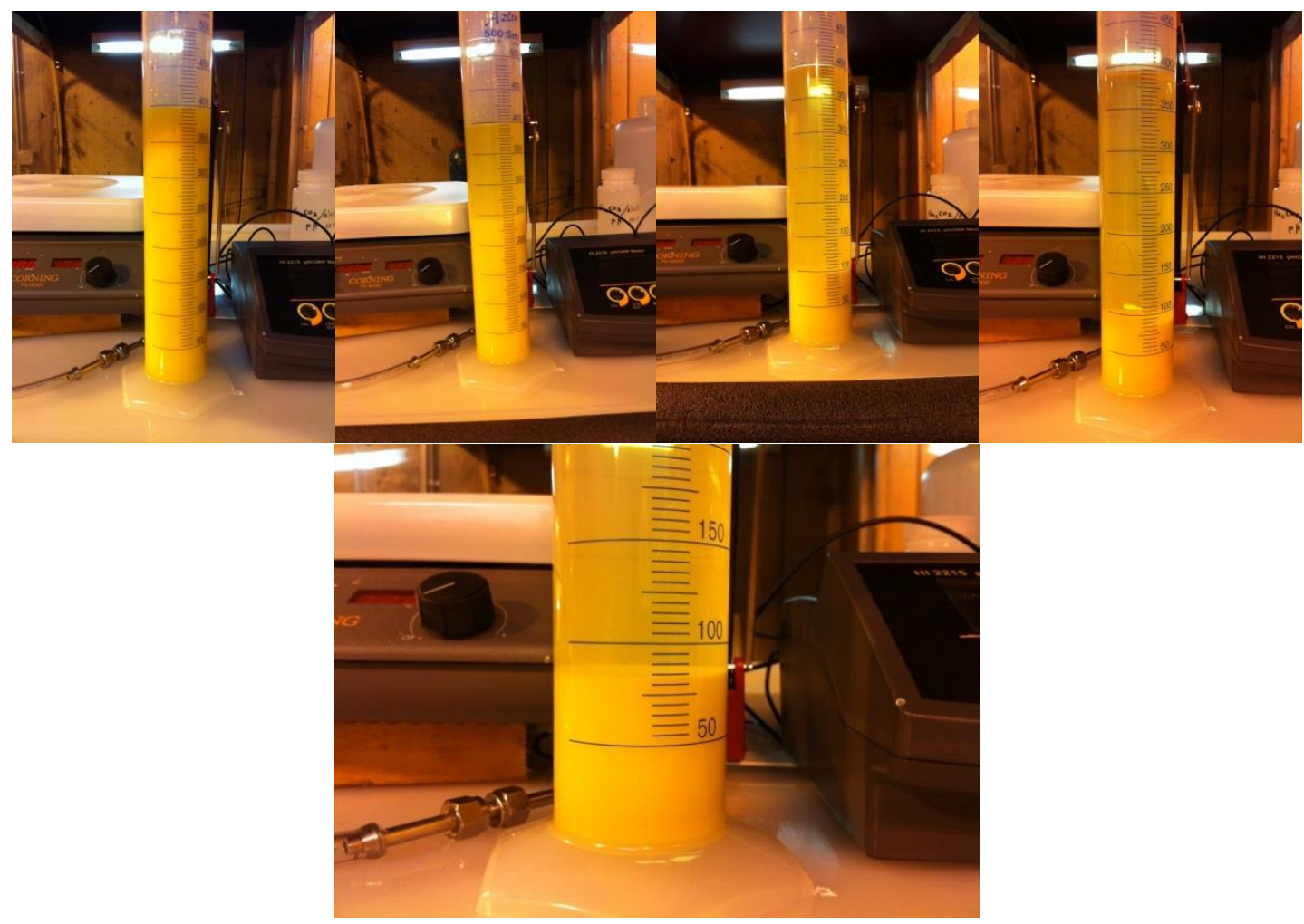

Figure 4.12 - Second Test Series, SDU settling after 2 hour digestion 
The next step in this series was used to convert the solid SDU into a solution of uranyl carbonate and further remove any carryover iron contamination. This was accomplished by mixing the $\mathrm{SDU}$ with a solution of $\mathrm{Na}_{2} \mathrm{CO}_{3}$ and/or $\mathrm{NaHCO}_{3}$ at a $\mathrm{pH}$ of about 10.1. The two carbonate reagents used were $10 \% \mathrm{Na}_{2} \mathrm{CO}_{3}$, which measured at a $\mathrm{pH}$ of 11.84, and saturated $\mathrm{NaHCO}_{3}$, which measured at a $\mathrm{pH}$ of 8.27.

The settled mixture from the graduated cylinder in the previous test was filtered to separate the SDU from the NaF solution present at that stage of the process. The SDU filter cake was recovered from the filter paper and put into a beaker with $300 \mathrm{~mL}$ of $10 \%$ $\mathrm{Na}_{2} \mathrm{CO}_{3}$ solution. This mixture was stirred for 45 minutes to break up the SDU filter cake, then heated to $35^{\circ} \mathrm{C}$ for one hour while stirring. The mixture was then poured into a storage bottle and allowed to settle overnight. The next day the mixture had separated into about two-thirds clear yellow solution and one-third tan colored sediment. The tan sediment color (instead of a bright yellow) indicated that some iron was still present, and because of the sizeable amount of sediment, not all of the SDU had been converted into soluble uranyl carbonate complex. The $\mathrm{pH}$ of the mixture was also high, at 11.83.

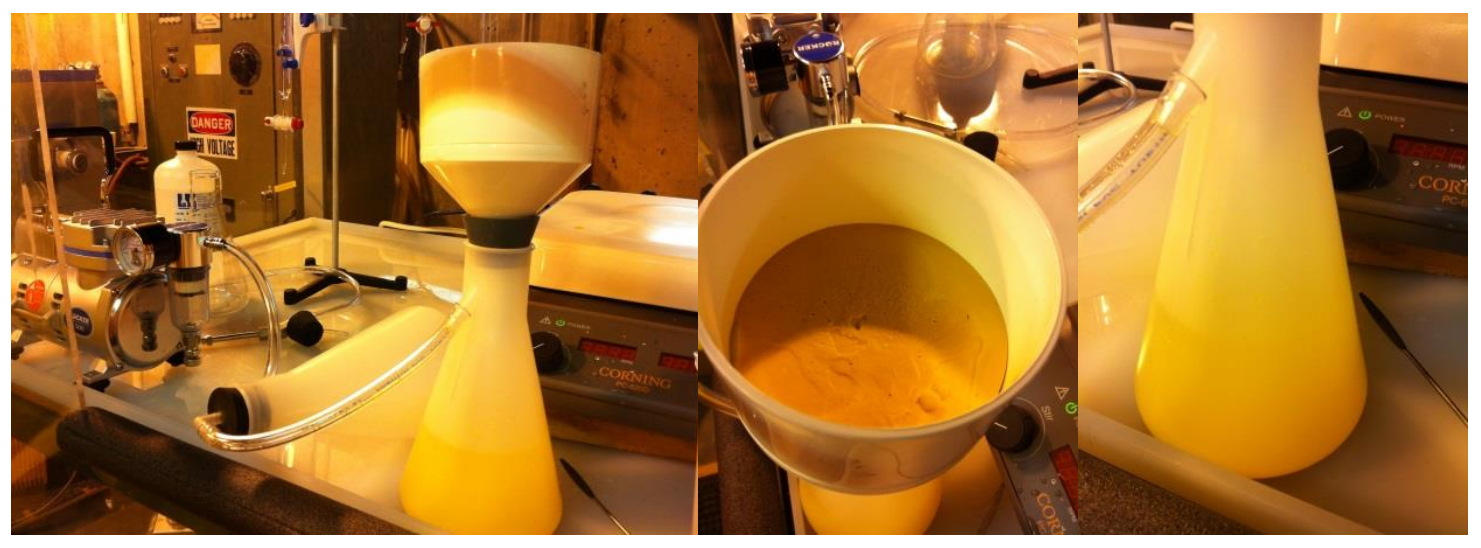

Figure 4.13 - Filtration set-up, SDU Filter Cake, SDU filtrate (NaF Solution) 


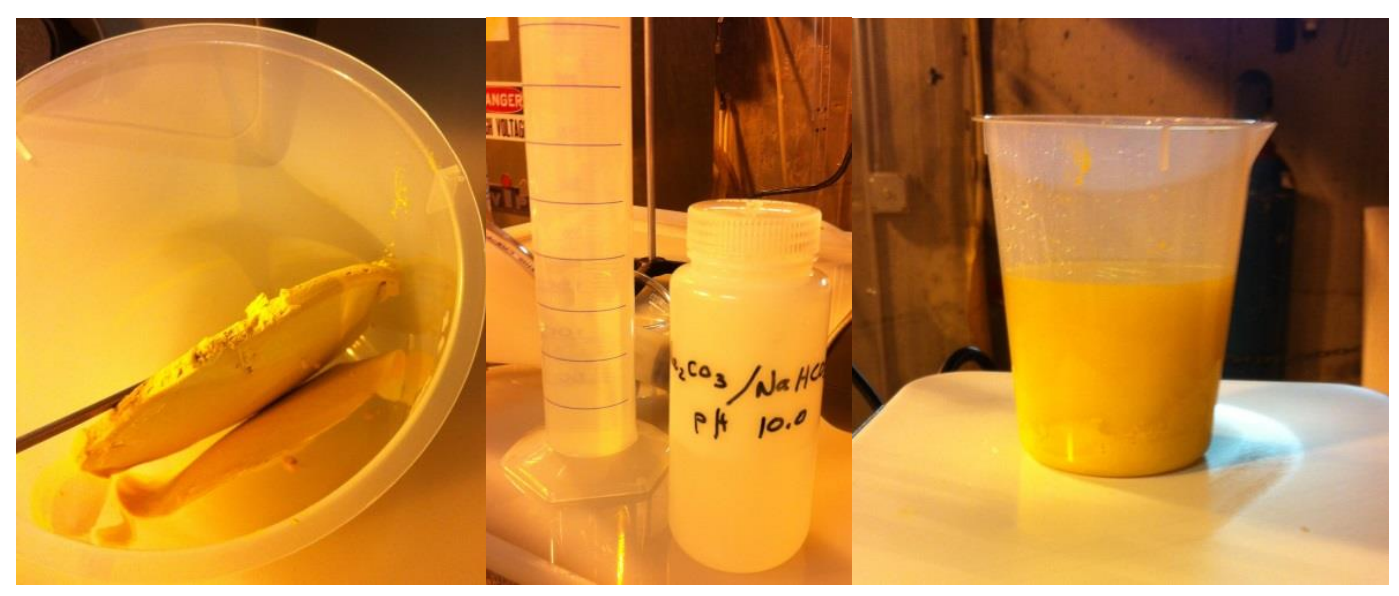

Figure 4.14 - SDU Filter Cake in Beaker, Sodium Carbonate/Bicarbonate mixture ( $\mathrm{pH}=10)$, Slurry of $\mathrm{SDU}$ and $300 \mathrm{~mL}$ of $10 \% \mathrm{Na}_{2} \mathrm{CO}_{3}$ solution

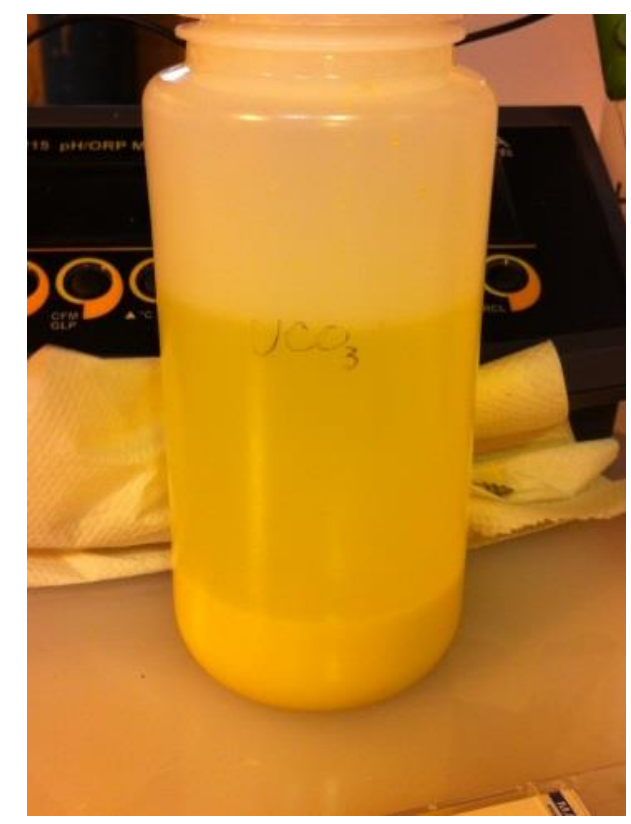

Figure 4.15 - Uranyl Carbonate Solution after overnight settling. Yellow sediment at the bottom shows that not all of the SDU has been converted.

These results led to a decision to re-treat the mixture with additional carbonate this time using the $8.27 \mathrm{pH}, \mathrm{NaHCO}_{3}$ solution as the carbonate source in order to lower the $\mathrm{pH}$ of the mixture toward the target of 10.1 . First, $50 \mathrm{~mL}$ of water was added and the $\mathrm{pH}$ was checked again. It was measured at 11.81 , which was almost exactly the same. 
Next, $100 \mathrm{~mL}$ of the $\mathrm{NaHCO}_{3}$ solution was loaded into a burette and slowly added to the mixture. The $\mathrm{pH}$ decreased to 10.45 . Another $100 \mathrm{~mL}$ increment was similarly added and the $\mathrm{pH}$ decreased to 10.12 . By this time the $600 \mathrm{~mL}$ beaker being used was nearly full, so the mixture was split into two portions with one portion placed into a storage bottle for an extended settling period and the other portion returned to the beaker for additional processing.

Addition of another $50 \mathrm{~mL}$ of $\mathrm{NaHCO}_{3}$ to the beaker decreased the $\mathrm{pH}$ to 9.95 , at which point no further $\mathrm{NaHCO}_{3}$ was added. The mixture was then heated to $40^{\circ} \mathrm{C}$ and poured into a storage bottle. The final $\mathrm{pH}$ of the heated mixture was 9.84. After overnight settling both halves of the mixture had light brown flocculent precipitates with the volume of precipitate in the heated portion about half the volume in the unheated portion.

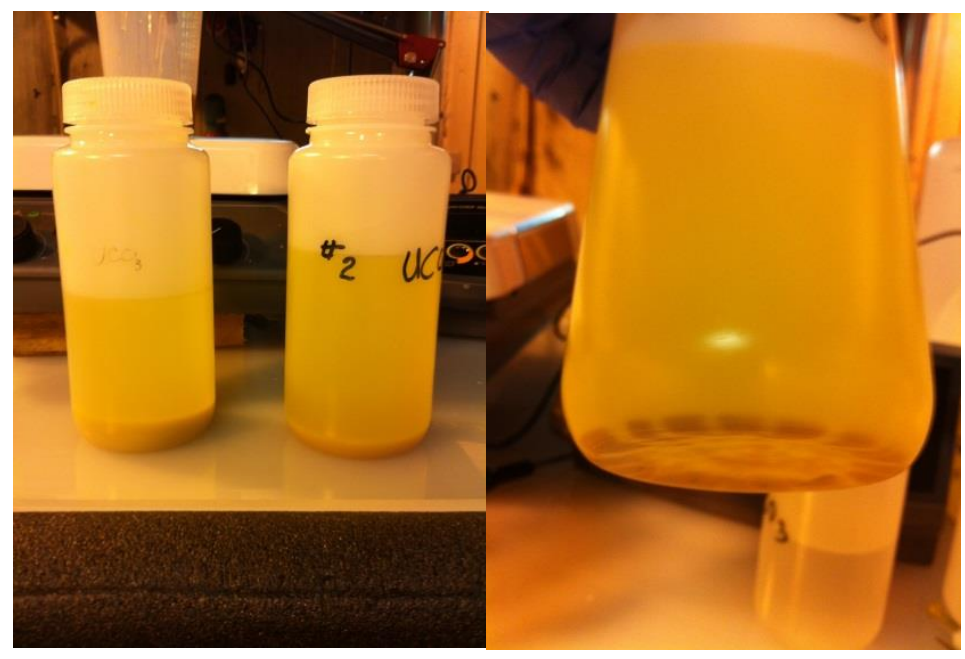

Figure 4.16 - Final $\mathrm{UCO}_{3}$ Products. Clear, yellow uranyl carbonate solution, with thin layers of brown sediment (most likely iron carryover). 
The continuing presence of the light brown flocculent precipitate indicated that there was some iron carryover from the earlier $\mathrm{pH} 4.5$ separation step. That, coupled with the indication that some uranium also precipitated around the $\mathrm{pH} 4.5$ region, pointed to a precipitation overlap, and suggested that the anticipated clean separation of the two elements at that condition does not occur. With that being the case, a decision was made to modify the process to completely precipitate the iron and uranium together at $\mathrm{pH} 11-$ 12 , then use the carbonate extraction of the uranium step to separate the two elements.

The purpose of the next test in the second series was to separate the uranium from the solution of residual sodium compounds. The technique was to precipitate the uranium as uranyl peroxide, perform a settling test on the peroxide crystals, and then physically separate the peroxide crystals from the solution mixture of sodium compounds.

To begin, the first half of the sodium uranyl carbonate solution produced in the previous test was filtered to remove the iron precipitate remnant. A $50 \mathrm{~mL}$ portion of the filtrate ( $\mathrm{pH} 10)$ was then put in a beaker to serve as the initiation solution. A total of 25 $\mathrm{mL}$ of $20 \%$ nitric acid was slowly added to the carbonate until the $\mathrm{pH}$ was reduced to 2.0 . Bubbles of $\mathrm{CO}_{2}$ formed and dissipated as the acid reacted with the carbonate. One burette was filled with $100 \mathrm{~mL}$ of $35 \% \mathrm{H}_{2} \mathrm{O}_{2}$ and another burette was filled with $100 \mathrm{~mL}$ of the carbonate filtrate. Both burettes were mounted above the beaker of starter solution. A $125 \mathrm{~mL}$ squeeze bottle of $20 \%$ nitric acid was on standby.

A slow drip of $\mathrm{H}_{2} \mathrm{O}_{2}$ was started and immediately a pale yellow (almost white) precipitate began forming in the starter solution. Next a drip of the carbonate solution was started and the heating plate was turned on. The $\mathrm{pH}$ gradually started to increase and 
when it reached 7.0, nitric acid was added from the squeeze bottle to bring it back down. The two burette drips and intermittent squirts of nitric acid were continued with frequent $\mathrm{pH}$ checks attempting to hold the $\mathrm{pH}$ in the desired $3.5-4.5$ range during the reaction. At the beginning there were both high and low excursions out of the desired $\mathrm{pH}$ range as the flows were juggled, but as experience developed, better $\mathrm{pH}$ control resulted. The additions continued until all of the carbonate solution had been used up. The final tally of inputs was: $230 \mathrm{~mL}$ carbonate solution, $35.6 \mathrm{~mL} \mathrm{35 \%} \mathrm{H}_{2} \mathrm{O}_{2}$, and $95 \mathrm{~mL} 20 \% \mathrm{HNO}_{3}$. The mixture was stirred while heated to $45^{\circ} \mathrm{C}$ for 1.5 hours, then the heat was turned off and the mixture was left stirring slowly for 72 hours, to allow the peroxide precipitation to complete. The $\mathrm{pH}$ after the heating had fallen to 3.0, evidence of a continuing peroxide precipitation reaction.

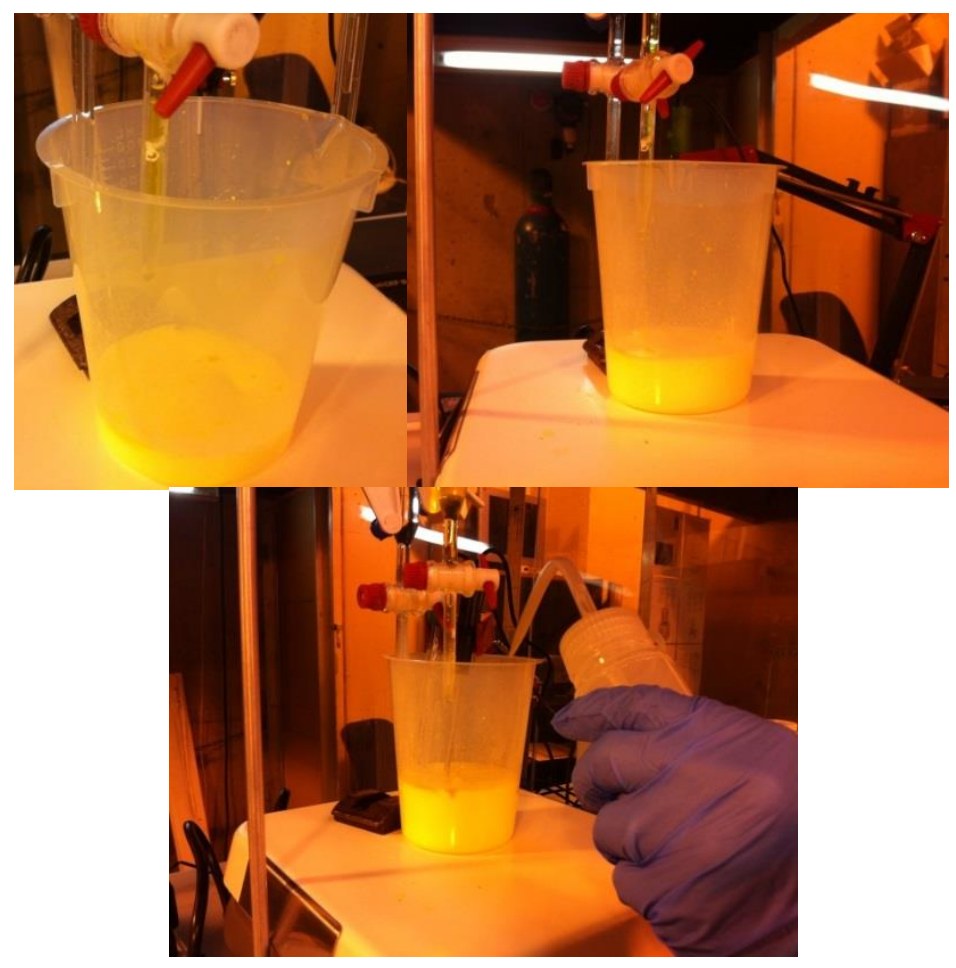

Figure $4.17-\mathrm{UO}_{4}$ Precipitation 
After the 72-hour stirring period, the $\mathrm{pH}$ had fallen further to 1.5 , so some extra $\mathrm{Na}_{2} \mathrm{CO}_{3} / \mathrm{NaHCO}_{3}$ mix was added to bring the $\mathrm{pH}$ back up to 4.0 . During the 72 -hour period, there had also been a substantial evaporation loss from the beaker such that only $195 \mathrm{~mL}$ remained of what had started out as $360 \mathrm{~mL}$. The mixture was poured into a graduated cylinder for a settling test, which test data can be found in Table 4.6.

Table 4.6 - Second Test Series, First Half, $\mathrm{UO}_{4}$ Settling Test

\begin{tabular}{|c|c|c|}
\hline Time $(\min )$ & Supernate Volume $(\mathrm{mL})$ & Slurry Volume $(\mathrm{mL})$ \\
\hline 0 & 0 & 195 \\
\hline 10 & 5 & 190 \\
\hline 20 & 5 & 190 \\
\hline 30 & 10 & 185 \\
\hline 60 & 15 & 180 \\
\hline 80 & 20 & 175 \\
\hline 100 & 22 & 173 \\
\hline 120 & 25 & 170 \\
\hline 2 days & 42 & 153 \\
\hline
\end{tabular}

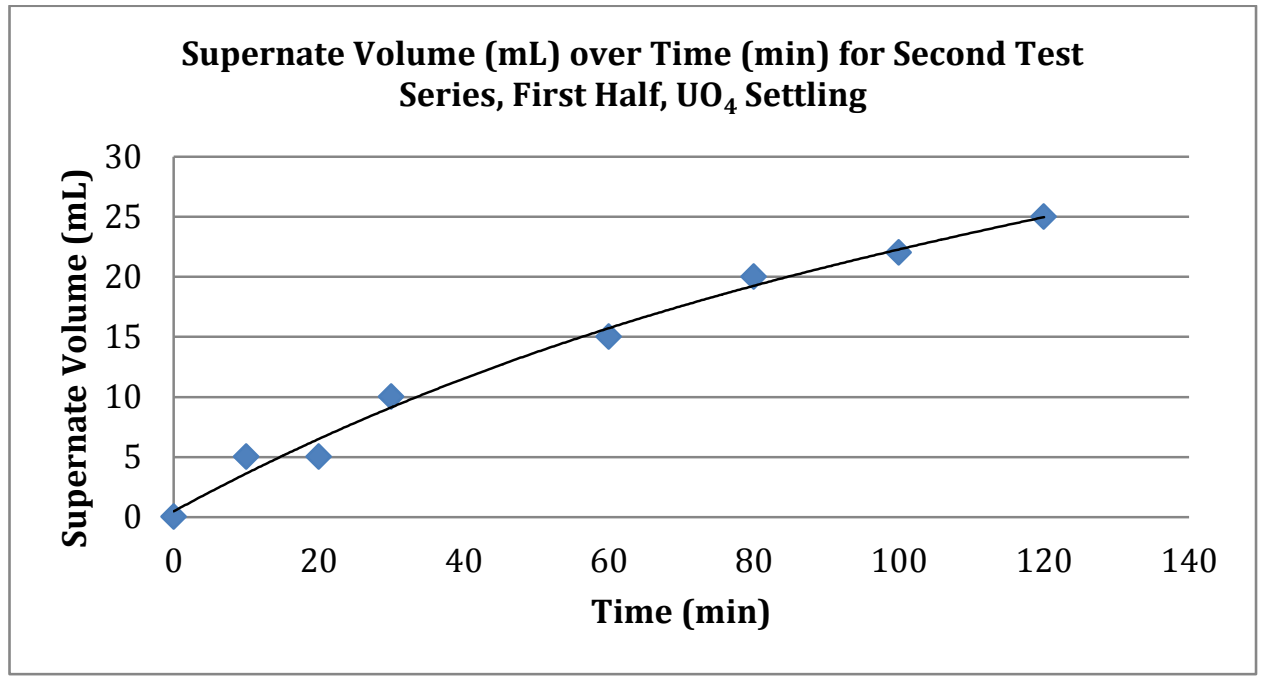

Figure 4.18 - Graph of Supernate Volume (mL) over Time (min) for Second Test Series, First Half, $\mathrm{UO}_{4}$ Settling 


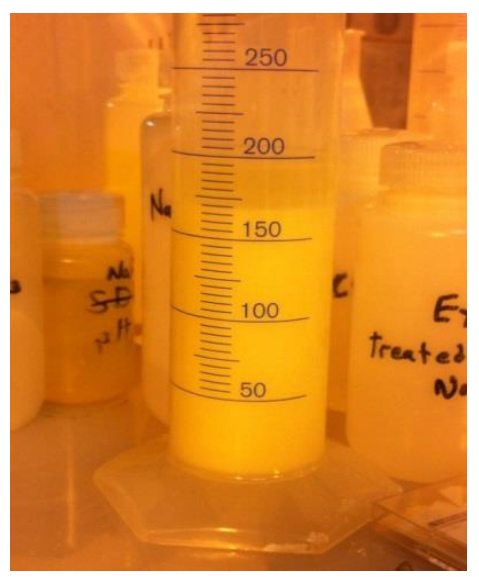

Figure 4.19 - Settling of Second Test Series, First Half, $\mathrm{UO}_{4}$

The settling data indicated that the peroxide particle size was very small and that separation may be quite difficult. This was not the case, however, as the subsequent filtration required only 23 minutes. The peroxide crystals were scraped off the filter paper and placed in an open container in the process hood to air dry. The dried crystals were placed in a tared sample bottle, and had a net weight of $30.24 \mathrm{~g} \mathrm{UO}_{4} \cdot \mathrm{nH}_{2} \mathrm{O}$. The filtrate was a clear solution and a portion of it was also placed in a sample bottle for subsequent analyses.

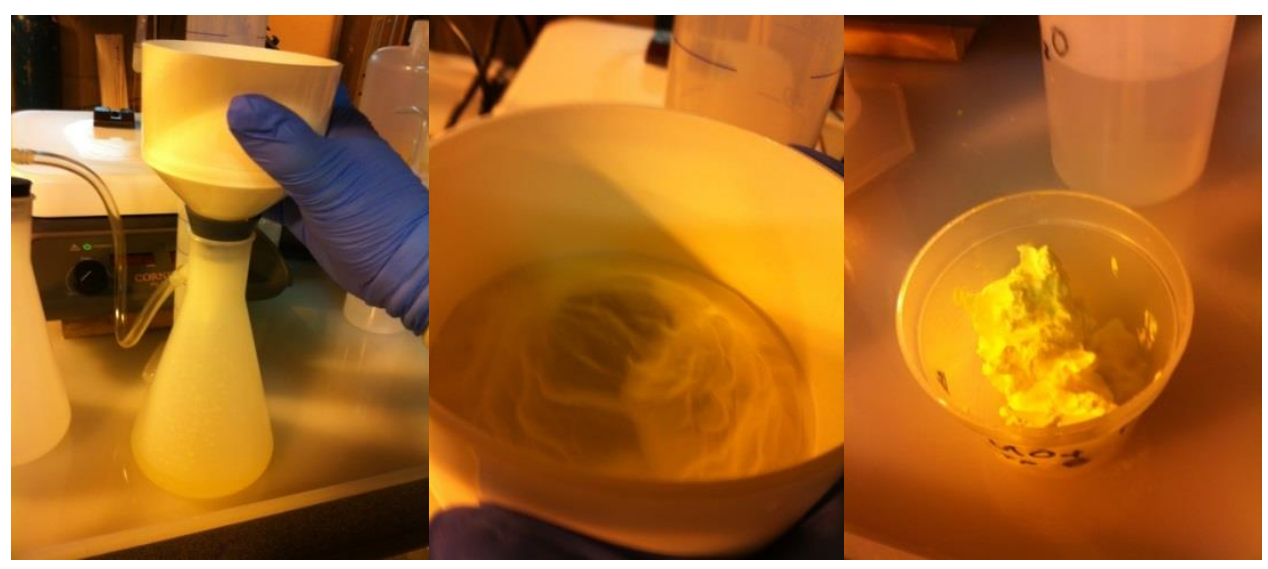

Figure 4.20 - Filtration of Second Test Series, First Half, $\mathrm{UO}_{4}$. From left to right: filtration apparatus, $\mathrm{UO}_{4}$ filter cake, $\mathrm{UO}_{4}$ in container to air dry. 
The second half of the second series carbonate extract solution was then filtered to remove the trace of $\mathrm{Fe}(\mathrm{OH})_{3}$ solid and was transferred to a beaker. The solution was precipitated with hydrogen peroxide using the same burette setup and titration technique described previously for the first half to completely precipitate the $\mathrm{UO}_{4}$ from the solution. The total reagents used were $394 \mathrm{~mL}$ carbonate solution, $65.6 \mathrm{~mL} \mathrm{35 \%} \mathrm{H}_{2} \mathrm{O}_{2}$, and 156 $\mathrm{mL} 20 \% \mathrm{HNO}_{3}$. The final slurry was put into a graduated cylinder for a settling test with the results in Table 4.7, below.

Table 4.7 - Second Test Series, Second Half, $\mathrm{UO}_{4}$ Settling Test

\begin{tabular}{|c|c|c|}
\hline Time $(\mathrm{min})$ & Supernate Volume $(\mathrm{mL})$ & Slurry Volume $(\mathrm{mL})$ \\
\hline 0 & 0 & 500 \\
\hline 10 & 452 & 48 \\
\hline 20 & 460 & 40 \\
\hline 30 & 460 & 40 \\
\hline 40 & 470 & 30 \\
\hline 50 & 470 & 30 \\
\hline 60 & 470 & 30 \\
\hline
\end{tabular}

The settling data showed very rapid initial settling and a very complete separation of $6 \%$ slurry and $94 \%$ supernate liquid, after 40 minutes. The mixture was then filtered, along with the remaining slurry that would not fit into the settling test cylinder and the $\mathrm{UO}_{4}$ cake was air dried for one week. The air-dried cake weighed $27.82 \mathrm{~g}$.

\section{Auxiliary Tests on First Test Series SDU}

An auxiliary series of processing was carried out using the $\mathrm{SDU} / \mathrm{Fe}(\mathrm{OH})_{3}$ coprecipitate slurry made from the first test series. The purpose of these tests was to evaluate an iron-uranium separation after a complete co-precipitation of both had been 
done. Since an iron separation on this slurry had not been attempted, it was ideal to use it to test the concept of making the iron separation at the carbonate extraction step rather than at the $\mathrm{pH} 4.5$ partial precipitation step used in the Series 2 sequence. Also, since the $\mathrm{Na}_{2} \mathrm{CO}_{3} / \mathrm{NaHCO}_{3}$ mixture used in the Series 2 carbonate extraction yielded such a high final $\mathrm{pH}$ (11.84), it was decided to use only $\mathrm{NaHCO}_{3}(\mathrm{pH} 8.27)$ as the extractant in the auxiliary test. Processing at room temperature (no heating) was a third variant added to the test technique.

The $\mathrm{SDU} / \mathrm{FeOH}_{3}$ slurry from the Series 1 precipitation was filtered and the solids were scraped off the filter paper into a beaker. A $50 \mathrm{~mL}$ allotment of water was used to help wash off the filter paper, and was added to the beaker and stirred to re-slurry the $\mathrm{SDU} / \mathrm{FeOH}_{3}$ solids. The $\mathrm{pH}$ of the mixture was 7.6.

A burette was filled with $100 \mathrm{~mL}$ of the saturated $\mathrm{NaHCO}_{3}$ solution and a drip was started, adding $\mathrm{NaHCO}_{3}$ solution to the $\mathrm{SDU} / \mathrm{FeOH}_{3}$ slurry. The beaker was not heated during this test. The $\mathrm{pH}$ measured 7.5 after $50 \mathrm{~mL}$ of the carbonate solution was added and 7.7 after $100 \mathrm{~mL}$ was added. Addition of carbonate solution was halted at this point and the mixture was put into a storage bottle and left to settle. After settling, the solids had almost completely dissolved leaving a bright yellow solution over a thin, darkbrown sediment layer.

This mixture was filtered to remove the dark-brown iron sediment, and $50 \mathrm{~mL}$ of the filtrate was put into a small container as a starter solution. 


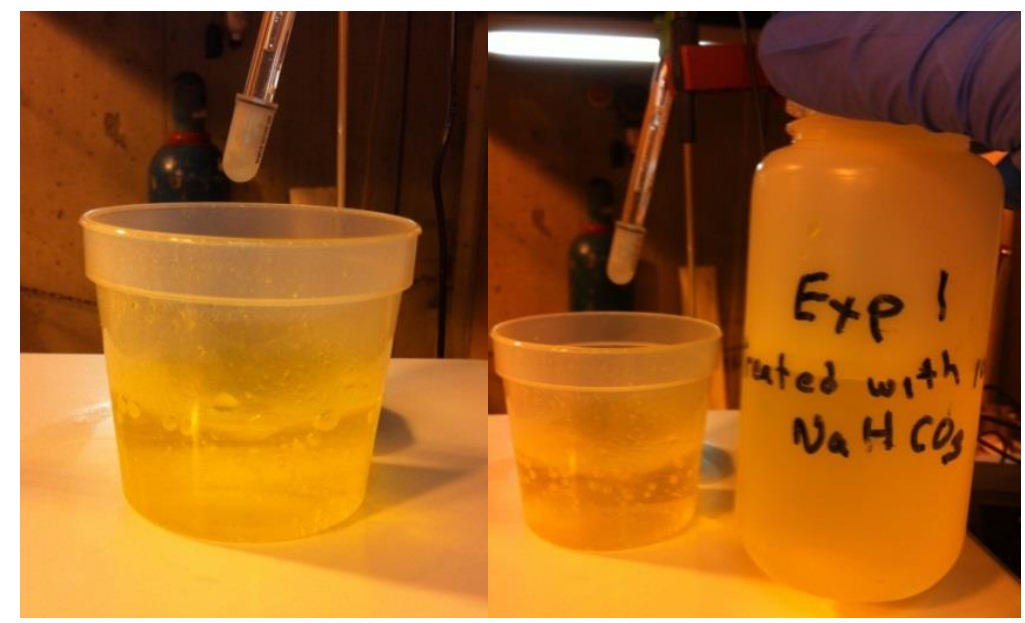

Figure 4.21 - Uranyl Carbonate Solution prepared from First Test Series SDU and $\mathrm{NaHCO}_{3}$, then filtered. This is the $50 \mathrm{~mL}$ put into a small container that served as a starter solution.

A burette was filled with $100 \mathrm{~mL}$ of the filtrate, and was mounted above the small starter solution container, along with a second burette containing $35 \% \mathrm{H}_{2} \mathrm{O}_{2}$. To begin the uranyl peroxide precipitation, $18.4 \mathrm{~mL}$ of $20 \% \mathrm{HNO}_{3}$ plus $1.6 \mathrm{~mL}$ of $35 \% \mathrm{H}_{2} \mathrm{O}_{2}$, plus an additional $20 \mathrm{~mL}$ of the filtrate were added to the container, at which point the mixture was transferred to a $600 \mathrm{~mL}$ beaker. Additional carbonate, acid and peroxide were slowly added in proportions to keep the $\mathrm{pH}$ in the $3.0-4.0$ range. Once again the beaker was not heated. The tally of reagents at the end of the precipitation was $194 \mathrm{~mL}$ carbonate solution, $32.1 \mathrm{~mL} 35 \% \mathrm{H}_{2} \mathrm{O}_{2}$, and $27.3 \mathrm{~mL} 20 \% \mathrm{HNO}_{3}$. The final $\mathrm{pH}$ was 3.5 . The mixture was poured into a graduated cylinder for a settling test, with data shown in Table 4.8, below.

Table 4.8 - First Test Series, Auxiliary Testing, $\mathrm{UO}_{4}$ Settling

\begin{tabular}{|c|c|c|}
\hline Time $(\mathrm{min})$ & Supernate Volume $(\mathrm{mL})$ & Slurry Volume $(\mathrm{mL})$ \\
\hline 0 & 0 & 235 \\
\hline 10 & 10 & 225 \\
\hline 20 & 14 & 221 \\
\hline
\end{tabular}




\begin{tabular}{|c|c|c|}
\hline 30 & 25 & 210 \\
\hline 40 & 40 & 195 \\
\hline 50 & 57 & 178 \\
\hline 60 & 85 & 150 \\
\hline 80 & 97 & 138 \\
\hline 100 & 105 & 130 \\
\hline 120 & 110 & 125 \\
\hline 2 days & 155 & 80 \\
\hline
\end{tabular}

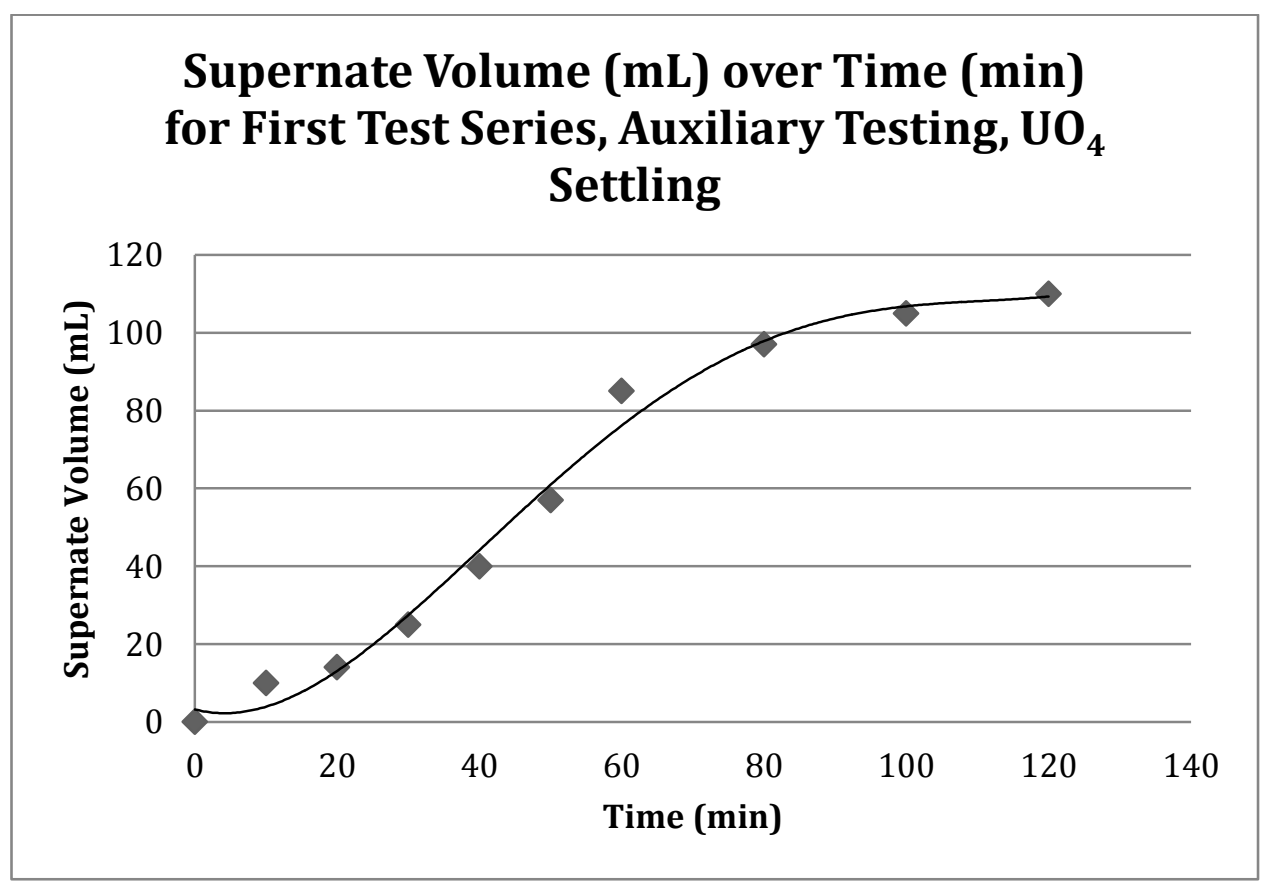

Figure 4.22 - Graph of Supernate Volume (mL) over Time (min) for First Test Series, Auxiliary Testing, $\mathrm{UO}_{4}$ Settling

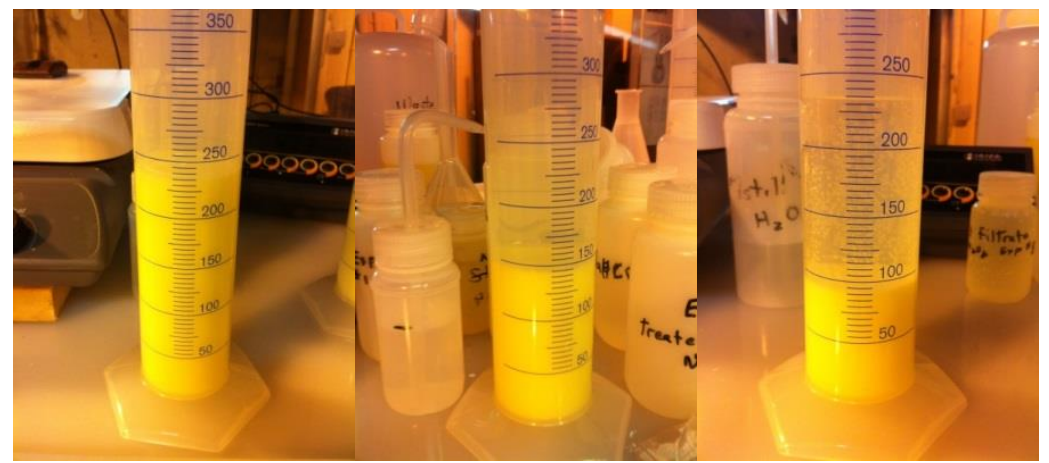

Figure 4.23 - First Test Series, Auxiliary Testing, $\mathrm{UO}_{4}$ Settling 
It is noteworthy that the settling results for the room temperature tests in the auxiliary and second half of Series Two portions were considerably better than the results of the same settling test in the first half of the Series Two work, indicating that larger particle sizes resulted from room temperature reaction conditions.

After 48 hours of settling, the mixture was filtered and the $\mathrm{UO}_{4} \cdot \mathrm{nH}_{2} \mathrm{O}$ crystals were scraped off the filter paper and put into an open container in the work hood. After air-drying for 48 hours, the crystals were put into a tared sample bottle, and the net weight of the dried crystals was $17.76 \mathrm{~g}$. A uranium material balance calculation on this weight, however, indicated some water was still present in the crystals so a heated redrying was planned for later. A sample bottle of the filtrate was also collected for analysis.

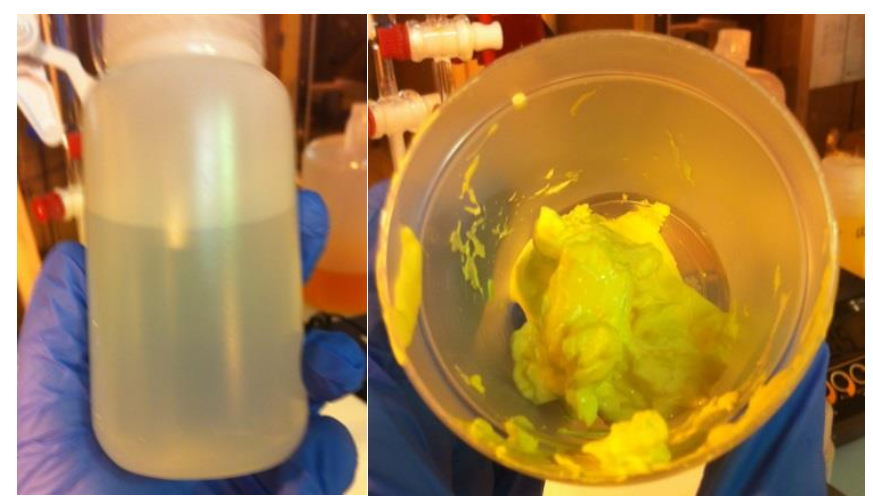

Figure 4.24 - First Test Series, Auxiliary Testing, $\mathrm{UO}_{4}$ (yellow solids) and filtrate (clear liquid)

\section{Third Test Series: KDU Testing with Potassium Bicarbonate}

A third test series was done using analogous potassium compounds in place of sodium compounds as the reagents. The purpose of this series was to identify process differences and detect any possible advantages for using potassium compounds. Very 
little information exists regarding the use of potassium compounds in uranium processes so another goal was to expand the knowledge of what results can be expected. The experiment protocols used were, for the most part, the same as those used for the sodium tests, but followed the modified recovery process outlined at the end of Chapter 3 , and in Figure 4.7.

The first test started with $50 \mathrm{~g}$ of the $\mathrm{UO}_{2} \mathrm{~F}_{2}$ powder dissolved in $300 \mathrm{~mL}$ of distilled water. That mixture was titrated using a burette filled with $100 \mathrm{~mL}$ of $15 \%$ $\mathrm{KOH}$ solution, and a $\mathrm{KDU} / \mathrm{Fe}(\mathrm{OH})_{3}$ mixture was produced. The titration was done very slowly, with heating, to observe any differences and keep the reaction mixture close to equilibrium. Table 4.9 below shows the data collected.

Table 4.9 - Third Test Series, KDU Precipitation

\begin{tabular}{|c|c|c|l|}
\hline $\begin{array}{c}\text { Vol. KOH Added } \\
(\mathrm{mL})\end{array}$ & $\mathrm{pH}$ & Temp. $\left({ }^{\circ} \mathrm{C}\right)$ & \multicolumn{1}{c|}{ Comments } \\
\hline 0 & 1.0 & 22 & Clumps of precipitate, redissolved \\
\hline 4 & 1.5 & 30 & \\
\hline 6 & 2.0 & 32 & \\
\hline 8 & 3.5 & 35 & \\
\hline 10 & 3.5 & 36 & \\
\hline 12 & 4.0 & 37 & \\
\hline 14 & 4.0 & 38 & Clumps more persistent \\
\hline 16 & 4.5 & 39 & Color darkening yellow/brown \\
\hline 18 & 5.0 & 39 & \\
\hline 20 & 5.0 & 39 & \\
\hline 24 & 5.5 & 39 & Clumps stopped forming \\
\hline 28 & 6.0 & 39 & Persistent yellow/brown precipitate \\
\hline 32 & 6.5 & 39 & Precipitate more grainy \\
\hline 36 & 6.5 & 39 & Precipitate getting uniform \\
\hline 40 & 7.0 & 39 & \\
\hline 44 & 7.0 & 39 & \\
\hline 49 & 7.0 & 39 & \\
\hline 57 & 7.5 & 39 & Precipitate very uniform \\
\hline 67 & 7.5 & 39 & \\
\hline 77 & 8.0 & 39 & \\
\hline & & & \\
\hline
\end{tabular}




\begin{tabular}{|c|c|c|l|}
\hline 87 & 9.0 & 39 & \\
\hline 100 & 9.5 & 38 & Precipitation appears complete \\
\hline
\end{tabular}

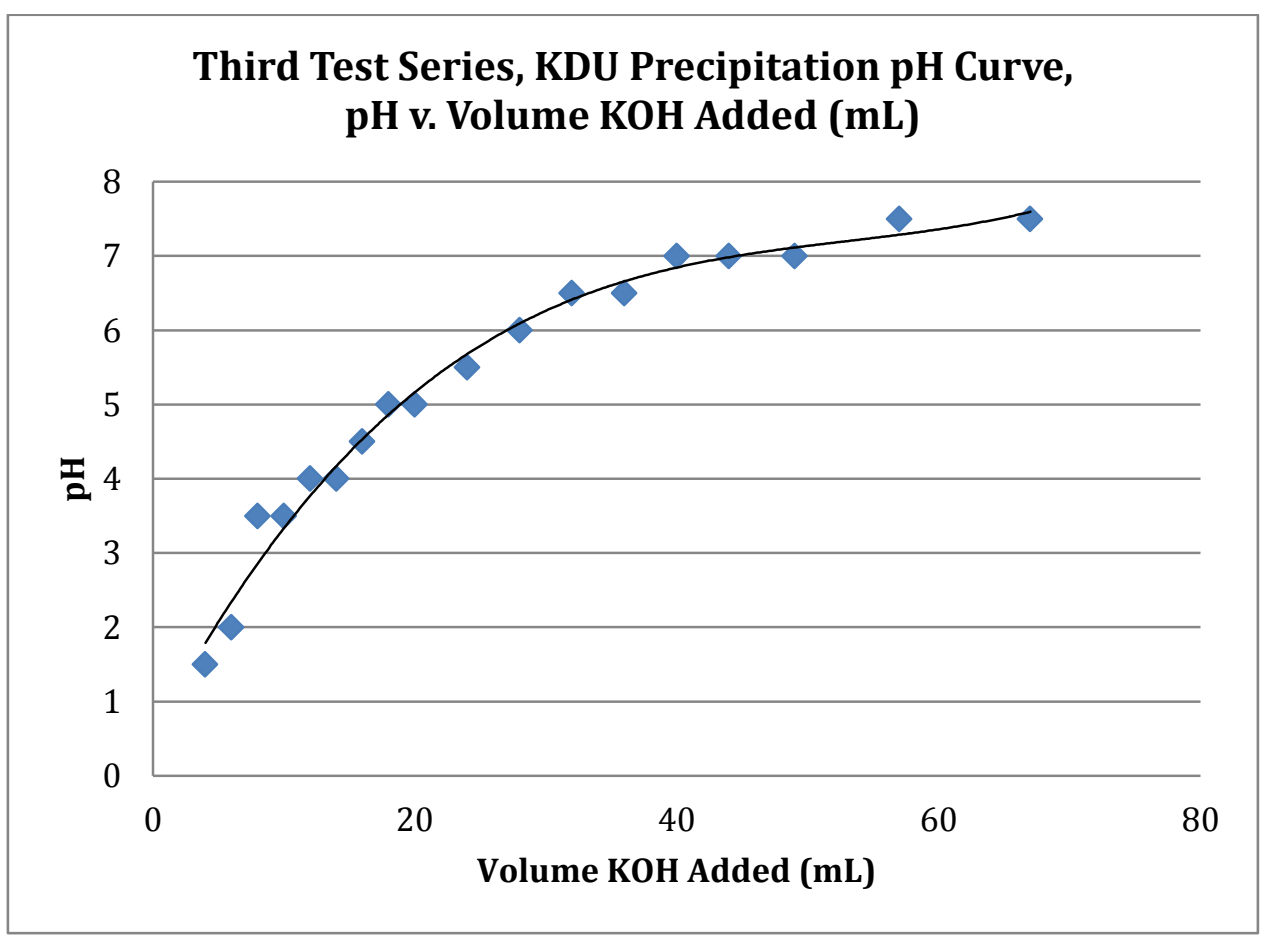

Figure 4.25 - Graph of $\mathrm{pH}$ v. Time (min) for Third Test Series, KDU Precipitation

The KDU mixture was poured into a graduated cylinder for a settling test. Of the $400 \mathrm{~mL}$ of liquid titrated, $20 \mathrm{~mL}$ were lost to evaporation during the 2 hour titration so the volume for the settling test was $380 \mathrm{~mL}$. Table 4.10, below, shows the settling data.

Table 4.10 - Third Test Series, KDU Settling

\begin{tabular}{|c|c|c|}
\hline Time (min) & Supernate Volume (mL) & Slurry Volume $(\mathrm{mL})$ \\
\hline 0 & 0 & 380 \\
\hline 10 & 95 & 285 \\
\hline 20 & 160 & 220 \\
\hline 30 & 200 & 180 \\
\hline 40 & 225 & 155 \\
\hline 50 & 240 & 140 \\
\hline
\end{tabular}




\begin{tabular}{|c|c|c|}
\hline 60 & 245 & 135 \\
\hline 80 & 255 & 125 \\
\hline 100 & 255 & 125 \\
\hline 120 & 257.5 & 122.5 \\
\hline 2 days & 260 & 120 \\
\hline
\end{tabular}

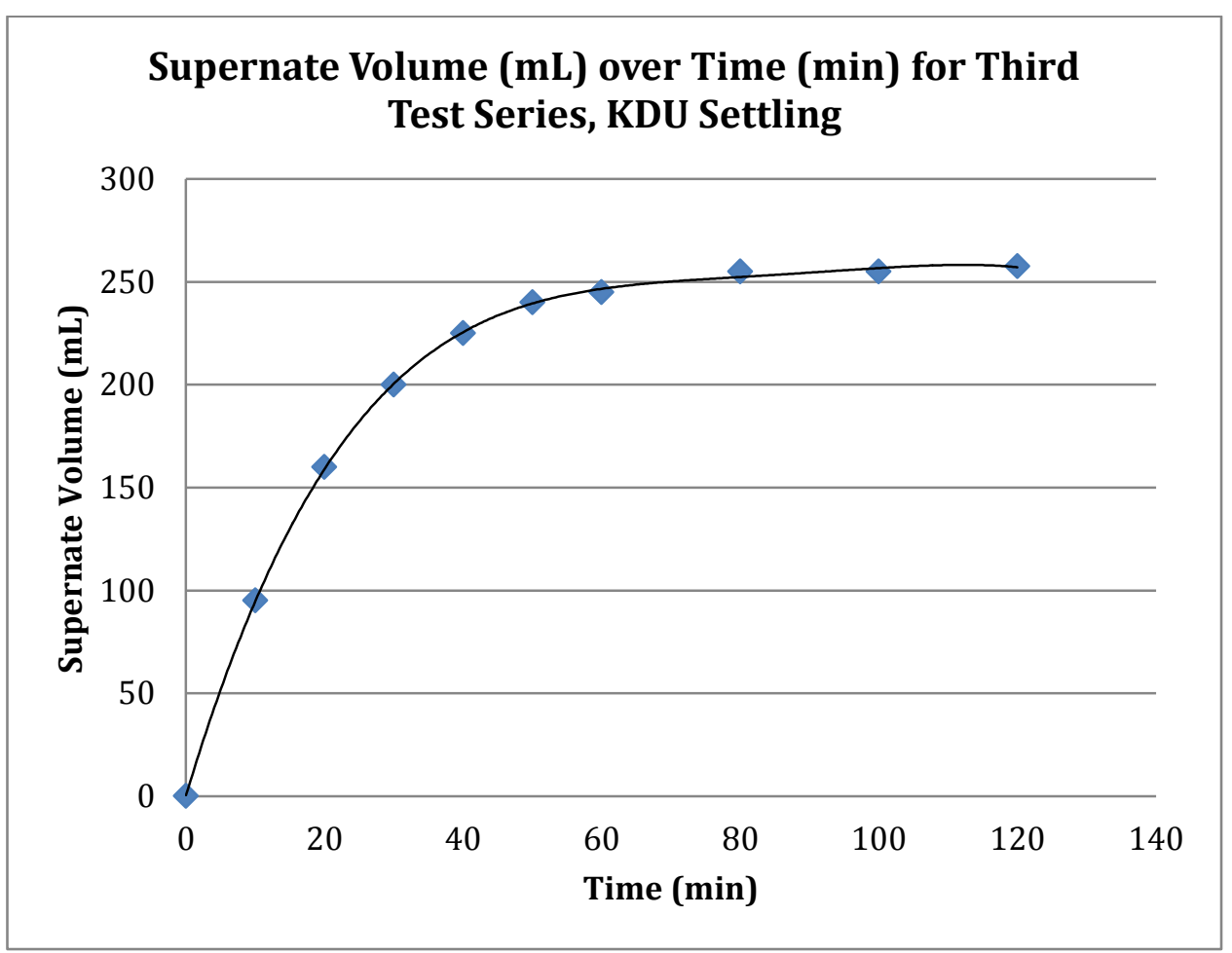

Figure 4.26 - Graph of Supernate Volume (mL) over Time (min) for Third Test Series, KDU Precipitate Settling

After 7 days, the settled mixture was filtered to recover the precipitate. An additional $13 \mathrm{~mL}$ of evaporation loss had occurred from the graduated cylinder, so a total of $367 \mathrm{~mL}$ of mixture plus a few $\mathrm{mL}$ of water used to rinse out the graduated cylinder were filtered. The filter cake was scraped of the filter paper, was re-slurried in $50 \mathrm{~mL}$ of water, and was put in a storage bottle. The filtrate had a $\mathrm{pH}$ of 7.0 , indicating that the precipitation reaction had continued after the titration had stopped causing the $\mathrm{pH}$ to decrease from 9.5 to 7.0. A few drops of $\mathrm{KOH}$ solution were added to the filtrate, 
resulting in more precipitate forming in the filtrate, so the decision was made to resume the titration on the filtrate. Two $10 \mathrm{~mL}$ portions of $\mathrm{KOH}$ were then added to the filtrate. The first raised the $\mathrm{pH}$ to 8.5 and the second raised the $\mathrm{pH}$ to 11.5. A moderate amount of additional precipitate formed in the filtrate, so the $395 \mathrm{~mL}$ of mixture was heated to $40^{\circ} \mathrm{C}$ for a one-hour digestion, and was then poured back into a graduated cylinder for a settling test, the data of which is shown in Table 4.11.

Table 4.11 - Third Test Series, Additional KDU Settling

\begin{tabular}{|c|c|c|}
\hline Time $(\mathrm{min})$ & Supernate Volume $(\mathrm{mL})$ & Slurry Volume $(\mathrm{mL})$ \\
\hline 0 & 0 & 395 \\
\hline 10 & 75 & 320 \\
\hline 20 & 135 & 260 \\
\hline 30 & 185 & 210 \\
\hline 40 & 220 & 175 \\
\hline 50 & 245 & 150 \\
\hline 60 & 265 & 130 \\
\hline 2 days & 332 & 63 \\
\hline
\end{tabular}

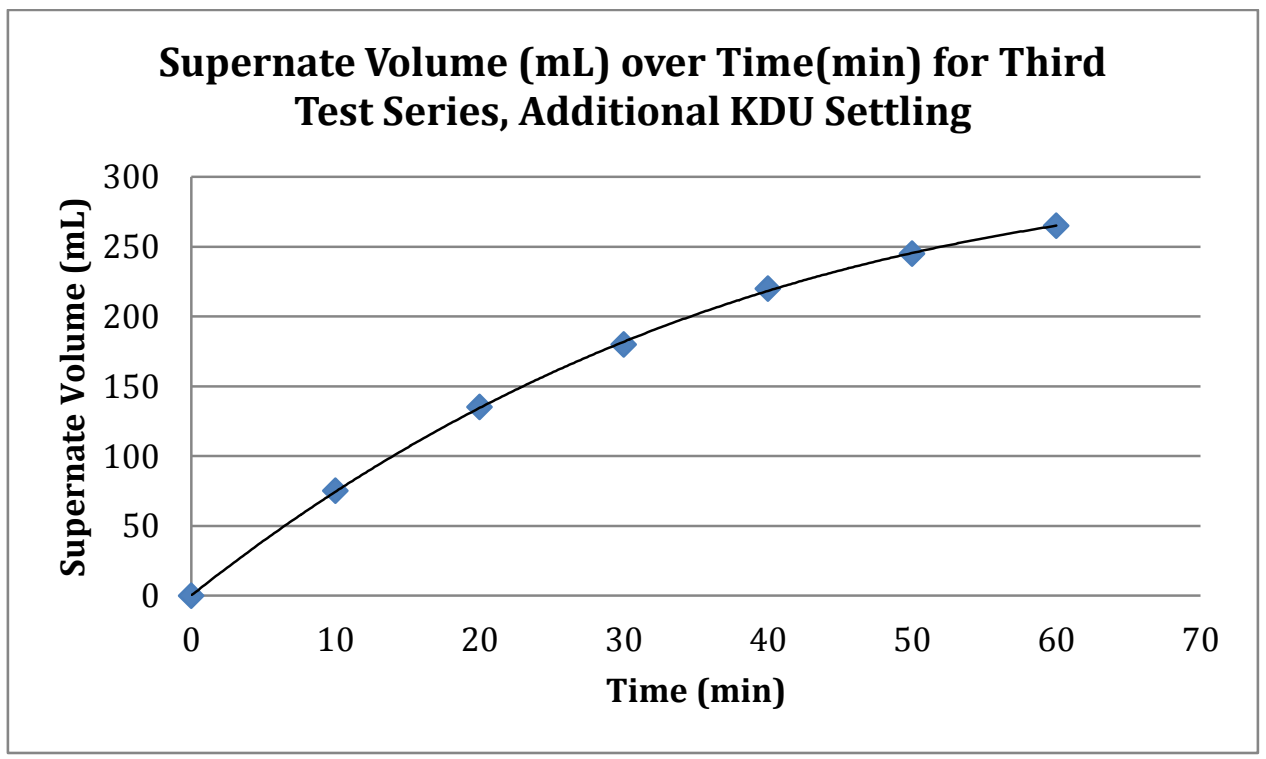

Figure 4.27 - Graph of Supernate Volume (mL) over Time (min) for Third Test Series, Additional KDU Settling 


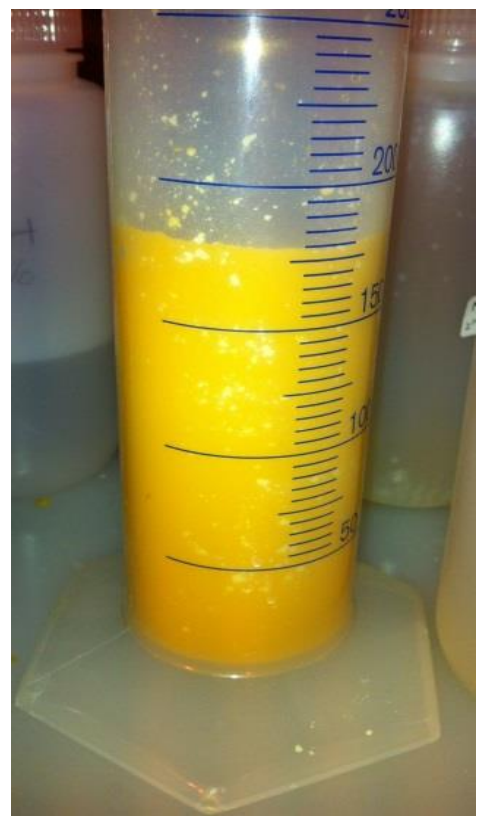

Figure 4.28 - Third Test Series KDU Extraction after settling.

After two days the settled mixture was filtered and the filter cake was re-slurried in $50 \mathrm{~mL}$ of water and put into a storage bottle. The filtrate test $\mathrm{pH} 11.5$ indicating the precipitation reaction had gone to completion in the second titration. The filtrate was saved in a storage bottle for later analysis.

The next step was to set up for carbonate extraction of the KDU filter cakes. Because of the good results using $\mathrm{NaHCO}_{3}$ as the extractant in the auxiliary series above, it was decided to use its analog, $\mathrm{KHCO}_{3}$, for the first potassium-based carbonate extraction. A solution of $\mathrm{KHCO}_{3}$ could not be obtained, so a crystalline solid version of the compound was procured, and a solution was prepared by dissolving $90 \mathrm{~g}$ of the $\mathrm{KHCO}_{3}$ crystals in $300 \mathrm{~mL}$ of distilled water. This solution tested at $\mathrm{pH} 7.5$, somewhat lower than the 8.27 measured for the $\mathrm{NaHCO}_{3}$ solution. The filter cakes from the two $\mathrm{KDU} / \mathrm{Fe}(\mathrm{OH})_{3}$ filtrations, $100 \mathrm{~mL}$ of water, and the filter paper rinse waters were combined in a beaker and stirred to re-slurry the solids. The combined mixture volume 
was $175 \mathrm{~mL}$. A burette was filled with $100 \mathrm{~mL}$ of the $\mathrm{KHCO}_{3}$ solution, as prepared above, and was mounted over the beaker. The titration data is shown in Table 4.12.

Table 4.12 - Third Test Series, First Uranyl Carbonate Extraction Titration

\begin{tabular}{|c|c|c|l|}
\hline Time (min) & Vol. $\mathrm{KHCO}_{3}$ Added $(\mathrm{mL})$ & $\mathrm{pH}$ & \multicolumn{1}{|c|}{ Comments } \\
\hline 0 & 0 & 7.0 & \\
\hline 4 & 10 & 7.0 & \\
\hline 13 & 20 & 7.0 & \\
\hline 19 & 30 & 7.0 & \\
\hline 22 & 40 & 7.0 & Beginning to see bubbles \\
\hline 25 & 50 & 7.0 & \\
\hline 28 & 60 & 7.0 & More vigorous bubbles \\
\hline 31 & 70 & 7.0 & \\
\hline 33 & 80 & 7.0 & \\
\hline 37 & 90 & 7.0 & \\
\hline 39 & 100 & 7.0 & Stopped to reload burette \\
\hline 43 & - & - & Started back up \\
\hline 46 & 110 & 7.0 & Getting brown color in slurry \\
\hline 49 & 120 & 6.7 & Stopped titration \\
\hline
\end{tabular}

The slurry was then poured into a graduated cylinder to start a settling test.

Bubbles continued to form but no settling was observed, so the settling test was aborted and the mixture was put back into a beaker and placed on the stir plate. The heater was turned on and the mixture was warmed to $40^{\circ} \mathrm{C}$. Once this temperature was reached, an additional $40 \mathrm{~mL}$ of $\mathrm{KHCO}_{3}$ solution was slowly added, which generated even more bubbles, indicating that the $\mathrm{pH}$ was so low that the carbonate was breaking down into $\mathrm{CO}_{2}$. At a low enough $\mathrm{pH}$, the carbonate reacts with the nitric acid before it can react with the uranium and following reaction takes place before the uranyl carbonate can form.

$$
\mathrm{KHCO}_{3}+\mathrm{HNO}_{3} \rightarrow \mathrm{CO}_{2}+\mathrm{H}_{2} \mathrm{O}+\mathrm{KNO}_{3}
$$


To counteract this, a $4 \mathrm{~mL}$ allotment of $15 \% \mathrm{KOH}$ solution was added to the mixture to pull the $\mathrm{pH}$ back up, and the bubbling stopped. The mixture was poured back into the graduated cylinder, but no immediate settling occurred. The mixture was left in the graduated cylinder for 72 hours, after which the solids slurry had settled to $190 \mathrm{~mL}$ supernate liquid and $145 \mathrm{~mL}$ of combination $\mathrm{KDU} / \mathrm{Fe}(\mathrm{OH})_{3}$ solids. The mixture was filtered and the filter cake was scraped off the filter paper into a beaker. The yellow colored filtrate was put into a storage bottle as the first carbonate extraction.

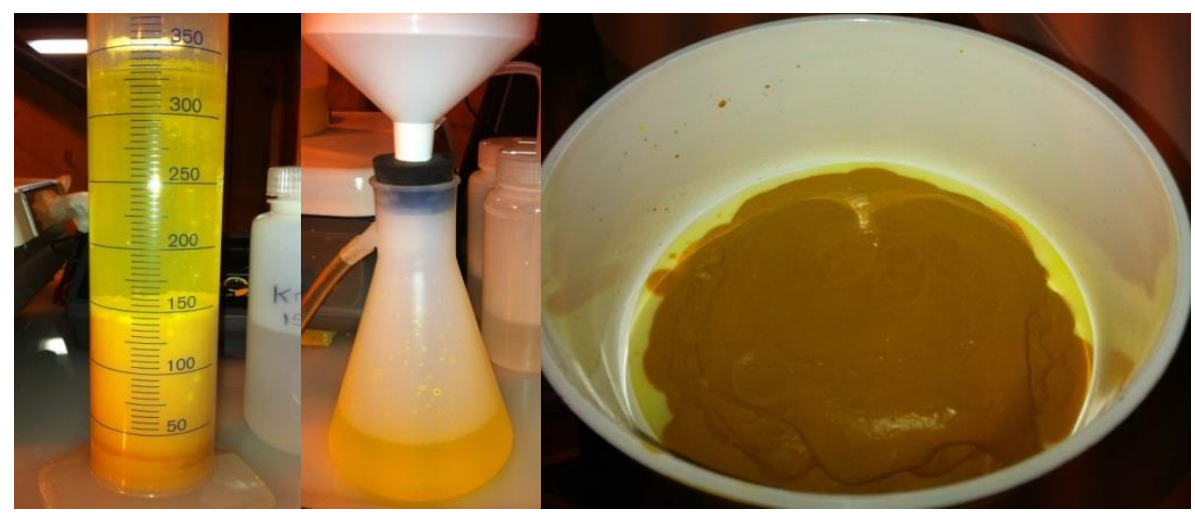

Figure 4.29 - Third Test Series, First Carbonate Extraction. High volume of solids on filter led to the belief that not all of the uranium had been extracted, so a second attempt was made.

The substantial amount of solids left after the first uranyl carbonate extraction indicated that a significant amount of KDU did not dissolve as carbonate complex, so the cake in the beaker was mixed with $120 \mathrm{~mL}$ more $\mathrm{KHCO}_{3}$ solution. That mixture was stirred and heated to $40^{\circ} \mathrm{C}$ for one hour and was then poured back into a graduated cylinder for four days. The mixture $\mathrm{pH}$ was 9.0. After four days, the mixture was filtered and the yellow colored filtrate was put into a storage bottle as the second carbonate extraction. The filter cake was scraped off the filter paper, re-slurried in water and put into a storage bottle. 


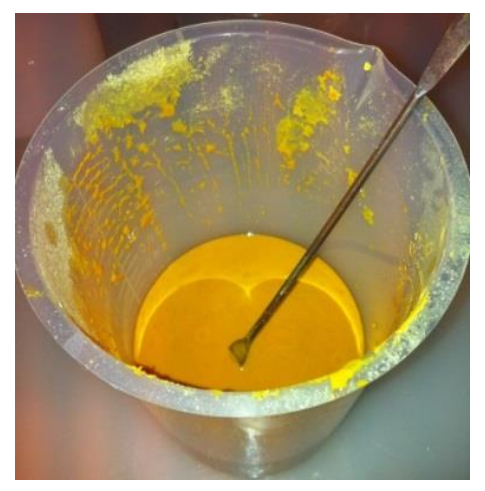

Figure 4.30 - Re-slurried solids from Third Test Series, first carbonate extraction

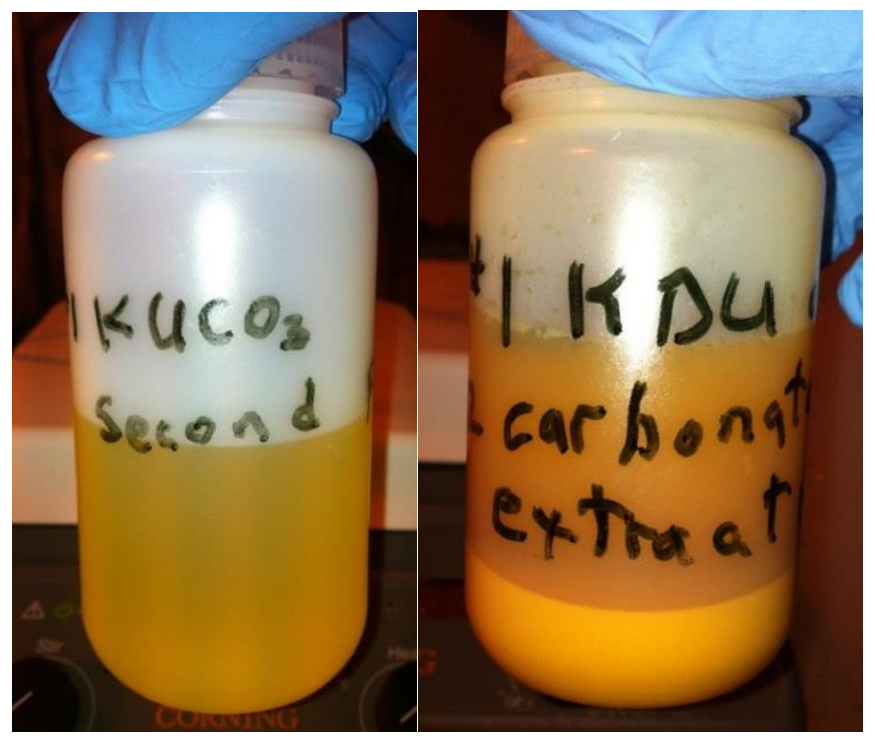

Figure 4.31 - Left to right: Third Test Series, second carbonate extraction filtrate; Solids from second carbonate extraction, re-slurried in water.

Three days later, the slurry in the storage bottle was put back into a beaker and a third carbonate extraction was done. The mixture was heated to $40^{\circ} \mathrm{C}$ and $100 \mathrm{~mL}$ more of $\mathrm{KHCO}_{3}$ was slowly added. The $\mathrm{pH}$ of the mixture started at 8.0 and remained at 8.0 throughout the carbonate addition. No evolution of bubbles occurred. The heat was turned off and filtering preparations were started. Before filtration was started, however, 
the mixture separated quickly into a dark brown slurry above a tan sediment, as shown in Figure 4.32 .

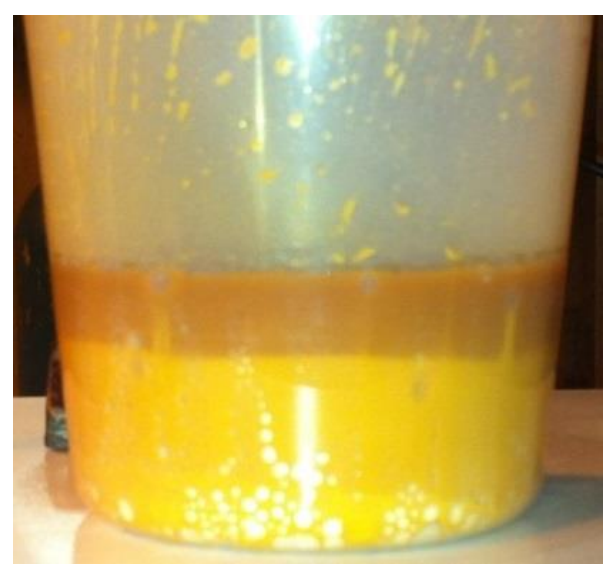

Figure 4.32 - Attempted third carbonate extraction

When filtration was started the slurry portion easily separated from the sediment layer so it was decanted off the top, through the filter. Nearly all of the dark brown material decanted off the sediment so the filtration was stopped at the end of the decanting. The filtered solid was a grainy, almost black material on the filter paper. The filter paper was set aside to air dry and the sediment slurry was poured back into its storage bottle with enough $\mathrm{KHCO}_{3}$ solution to fill the bottle. The filtrate was put in a separate storage bottle and set aside as the third carbonate extraction. 


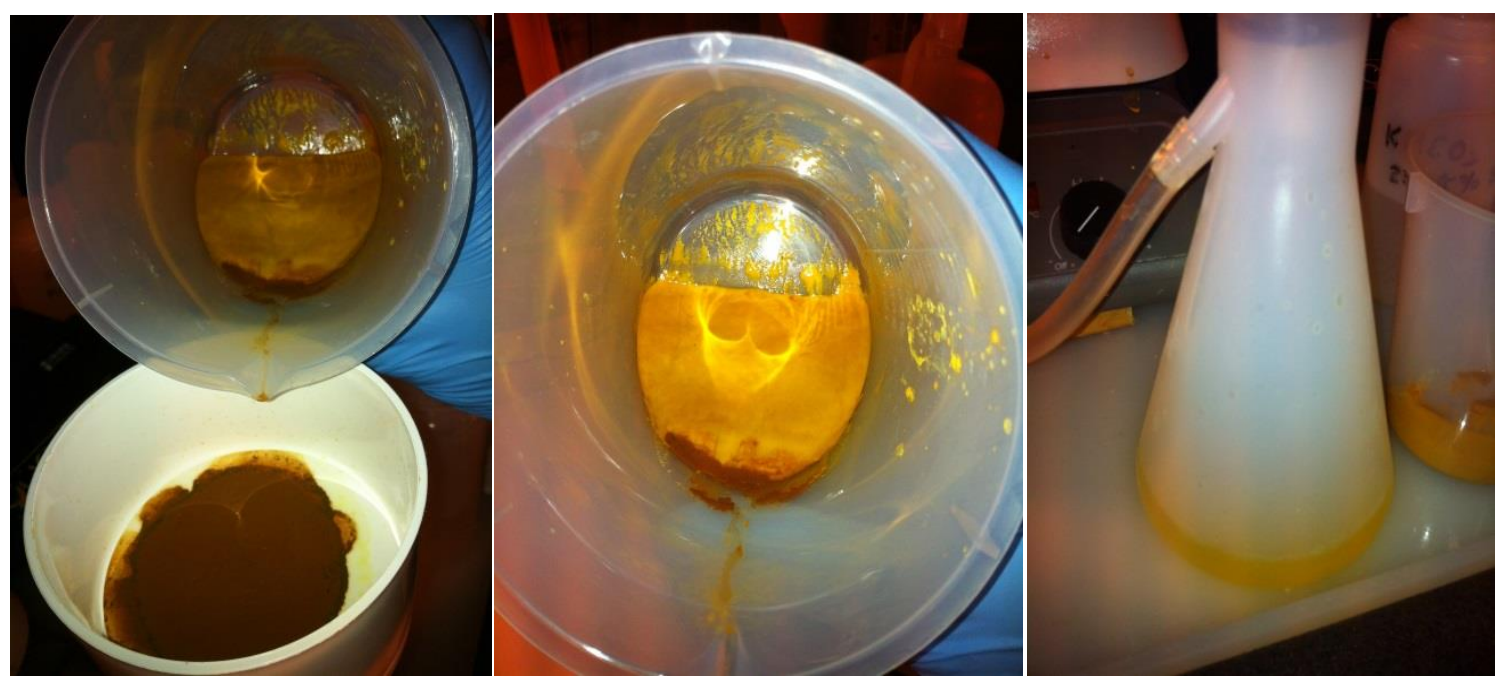

Figure 4.33 - Third Test Series, Third Carbonate Extraction filtration.

Dark brown solids on filter are mostly iron; the yellow solids indicate the presence of even more uranium. It was determined that the potassium series made total uranium extraction too difficult. The yellow liquid on the left is the third carbonate extraction filtrate.

With the result so far that the KDU was substantially too resistant to the $\mathrm{KHCO}_{3}$ extraction attempts, the decision was made to abandon further efforts on this approach. One final idea for using a potassium-based reagent was to repeat the carbonate extraction attempts with $\mathrm{K}_{2} \mathrm{CO}_{3}$ solution in place of $\mathrm{KHCO}_{3}$ solution.

\section{Fourth Test Series: KDU Testing with Potassium Carbonate}

The fourth test series was put forth to duplicate the $\mathrm{KOH}$ precipitation sequence, then attempt to extract the uranium from the $\mathrm{KDU}$ with $\mathrm{K}_{2} \mathrm{CO}_{3}$ solution, while heating the reactions to about $40^{\circ} \mathrm{C}$. The batch size was reduced to half, so the series started with $25 \mathrm{~g} \mathrm{UO}_{2} \mathrm{~F}_{2}$ dissolved in $150 \mathrm{~mL}$ water. This solution was titrated with $15 \% \mathrm{KOH}$ and Table 4.13 below shows the titration results. 
Table 4.13 - Fourth Test Series, KDU Precipitation

\begin{tabular}{|c|c|c|c|}
\hline Time & Vol. KOH Added $(\mathrm{mL})$ & $\mathrm{pH}$ & Temp. $\left({ }^{\circ} \mathrm{C}\right)$ \\
\hline $1: 52$ & 0 & 1.0 & 22 \\
\hline $1: 56$ & 10 & 3.5 & 35 \\
\hline $2: 01$ & 20 & 5.0 & 37 \\
\hline $2: 06$ & 30 & 6.5 & 38 \\
\hline $2: 12$ & 40 & 7.0 & 39 \\
\hline $2: 18$ & 50 & 7.5 & 40 \\
\hline $2: 24$ & 60 & 8.0 & 40 \\
\hline $2: 28$ & 65 & 9.0 & 40 \\
\hline $2: 33$ & 70 & 9.5 & 40 \\
\hline $2: 38$ & 75 & 10.0 & 40 \\
\hline
\end{tabular}

The mixture was held at $40^{\circ} \mathrm{C}$ for one hour and was then poured into a graduated cylinder. After four days, the $\mathrm{pH}$ of the mixture had decreased to 7.0, so $3 \mathrm{~mL}$ of $\mathrm{KOH}$ solution were added to bring the $\mathrm{pH}$ up to 12 . The mixture was filtered and the KDU cake was mixed with water and put into a storage bottle.

A solution of $150 \mathrm{~g} \mathrm{~K}_{2} \mathrm{CO}_{3}$ in $300 \mathrm{~mL}$ water was prepared which measured $\mathrm{pH} 12$. The water slurry of KDU was put in a beaker and titrated with the prepared $\mathrm{K}_{2} \mathrm{CO}_{3}$ solution. A total of $200 \mathrm{~mL}$ of carbonate solution were added to the mixture while holding the temperature at $40^{\circ} \mathrm{C}$, then the heat was turned off and the mixture was continually stirred for 72 hours as a digestion step. Even after the extended digestion time there was still substantial un-dissolved KDU remaining in the mixture, so further efforts were abandoned, and this concluded the study of potassium-based reagents. The conclusion drawn from the testing was that while the KDU precipitation is just as adequate as the SDU precipitation, subsequent complete recovery of soluble uranyl carbonate from the KDU is much more difficult and not practical. 


\section{Fifth Test Series: Modified SDU Confirmation}

A final uranium test series was performed as a confirmation run of the SDU techniques developed from the results of the first and second test series. The tests started with $50 \mathrm{~g}$ of $\mathrm{UO}_{2} \mathrm{~F}_{2}$ powder dissolved in $300 \mathrm{~mL}$ water which was put into a beaker and titrated with $8 \% \mathrm{NaOH}$, at room temperature. The titration is recorded in Table 4.14 below.

Table 4.14 - Fifth Test Series, SDU Precipitation

\begin{tabular}{|c|c|c|l|}
\hline Time & Vol. NaOH Added $(\mathrm{mL})$ & $\mathrm{pH}$ & \multicolumn{1}{|c|}{ Comments } \\
\hline $9: 23$ & 0 & 1.0 & Light green solution \\
\hline $9: 27$ & 20 & 4.5 & Local precipitate clumps, dark color \\
\hline $9: 32$ & 40 & 5.0 & More persistent precipitate \\
\hline $9: 37$ & 60 & 7.0 & More persistent heavy precipitate \\
\hline $9: 41$ & 80 & 8.0 & Heavy precipitate, dark yellow \\
\hline $9: 45$ & 100 & 8.0 & \\
\hline $9: 52$ & 120 & 8.0 & \\
\hline $9: 56$ & 130 & 8.5 & \\
\hline $10: 02$ & 140 & 9.0 & \\
\hline $10: 07$ & 150 & 9.0 & \\
\hline $10: 11$ & 160 & 9.5 & \\
\hline $10: 16$ & 170 & 10.0 & \\
\hline $10: 19$ & 180 & 11.0 & \\
\hline $10: 20$ & 180 & 11.0 & Started one-hour digestion \\
\hline $11: 20$ & 180 & 8.0 & Still heavy precipitate, but low pH \\
\hline $11: 21$ & 185 & 9.0 & \\
\hline $11: 22$ & 190 & 9.5 & \\
\hline $11: 23$ & 195 & 9.5 & \\
\hline $11: 24$ & 200 & 9.5 & \\
\hline $11: 25$ & 205 & 9.7 & \\
\hline $11: 26$ & 210 & 10.0 & \\
\hline $11: 26$ & 215 & 11.0 & Started second hour-long digestion \\
\hline $12: 26$ & 215 & 9.5 & \\
\hline $12: 27$ & 225 & 11.0 & Precipitation complete \\
\hline & & & \\
\hline
\end{tabular}




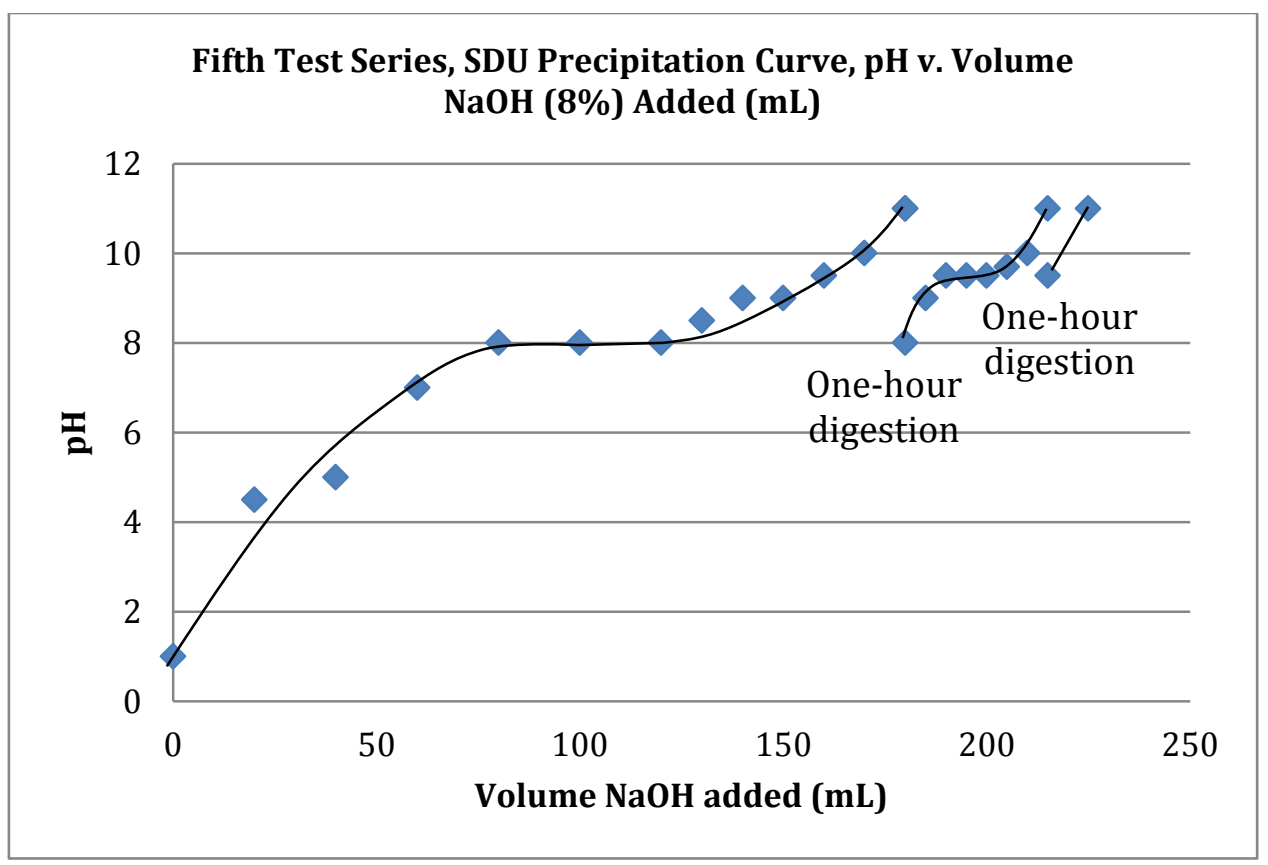

Figure 4.34 - Graph of Fifth Test Series, SDU Precipitation pH Curve, pH v. Volume $\mathrm{NaOH}$ Added $(\mathrm{mL})$

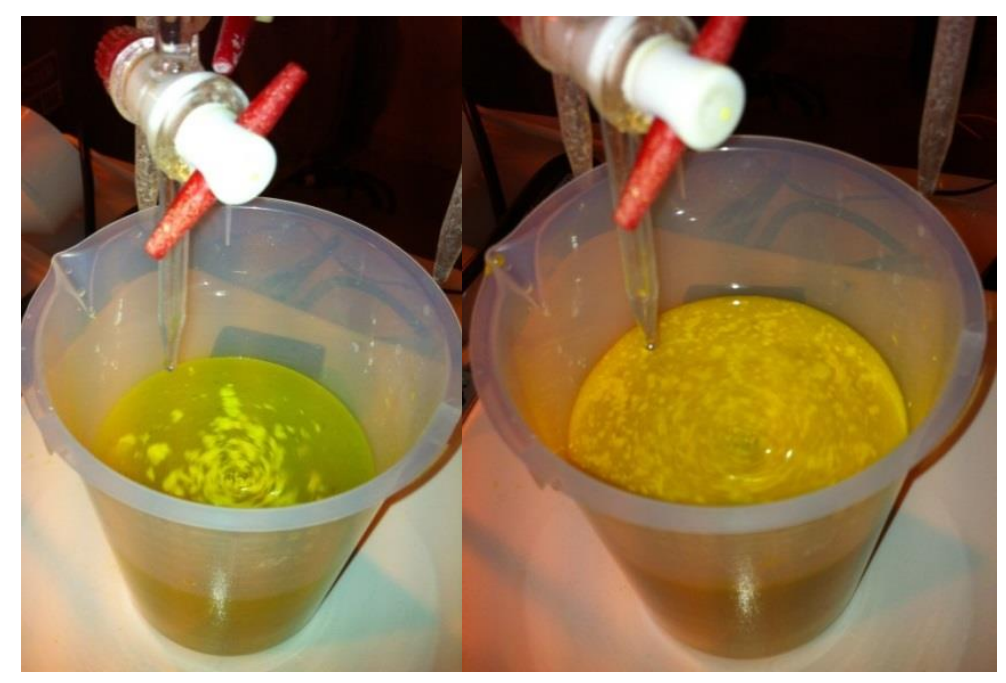

Figure 4.35 - Fifth Test Series SDU Precipitation

The precipitation slurry and a small amount of rinse water were transferred to a graduated cylinder for a settling test. Results of that test are in Table 4.15. 
Table 4.15 - Fifth Test Series, SDU Settling

\begin{tabular}{|c|c|c|}
\hline Time & Supernate Volume $(\mathrm{mL})$ & Slurry Volume $(\mathrm{mL})$ \\
\hline $12: 42$ & 0 & 528 \\
\hline $12: 52$ & 63 & 465 \\
\hline $13: 02$ & 108 & 420 \\
\hline $13: 12$ & 153 & 375 \\
\hline $13: 22$ & 191 & 337 \\
\hline $13: 32$ & 228 & 300 \\
\hline $13: 42$ & 253 & 275 \\
\hline $13: 52$ & 298 & 230 \\
\hline $14: 02$ & 318 & 210 \\
\hline $14: 12$ & 328 & 200 \\
\hline $14: 22$ & 343 & 185 \\
\hline $14: 32$ & 358 & 170 \\
\hline $14: 42$ & 363 & 165 \\
\hline Overnight & $383(\mathrm{pH}=10.5)$ & $145(27.5 \%$ of total volume $)$ \\
\hline
\end{tabular}

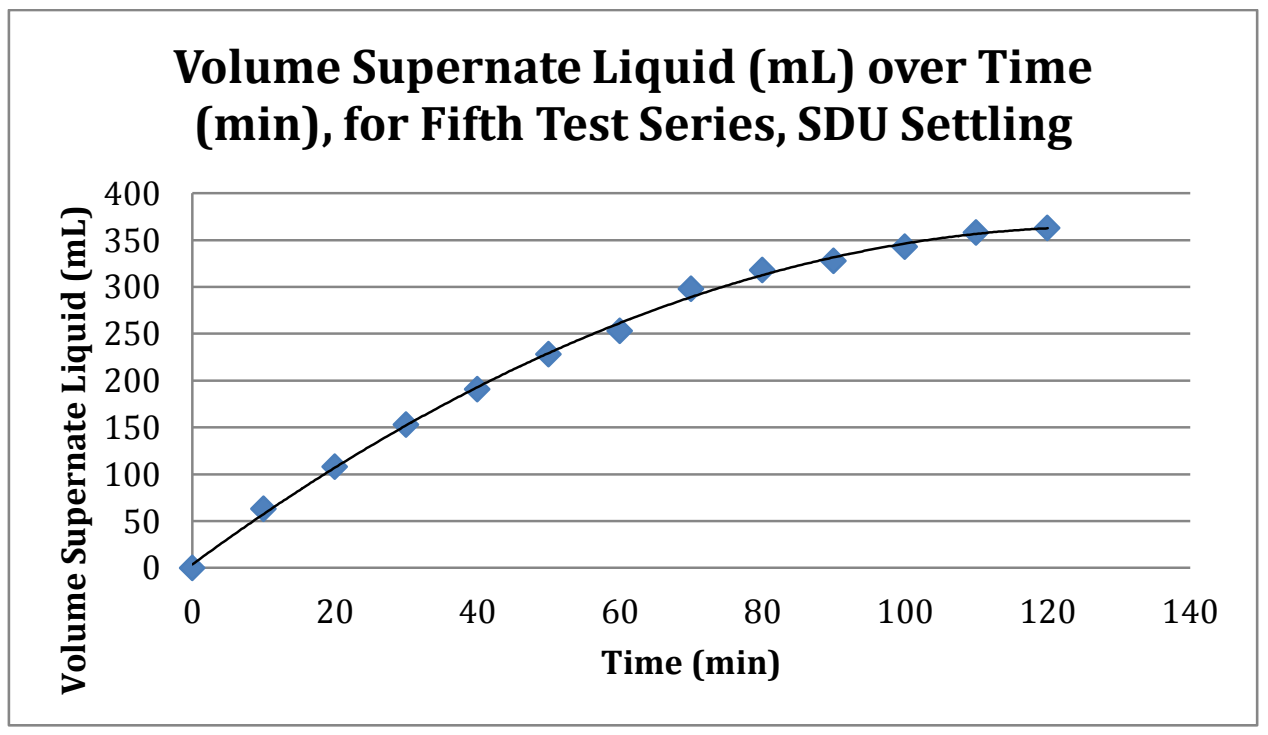

Figure 4.36 - Graph of Volume Supernate Liquid (mL) over Time (min) for Fifth Test Series, SDU Settling 


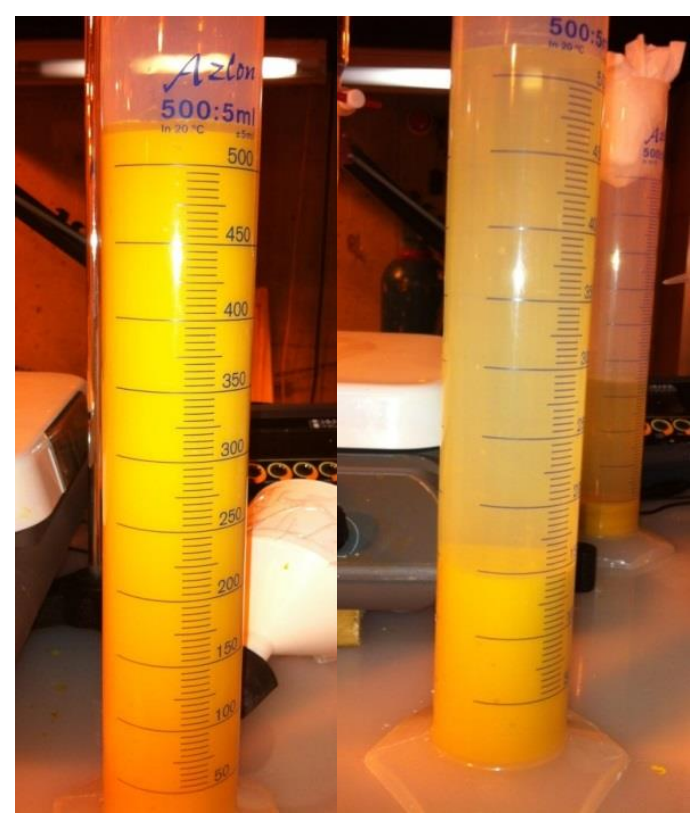

Figure 4.37 - Fifth Test Series SDU Settling

The mixture in the graduated cylinder was then filtered (filtration time $=14$ minutes) and the filter cake was scraped into a beaker where $200 \mathrm{~mL}$ of saturated $\mathrm{NaHCO}_{3}$ solution was added. The mixture was stirred for about 15 minutes then another $100 \mathrm{~mL}$ of $\mathrm{NaHCO}_{3}$ and $150 \mathrm{~mL}$ water was added. The mixture was stirred for another hour, and the stirring was stopped and the slurry was allowed to settle for 15 minutes, so that the color intensity of the supernate liquid might be observed. The color was only moderately intense, indicating that not much uranyl carbonate had been produced, so the stirring was resumed and the heater was turned on. The slurry was heated to $40^{\circ} \mathrm{C}$ and stirred for an additional hour after which it was poured into a graduated cylinder for a settling test. The settling was slow with only $21 \%$ supernate separation after one hour of settling. The mixture was then filtered (filtration time $=1$ hour 35 minutes). The filtrate, which was the first carbonate extraction for this series, was put into a storage bottle. The 
filter cake was re-slurried in $250 \mathrm{~mL}$ water (slurry $\mathrm{pH} \mathrm{10)}$ and put into a storage bottle overnight.

The next day, the slurry was put back into a beaker and $8 \mathrm{~mL}$ of $20 \% \mathrm{HNO}_{3}$ was added to decrease the $\mathrm{pH}$ to 8.0 . $100 \mathrm{~mL}$ of saturated $\mathrm{NaHCO}_{3}$ solution was added and the mixture was stirred at room temperature for one hour, and then poured back into a graduated cylinder. Settling was observed to be once again very slow, so the mixture was put back into a beaker and another $8 \mathrm{~mL}$ of acid was added to decrease the $\mathrm{pH}$ to 7.5. The heater was turned on and the mixture was stirred for one hour at $40^{\circ} \mathrm{C}$. The volume of mixture at that point was $290 \mathrm{~mL}$, which was poured back into a graduated cylinder and kept there overnight.

The next day, the mixture had settled to $200 \mathrm{~mL}$ supernate liquid and $90 \mathrm{~mL}$ slurry, with a pH of 7.5. It was filtered, and the intensely colored filtrate was designated as the second carbonate extraction. The filter cake was re-slurried in $100 \mathrm{~mL}$ water and $100 \mathrm{~mL}$ saturated $\mathrm{NaHCO}_{3}$. It was then stirred and heated to $40^{\circ} \mathrm{C}$ for 1 hour 35 minutes, and then poured into a graduated cylinder. The $220 \mathrm{~mL}$ of mixture had completely separated into $200 \mathrm{~mL}$ of intensely colored supernate liquid and $40 \mathrm{~mL}$ of a dark brown slurry after one hour. The final $\mathrm{pH}$ was 8.0. After filtering, the filtrate was designated as the third carbonate extraction and the brown filter cake was placed in a small container to air dry. After 72 hours of drying, the brown residue net weight was $2.157 \mathrm{~g}$. The theoretical residue weight from $50 \mathrm{~g}$ of starting material dosed with $3 \% \mathrm{FeF}_{3}$ would be about $0.03 \times 50=1.5 \mathrm{~g} \mathrm{Fe}(\mathrm{OH})_{3}$, so the maximum SDU carryover possible is $0.657 \mathrm{~g}$ or $0.657 / 49.92 \times 100=0.013$ or $1.3 \%$ of the original SDU in this series. Un-evaporated 
water likely contributed some to the residue weight so the actual SDU carryover loss was likely less than $1 \%$.

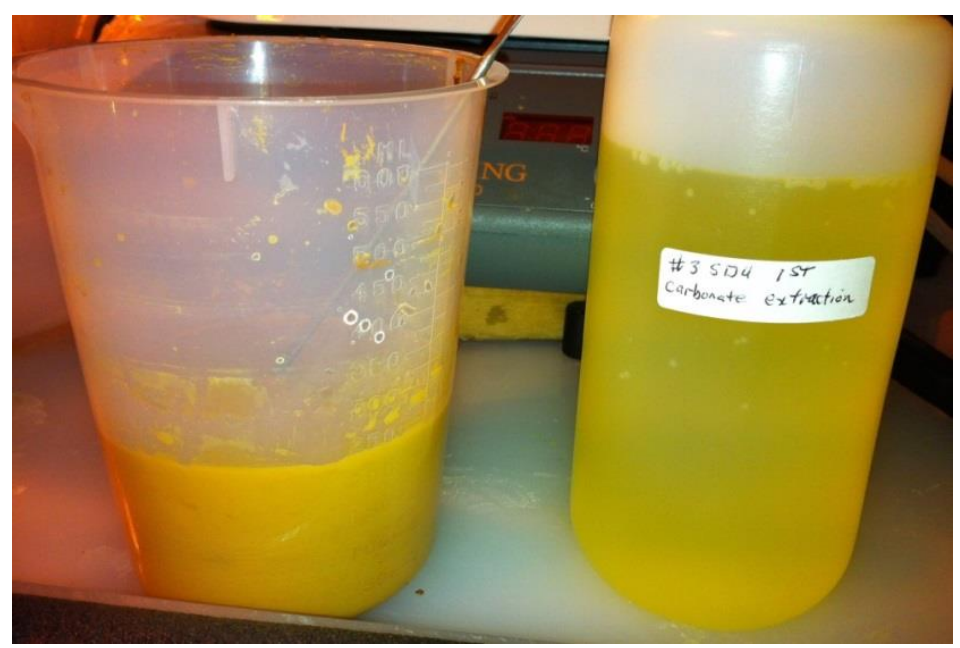

Figure 4.38 - Fifth Test Series SDU Carbonate Extraction 1. Residual solids are on the left, re-slurried in water. Carbonate extraction is on the right.

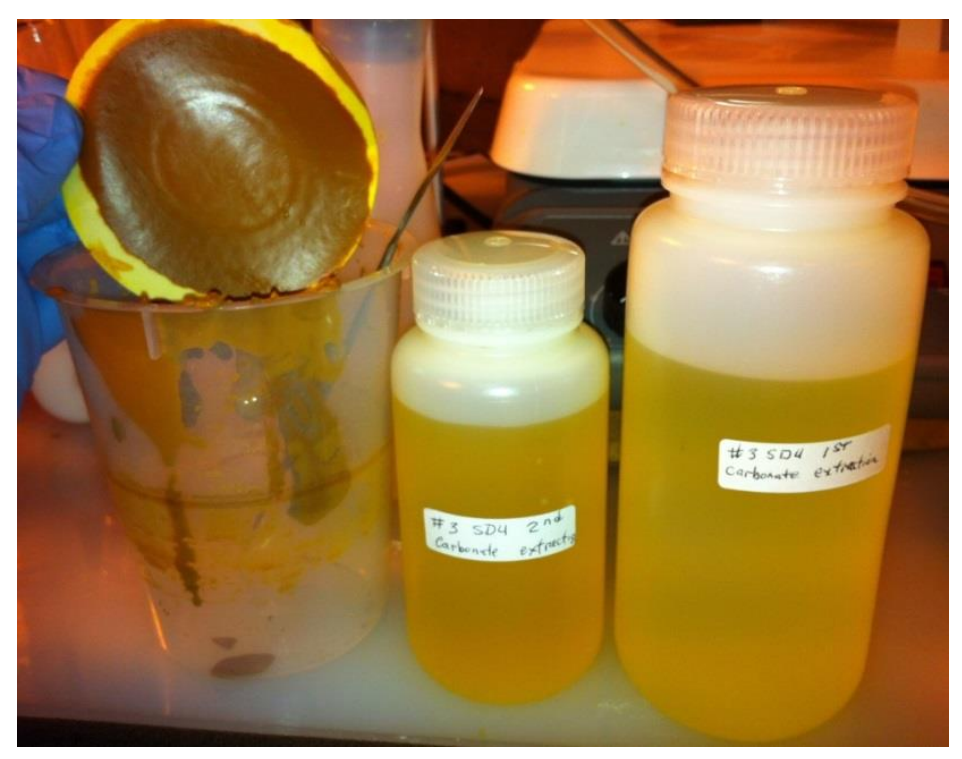

Figure 4.39 - Fifth Test Series SDU Carbonate Extraction 2. Residual solids on the left and carbonate extractions \#2 and \#1 on the right. 


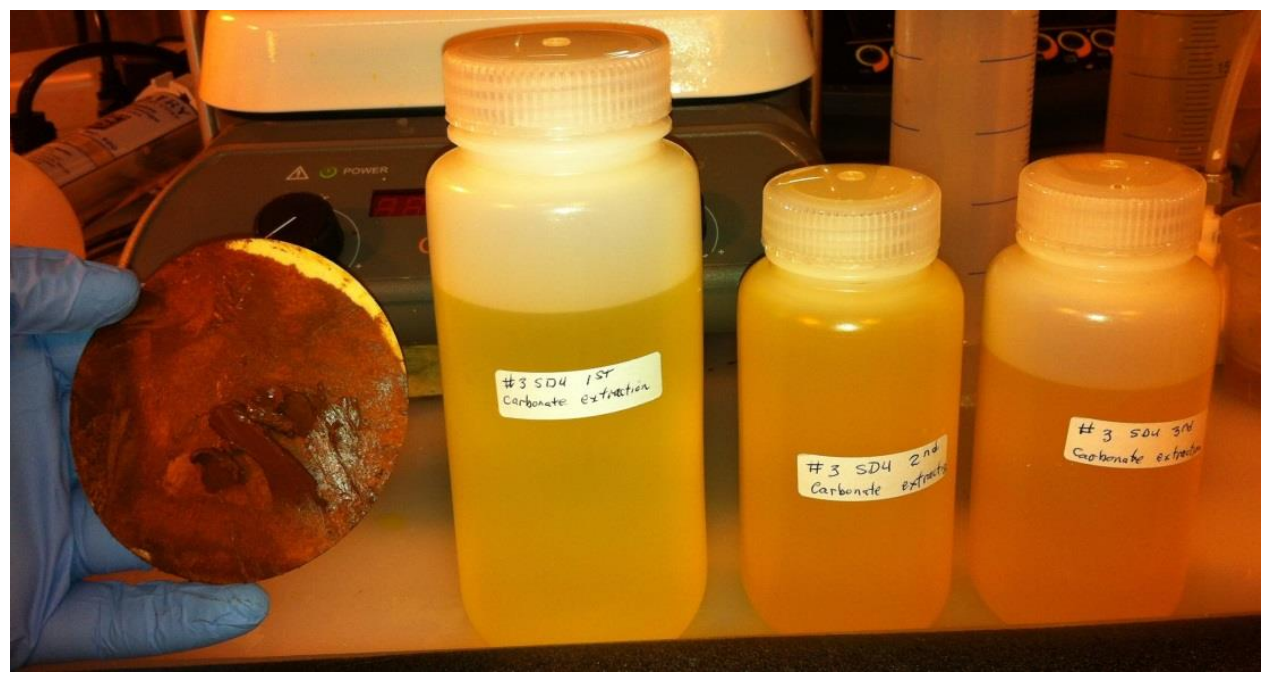

Figure 4.40 - Fifth Test Series SDU Carbonate Extraction 3.

The final bit of deep brown residue is on the left and all three carbonate extractions are on the right.

The three carbonate extractions totaled more than the capacity of the processing beaker, so they were peroxide precipitated in three batches comprised as follows:

1. Batch 1 was the entire first carbonate extraction

2. Extractions 2 and 3 were combined, then divided in half to make Batch 2 and Batch 3 for the peroxide precipitation.

The data for each of the batches follows.

\section{Batch 1}

First, $100 \mathrm{~mL}$ of extract starter solution was added to a beaker, and $20 \% \mathrm{HNO}_{3}$ was added slowly to reduce the $\mathrm{pH}$ to 3.5. Then the combined slow addition of $\mathrm{H}_{2} \mathrm{O}_{2}$, extract solution, and acid commenced. The data is shown in Table 4.16 below. 
Table 4.16 - Fifth Test Series, Batch 1, $\mathrm{UO}_{4}$ Precipitation

\begin{tabular}{|c|c|c|c|}
\hline $\begin{array}{c}\text { Volume Carbonate } \\
(\mathrm{mL})\end{array}$ & Volume $\mathrm{H}_{2} \mathrm{O}_{2}(\mathrm{~mL})$ & Volume $\mathrm{HNO}_{3}(\mathrm{~mL})$ & $\mathrm{pH}$ \\
\hline 100 & 0 & 0 & 11.5 \\
\hline 100 & 0 & 2 & 7.5 \\
\hline 100 & 0 & 4 & 7.0 \\
\hline 100 & 0 & 15 & 6.0 \\
\hline 100 & 0 & 17 & 5.0 \\
\hline 100 & 0 & 20 & 5.0 \\
\hline 100 & 0 & 21 & 4.5 \\
\hline 100 & 0 & 22 & 3.5 \\
\hline 200 & 26 & 42 & 3.5 \\
\hline 300 & 55 & 64 & 2.5 \\
\hline 400 & 82 & 83 & 4.0 \\
\hline 412 & 84 & 87 & 3.5 \\
\hline
\end{tabular}

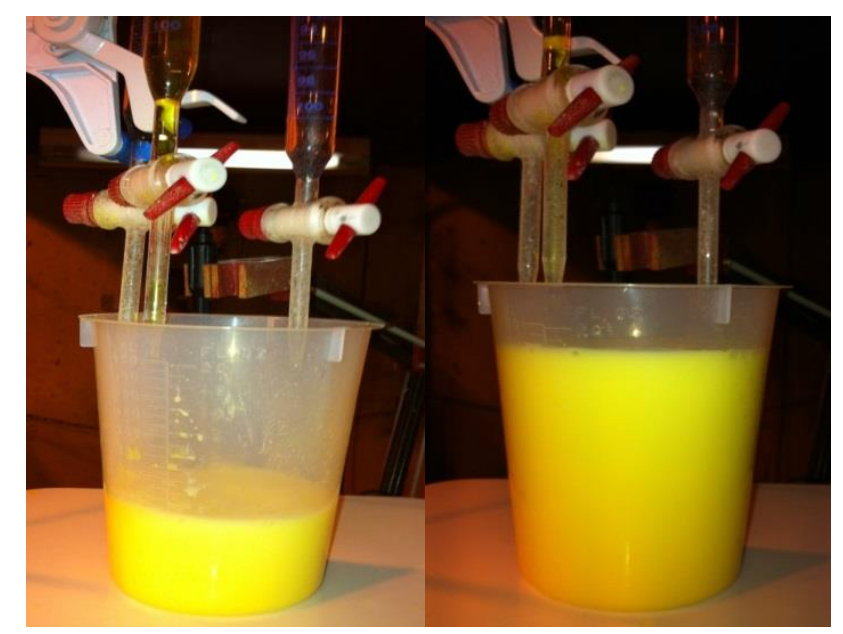

Figure 4.41 - Fifth Test Series, Batch 1, $\mathrm{UO}_{4}$ precipitation.

The mixture was stirred overnight, then put into a graduated cylinder for a settling test. The data from the settling test is shown in Table 4.17. 
Table 4.17 - Fifth Test Series, Batch 1, $\mathrm{UO}_{4}$ Settling

\begin{tabular}{|c|c|c|}
\hline Time $(\mathrm{min})$ & Supernate Volume $(\mathrm{mL})$ & Slurry Volume $(\mathrm{mL})$ \\
\hline 0 & 0 & 550 \\
\hline 10 & 180 & 370 \\
\hline 20 & 235 & 315 \\
\hline 30 & 305 & 245 \\
\hline 40 & 365 & 185 \\
\hline 50 & 400 & 150 \\
\hline 60 & 425 & 125 \\
\hline 80 & 450 & 100 \\
\hline 100 & 455 & 95 \\
\hline 120 & 455 & $95(17.2 \%$ of total volume $)$ \\
\hline
\end{tabular}

The mixture was then filtered, and the filter cake was scraped into a container for air drying. The filtrate was put into a storage bottle.

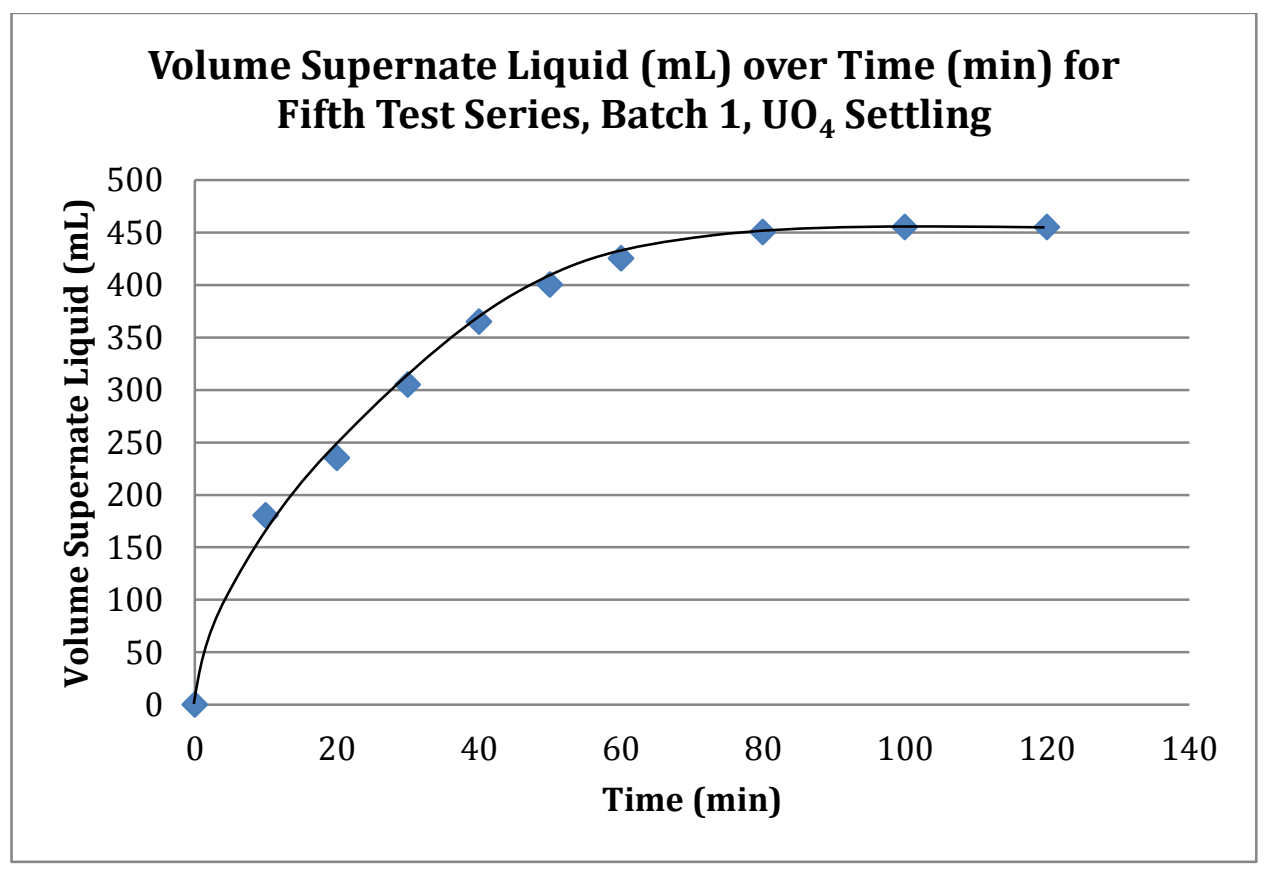

Figure 4.42 - Graph of Volume Supernate Liquid (mL) over Time (min) for Fifth Test Series, Batch 1, $\mathrm{UO}_{4}$ Settling 


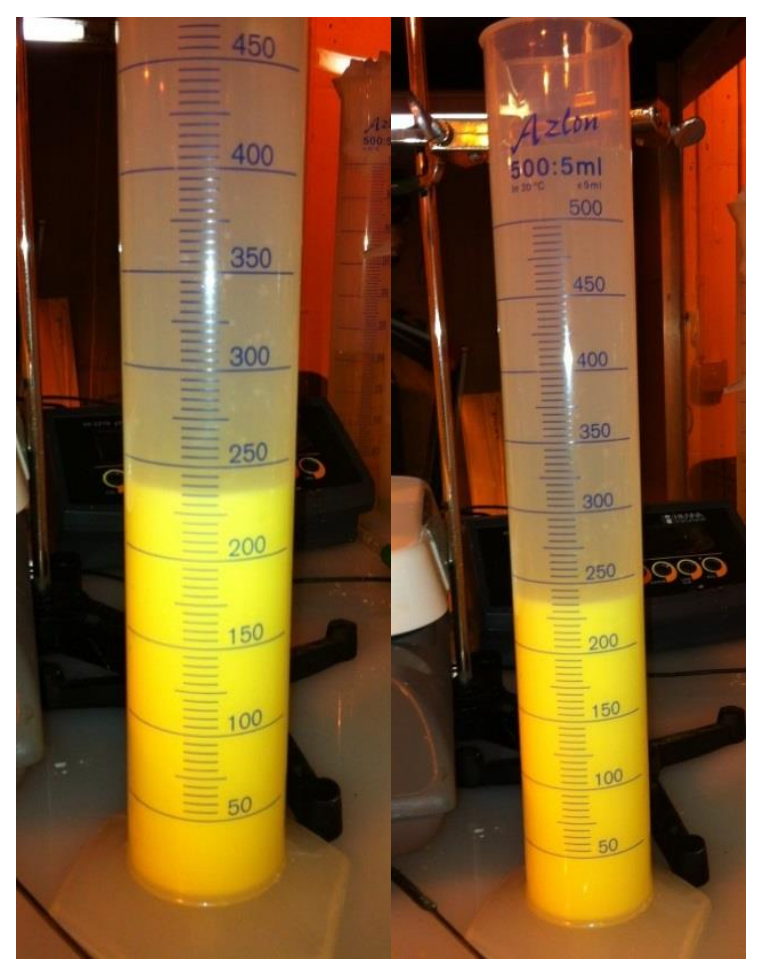

Figure 4.43 - Fifth Test Series, Batch 1, $\mathrm{UO}_{4}$ settling.

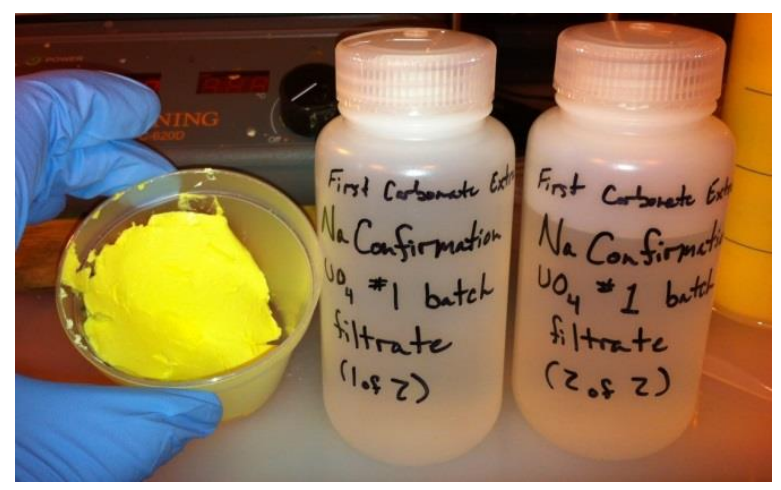

Figure 4.44 - Fifth Test Series, Batch 1, $\mathrm{UO}_{4}$ filter cake (left) and filtrate (right).

\section{Batch 2}

The peroxide precipitation technique was the same as Batch 1 and the data is in Table 4.18. 
Table 4.18 - Fifth Test Series, Batch 2, $\mathrm{UO}_{4}$ Precipitation

\begin{tabular}{|c|c|c|c|}
\hline Volume Carbonate $(\mathrm{mL})$ & Volume H2O2 $(\mathrm{mL})$ & Volume HNO3 $(\mathrm{mL})$ & $\mathrm{pH}$ \\
\hline 100 & 0 & 0 & 8.8 \\
\hline 100 & 0 & 10 & 6.0 \\
\hline 100 & 0 & 12 & 3.5 \\
\hline 200 & 26 & 26 & 3.5 \\
\hline 300 & 50 & 40 & 4.0 \\
\hline
\end{tabular}

The mixture was stirred for 1.5 hours and then poured into a graduated cylinder for a settling test. Table 4.19 shows the settling data.

Table 4.19 - Fifth Test Series, Batch 2, $\mathrm{UO}_{4}$ Settling

\begin{tabular}{|c|c|c|}
\hline Time (min) & Supernate Volume $(\mathrm{mL})$ & Slurry Volume $(\mathrm{mL})$ \\
\hline 0 & 0 & 360 \\
\hline 10 & 30 & 330 \\
\hline 30 & 100 & 260 \\
\hline 40 & 130 & 230 \\
\hline 50 & 160 & 200 \\
\hline 60 & 190 & 170 \\
\hline 80 & 230 & 130 \\
\hline 100 & 265 & 95 \\
\hline 120 & 265 & 95 \\
\hline
\end{tabular}




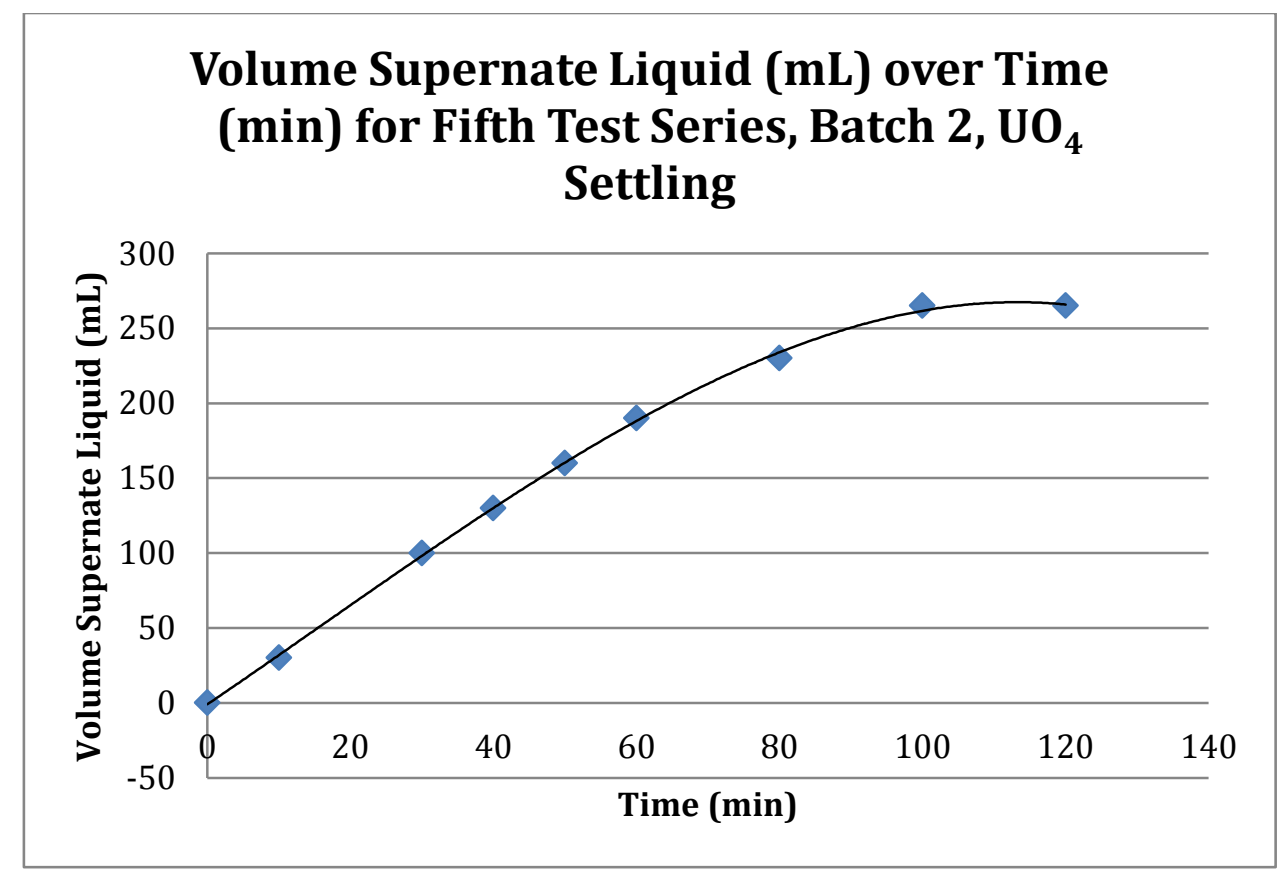

Figure 4.45 - Graph of Volume of Supernate Liquid (mL) over Time (min) for Fifth Test Series, Batch 2, $\mathrm{UO}_{4}$ Settling

The mixture was then filtered, and the filter cake was scraped into a container for air drying. The filtrate was put into a storage bottle.

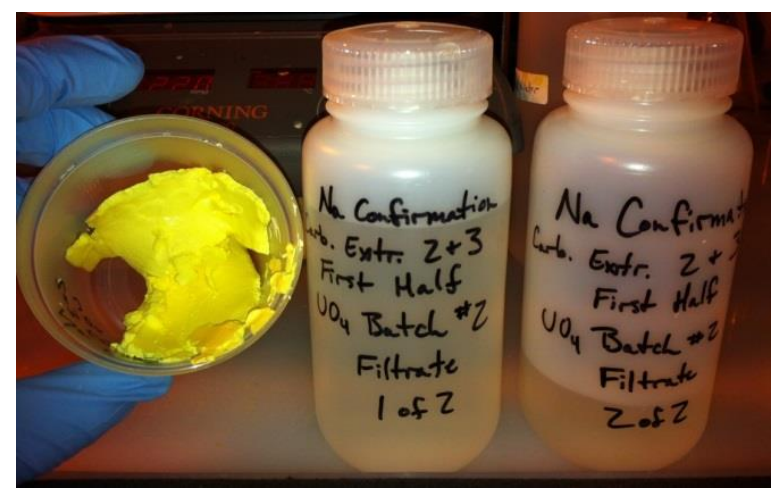

Figure 4.46 - Fifth Test Series, Batch 2, $\mathrm{UO}_{4}$ filter cake (left) and filtrate (right). 
Batch 3

Peroxide precipitation technique was the same as Batches 1 and 2, and the data is in Table 4.20.

Table 4.20 - Fifth Test Series, Batch 3, $\mathrm{UO}_{4}$ Precipitation

\begin{tabular}{|c|c|c|c|}
\hline Volume Carbonate $(\mathrm{mL})$ & Volume $\mathrm{H}_{2} \mathrm{O}_{2}(\mathrm{~mL})$ & Volume $\mathrm{HNO}_{3}(\mathrm{~mL})$ & $\mathrm{pH}$ \\
\hline 100 & 0 & 0 & 8.0 \\
\hline 100 & 0 & 11 & 3.0 \\
\hline 200 & 28 & 26 & 3.5 \\
\hline 221 & 34 & 29 & 4.0 \\
\hline
\end{tabular}

The mixture was stirred overnight then poured into a graduated cylinder for a settling test. Table 4.21 below shows the settling data.

Table 4.21 - Fifth Test Series, Batch 3, $\mathrm{UO}_{4}$ Settling

\begin{tabular}{|c|c|c|}
\hline Time (min) & Supernate Volume $(\mathrm{mL})$ & Slurry Volume $(\mathrm{mL})$ \\
\hline 0 & 0 & 253 \\
\hline 10 & 43 & 210 \\
\hline 20 & 88 & 165 \\
\hline 30 & 126 & 127 \\
\hline 40 & 163 & 90 \\
\hline 50 & 178 & 75 \\
\hline 60 & 183 & 70 \\
\hline 80 & 183 & 70 \\
\hline 100 & 183 & 70 \\
\hline \multirow{2}{*}{120} & 183 & $70(27.7 \%$ of total \\
& & volume $)$ \\
\hline
\end{tabular}




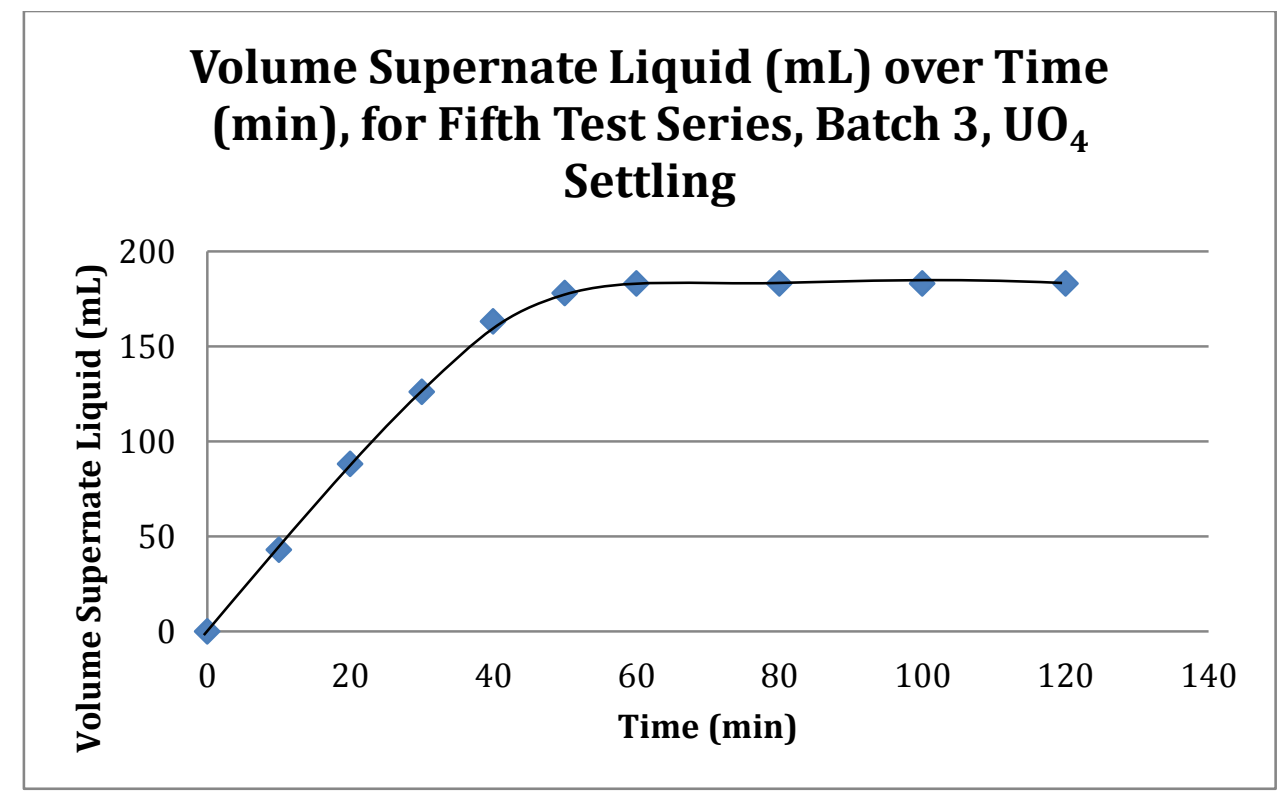

Figure 4.47 - Graph of Volume of Supernate Liquid (mL) over Time (min) for Fifth Test Series, Batch 3, $\mathrm{UO}_{4}$ Settling

The mixture was then filtered, and the filter cake was scraped into a container for air drying. The filtrate was put into a storage bottle.

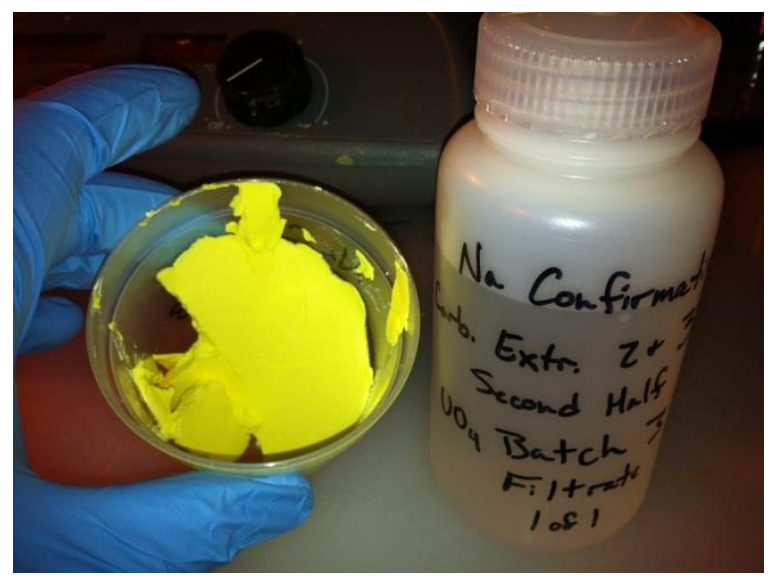

Figure 4.48 - Fifth Test Series, Batch 3, $\mathrm{UO}_{4}$ filter cake (left) and filtrate (right). 


\section{Removal of Fluoride Using a Calcite Bed}

The sodium fluoride $(\mathrm{NaF})$ solution recovered from the filtration of the Series

Five SDU slurry was heated to $70^{\circ} \mathrm{C}$ and percolated through a $2.54 \mathrm{~cm}$ diameter column, partially filled with a $0.04 \mathrm{~cm}$ sized granular calcite $\left(\mathrm{CaCO}_{3}\right)$, in order to test the ability of the calcite to capture the fluoride and remove it from the solution.

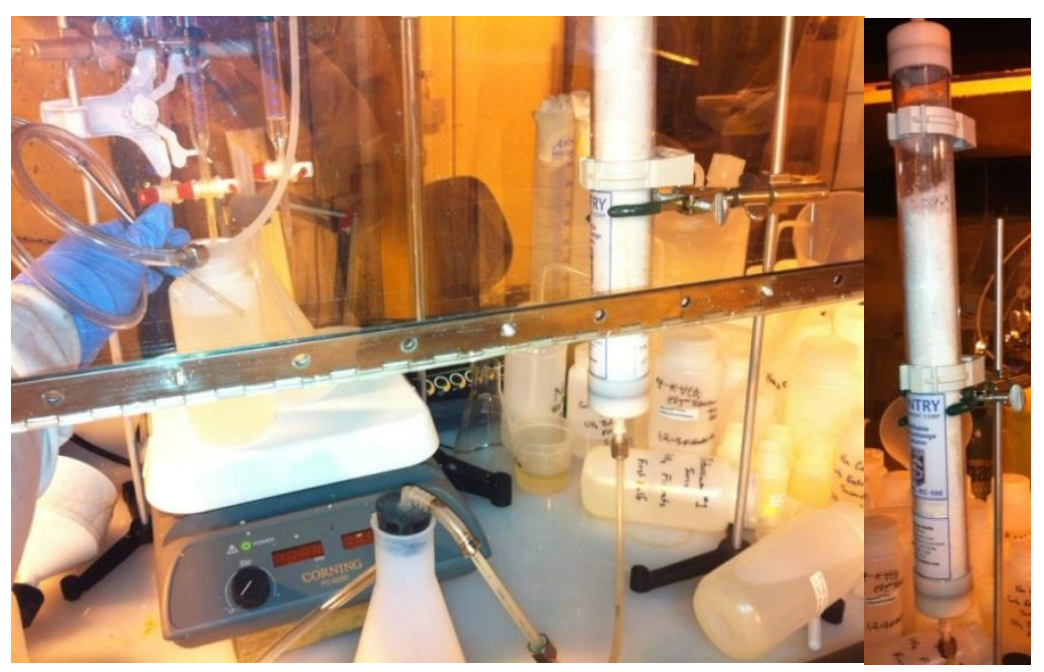

Figure 4.49 - Calcite column apparatus.

The reaction involved was the formation of $\mathrm{CaF}_{2}$ within the calcite crystal structure via the reaction given in Eqn. 3.6 and reiterated below.

$$
2 \mathrm{NaF}+\mathrm{CaCO}_{3} \rightarrow \mathrm{CaF}_{2}+\mathrm{Na}_{2} \mathrm{CO}_{3}
$$

Literature information indicated it was necessary to lower the $\mathrm{pH}$ of the solution from the original $\mathrm{pH}$ of 11 to about 6 or less, in order for the reaction to proceed. Early expectations were that a single pass of the solution through the calcite bed would remove 
nearly all the fluoride. The actual testing, however, showed this was not the case because, as the reaction progressed, the $\mathrm{Na}_{2} \mathrm{CO}_{3}$ produced quickly raised the $\mathrm{pH}$ back up to 11 and stopped the reaction long before all the fluoride was captured. To counter that situation, a technique was developed to collect the solution after each pass and re-acidify it back to below pH 6. A series of nine consecutive passes were performed using this technique, generating the following data:

Table 4.22 - pH Change with Each Pass through Calcite Column

\begin{tabular}{|c|c|c|c|}
\hline Pass Number & $\begin{array}{c}\text { Volume } 20 \% \mathrm{HNO}_{3} \\
\text { Added }(\mathrm{mL})\end{array}$ & $\mathrm{pH} \mathrm{In}$ & $\mathrm{pH}$ Out \\
\hline 1 & 37 & 5 & 11 \\
\hline 2 & 18 & 5 & 11 \\
\hline 3 & 12 & 5 & 10 \\
\hline 4 & 8 & 4 & 9 \\
\hline 5 & 2 & 5 & 8 \\
\hline 6 & 1.5 & 4 & 7 \\
\hline 7 & 1 & 3 & 6.75 \\
\hline 8 & 0.4 & 4 & 6.5 \\
\hline 9 & 0.2 & 5 & 6.5 \\
\hline
\end{tabular}

The data showed that after the seventh pass, the $\mathrm{pH}$ was stabilizing, indicating that nearly all the fluoride had reacted. The slight $\mathrm{pH}$ movement on pass 8 and 9 were likely a reaction of the acid present with the calcite itself rather than the formation of $\mathrm{Na}_{2} \mathrm{CO}_{3}$. Confirming fluoride analyses on samples of solution from each pass were not available due to a lack of analytical means for that element. The samples were saved for later analysis, if needed. Figure 4.49 displays a graph of the data. 


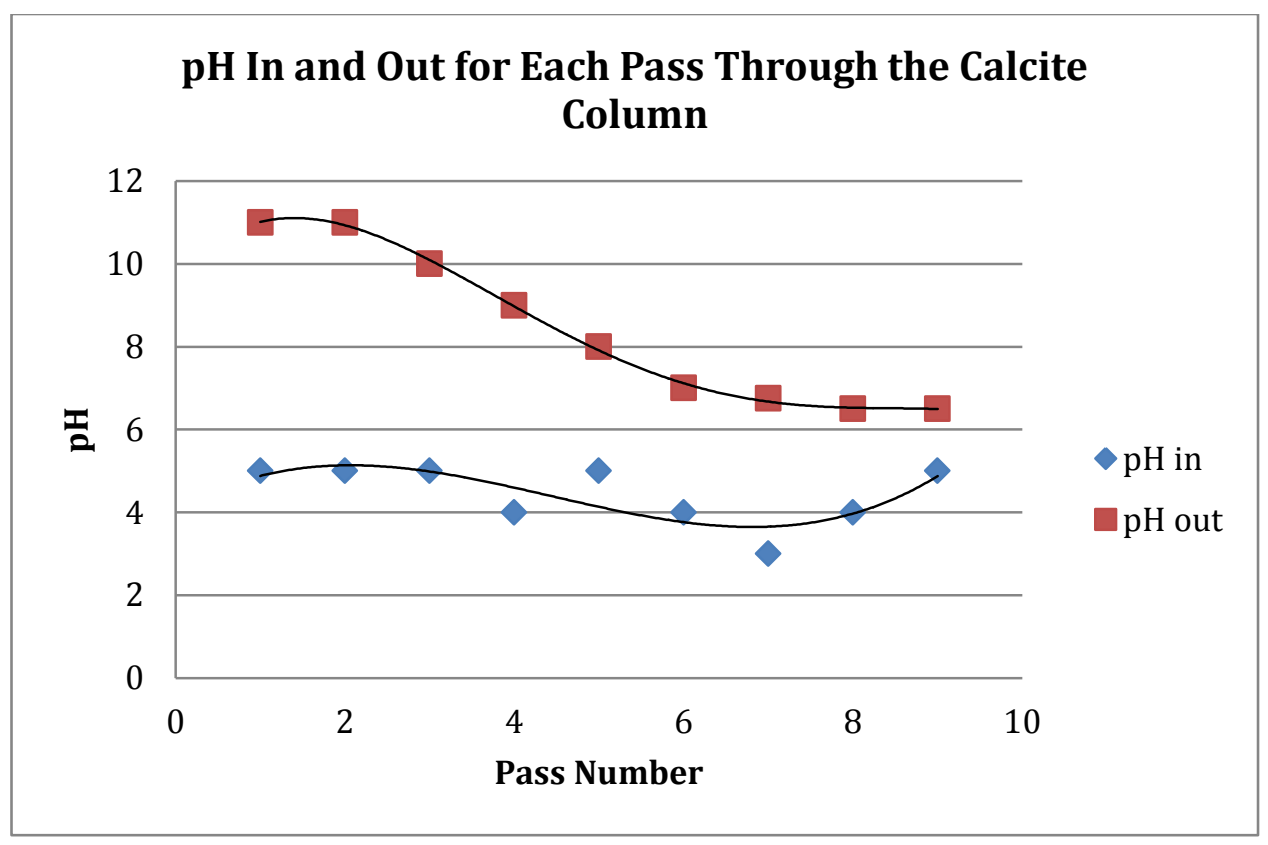

Figure 4.50 - Graph of $\mathrm{pH}$ In and $\mathrm{pH}$ Out for each pass through the calcite column.

\section{$\mathrm{UO}_{4}$ and Filtrate Analysis}

The $\mathrm{UO}_{4} \cdot \mathrm{nH}_{2} \mathrm{O}$ product collected from each portion of the precipitation test was first air dried at room temperature, then weighed on an analytical balance in order to project a material balance for each series of experiments. Preliminary calculations using the air-dried weights, however, gave uranium recoveries in excess of $100 \%$ so an add-on drying procedure was implemented in an attempt to remove as much excess water as possible. Each batch of filter cake was re-dried at $180^{\circ} \mathrm{C}$ for 1.5 hours then cooled and re-weighed. The results were then compared with the stoichiometric prediction from the precise weight of the starting feed material. The results are shown in Table 4.23 below. Note that the starting material $\mathrm{UO}_{2} \mathrm{~F}_{2}$ actual weight was decreased by the known $3 \%$ of $\mathrm{FeF}_{3}$ that was added to simulate cylinder wash solution. 
Table 4.23 - Mass $\mathrm{UO}_{4} \cdot \mathrm{nH}_{2} \mathrm{O}$ from Each Series

\begin{tabular}{|l|c|c|c|c|}
\hline Series Number & Net wt. $(\mathrm{g})$ & $\mathrm{UO}_{2} \mathrm{~F}_{2}$ wt. $(\mathrm{g})$ & $\begin{array}{c}\mathrm{UO}_{4} \text { predicted } \\
(\mathrm{g})\end{array}$ & $\begin{array}{c}\mathrm{UO}_{4} \cdot \mathrm{nH}_{2} \mathrm{O} \\
\text { actual }(\mathrm{g})\end{array}$ \\
\hline 1 (“Aux”) & 15.8142 & 15.3398 & 15.9375 & 16.4086 \\
\hline 2 (Combined) & 50.2060 & 48.6998 & 50.5972 & 50.9737 \\
\hline 5 (Confirm) & 50.0920 & 48.5892 & 50.4823 & 52.1118 \\
\hline
\end{tabular}

The results showed consistently more recovery than what was predicted from stoichiometric calculations indicating that there was likely still some water trapped in the matrix of the material.

To better evaluate the uranium recovery, samples of $\mathrm{UO}_{4} \cdot \mathrm{nH} 2 \mathrm{O}$ were taken from the second and fifth test series and were dried to remove the water from the $\mathrm{UO}_{4}$. This was done using a Netzsch TG 409 CD thermobalance. The initial mass was taken for a sample, it was loaded into the machine, and it was dried in an argon environment at 420$450^{\circ} \mathrm{C}$, for $2-3$ hours. After drying, the mass of each sample was taken to determine the percentage of mass lost, and this data was used to determine the amount of uranium recovered.

First, the mass of $\mathrm{UO}_{2} \mathrm{~F}_{2}$ powder, dosed with $3 \mathrm{wt} \% \mathrm{FeF}_{3}$, was corrected for just the $\mathrm{UO}_{2} \mathrm{~F}_{2}$ mass. This was then multiplied by the mass fraction of $\mathrm{U}$ in $\mathrm{UO}_{2} \mathrm{~F}_{2}$, to obtain the initial mass of uranium present in each series. This data is shown in Table 4.24.

Table 4.24 - Mass of Uranium before Recovery Process

\begin{tabular}{|c|c|c|c|}
\hline Series Number & Mass $\mathrm{UO}_{2} \mathrm{~F}_{2}(\mathrm{~g})$ & $\begin{array}{c}\text { Mass Fraction U in } \\
\mathrm{UO}_{2} \mathrm{~F}_{2}\end{array}$ & $\begin{array}{c}\text { Initial Mass U } \\
(\mathrm{g})\end{array}$ \\
\hline 1 & 15.3398 & 0.772727 & 11.8535 \\
\hline 2 & 48.6998 & 0.772727 & 37.6317 \\
\hline 5 & 48.5892 & 0.772727 & 37.5462 \\
\hline
\end{tabular}


Next, a small sample of $\mathrm{UO}_{4} \cdot \mathrm{nH}_{2} \mathrm{O}$ was taken from each series, and was dried in the thermobalance, which recorded the change in mass over time, while the drying took place. This allowed for a mass reduction percentage to be calculated, as seen in Table 4.25 .

Table 4.25 - Drying Data

\begin{tabular}{|c|c|c|c|c|c|}
\hline $\begin{array}{c}\text { Series } \\
\text { Number }\end{array}$ & $\begin{array}{c}\text { Initial Mass } \\
\mathrm{UO}_{4}(\mathrm{~g})\end{array}$ & $\begin{array}{c}\text { Drying } \\
\text { Temp }\left({ }^{\circ} \mathrm{C}\right)\end{array}$ & $\begin{array}{c}\text { Time Dried } \\
(\text { minutes })\end{array}$ & $\begin{array}{c}\text { Mass UO } \\
\text { After Drying } \\
(\mathrm{g})\end{array}$ & $\begin{array}{c}\% \\
\text { Reduction } \\
\text { in Mass }\end{array}$ \\
\hline 2 & 1.0364 & 420 & 120 & 0.7941 & 23.3790 \\
\hline 5 & 1.1681 & 450 & 180 & 0.9029 & 22.7035 \\
\hline
\end{tabular}

The mass reduction percentage of each sample was extrapolated to the entire mass of $\mathrm{UO}_{4} \cdot \mathrm{nH}_{2} \mathrm{O}$ for its respective series, in order to calculate the final mass of $\mathrm{UO}_{4}$ from the series. The mass fraction of $\mathrm{U}$ in $\mathrm{UO}_{4}$ was calculated and the mass of $\mathrm{UO}_{4}$ was multiplied by this fraction to determine the mass of uranium recovered from the process, for each series. This was then used to determine the percentage of uranium recovered in each series. This data can be seen in Table 4.26

Table 4.26 - Mass of Uranium Recovered

\begin{tabular}{|c|c|c|c|c|c|c|}
\hline $\begin{array}{c}\text { Series } \\
\text { Number }\end{array}$ & $\begin{array}{c}\text { Mass } \\
\mathrm{UO}_{4} \cdot \mathrm{nH}_{2} \mathrm{O} \\
(\mathrm{g})\end{array}$ & $\begin{array}{c}\text { Mass } \\
\text { Reduction } \\
\text { Fraction } \\
\text { During } \\
\text { Drying }\end{array}$ & $\begin{array}{c}\text { Mass } \\
\mathrm{UO}_{4}(\mathrm{~g})\end{array}$ & $\begin{array}{c}\text { Mass } \\
\text { Fraction } \\
\mathrm{U} \text { in } \mathrm{UO}_{4}\end{array}$ & $\begin{array}{c}\text { Mass U } \\
\text { Recovered } \\
(\mathrm{g})\end{array}$ & $\begin{array}{c}\% \\
\text { Uranium } \\
\text { Recovered }\end{array}$ \\
\hline 2 & 50.9737 & 0.766210 & 39.0566 & 0.788079 & 30.7797 & 81.7919 \\
\hline 5 & 52.1118 & 0.772965 & 40.2806 & 0.788079 & 31.7443 & 84.5473 \\
\hline
\end{tabular}


A sample of the $\mathrm{UO}_{4}$ produced by the first test series auxiliary testing was calcined using the same Netzsch TG 409 CD thermobalance, to see if different results were obtained. It was ground with a mortar and pestle to maximize the reaction surface area, and was then loaded into the thermobalance and calcined at $1000^{\circ} \mathrm{C}$, for 6 hours, in air, to convert it to $\mathrm{U}_{3} \mathrm{O}_{8}$. The same mass analysis was performed to determine how much uranium was recovered. This data is shown in Tables 4.24, 4.27, and 4.28.

Table 4.27 - Calcining Data

\begin{tabular}{|c|c|c|c|}
\hline $\begin{array}{c}\text { Series } \\
\text { Number }\end{array}$ & $\begin{array}{c}\text { Initial Mass } \\
\mathrm{UO}_{4}(\mathrm{~g})\end{array}$ & $\begin{array}{c}\text { Mass } \mathrm{U}_{3} \mathrm{O}_{8} \text { After } \\
\text { Calcining }(\mathrm{g})\end{array}$ & $\begin{array}{c}\text { \% Reduction } \\
\text { in Mass }\end{array}$ \\
\hline 1 & 0.56577 & 0.40813 & 27.8629 \\
\hline
\end{tabular}

Table 4.28 - Mass of Uranium Recovered through Calcination

\begin{tabular}{|c|c|c|c|c|c|c|}
\hline $\begin{array}{c}\text { Series } \\
\text { Number }\end{array}$ & $\begin{array}{c}\text { Mass } \\
\mathrm{UO}_{4} \cdot \mathrm{nH}_{2} \mathrm{O} \\
(\mathrm{g})\end{array}$ & $\begin{array}{c}\text { Mass } \\
\text { Reduction } \\
\text { Fraction } \\
\text { During } \\
\text { Calcination }\end{array}$ & $\begin{array}{c}\text { Total } \\
\text { Mass } \\
\mathrm{U}_{3} \mathrm{O}_{8} \\
(\mathrm{~g})\end{array}$ & $\begin{array}{c}\text { Mass } \\
\text { Fraction } \\
\mathrm{U} \text { in } \mathrm{U}_{3} \mathrm{O}_{8}\end{array}$ & $\begin{array}{c}\text { Mass U } \\
\text { Recovered } \\
\text { (g) }\end{array}$ & $\begin{array}{c}\% \\
\text { Uranium } \\
\text { Recovered }\end{array}$ \\
\hline 1 & 16.4086 & 0.721371 & 11.8367 & 0.847981 & 10.0373 & 84.6780 \\
\hline
\end{tabular}

The calcining did not show any significant change in results from the drying. Therefore, this testing suggested that $81-85 \%$ of the initial uranium was recovered as uranyl peroxide through the modified process.

Liquid filtrates from both the $\mathrm{SDU}$ and $\mathrm{UO}_{4}$ filtrations were also analyzed to determine how much residual uranium was left behind during precipitation and filtration. These samples were analyzed by Dr. Elizabeth Bair and the Center for Elemental Mass Spectrometry at the University of South Carolina, using a Thermo Scientific Element II 
high-resolution inductively coupled plasma mass spectrometer (ICP-MS). Data from the ICP-MS analysis shows that a very high uranium recovery was experienced for the SDU and $\mathrm{UO}_{4}$ precipitations. Table 4.29 shows this data.

Table 4.29 - Residual Uranium Content in $\mathrm{SDU}$ and $\mathrm{UO}_{4}$ Filtrates

\begin{tabular}{|l|c|c|}
\hline Series Number & $\begin{array}{c}\text { SDU Filtrate Uranium } \\
\text { Content (ppm) }\end{array}$ & $\begin{array}{c}\mathrm{UO}_{4} \text { Filtrate Uranium } \\
\text { Content (ppm) }\end{array}$ \\
\hline 1 (“Aux") & 19.6 & 25.0 \\
\hline 2 (Combined) & 16.2 & 6.3 \\
\hline 5 (Confirm) & 3.6 & 19.6 (avg. of 2 filtrations) \\
\hline
\end{tabular}

Uranium recovery from both the SDU precipitation step and the uranyl peroxide precipitation step were nearly complete as indicated by the filtrate uranium measurements after the mixtures were filtered. However, the drying and calcination data shows that only about $81-85 \%$ of the uranium was carried through the entire process from the wash solution to the $\mathrm{UO}_{4}$ product. This was a significant amount of loss, that had to be accounted for somewhere in the process other than the precipitation steps.

First, a detailed isotopic analysis of the $\mathrm{UO}_{2} \mathrm{~F}_{2}$ powder, dosed with $3 \mathrm{wt} \% \mathrm{FeF}_{3}$, was never obtained, so the purity of the material could not be determined. This fact likely accounts for the majority of the recovery discrepancy. Also, during experimentation, the uranium precipitates tended to be very sticky and would adhere to gloves, instruments, and the sides of the beakers and graduated cylinders, resulting in mass lost from the system throughout the procedure. The removal of $\mathrm{Fe}(\mathrm{OH})_{3}$ during the process lead to a bit of uranium loss from the system. For example, during the second test series, a small amount of uranium was lost during the attempted partial precipitation 
of $\mathrm{Fe}(\mathrm{OH})_{3}$, prior to SDU precipitation, and in the fifth series some losses occurred when filtering out the $\mathrm{Fe}(\mathrm{OH})_{3}$ precipitate after carbonate extraction. Error could also appear through the fact that small samples of each $\mathrm{UO}_{4}$ batch were taken for drying and calcination, which data may not be wholly applicable to the entire batch.

The $\mathrm{UO}_{4} \cdot \mathrm{nH}_{2} \mathrm{O}$ product was also analyzed via ICP Mass Spectrometry for sodium and iron content, and was found to have much less than ASTM limits for both elements, verifying a very high purity for the material. Maximum limits in ASTM C1348 for mixed oxides are 20 ppm Na and 150 ppm Fe. Table 4.30 below shows that data.

Table 4.30 - Sodium and Iron Contaminant Concentrations in $\mathrm{UO}_{4}$ Product

\begin{tabular}{|l|c|c|}
\hline Series Number & Product Na $(\mathrm{ppm})$ & Product Fe $(\mathrm{ppm})$ \\
\hline 1 (“Aux”) & 1.5 & 0.002 \\
\hline 2 (Sample A) & 0.4 & 0.002 \\
\hline 2 (Sample B) & 0.7 & 0.004 \\
\hline 5 (Sample A) & 1.1 & 0.004 \\
\hline 5 (Sample B) & 0.7 & 0.006 \\
\hline 5 (Sample C) & 0.2 & 0.007 \\
\hline
\end{tabular}

These impurity results are much less than the ASTM nuclear grade standards of $20 \mathrm{ppm}$ for $\mathrm{Na}$ maximum and $150 \mathrm{ppm}$ maximum for Fe and are conclusive evidence of the uranium-selective capability of the peroxide precipitation process. 


\section{CHAPTER 5: CONCLUSIONS}

During the first, second, and fifth test series, it was observed that precipitation of sodium diuranate (SDU) was very nearly complete at a $\mathrm{pH}$ of 11-12, using room temperature conditions. ICP-MS analysis of the NaF solution filtered from the SDU showed that residual uranium levels ranged from $3.6-19.6 \mathrm{ppm}$, meaning almost complete precipitation of the uranium as SDU. It was postulated that a tailing reaction occurs during SDU precipitation, which necessitates a digestion period of about 2 hours to complete the precipitation, this was verified during experimentation. Further, it was shown in the second test series that a partial precipitation step to precipitate $\mathrm{Fe}(\mathrm{OH})_{3}$ at $\mathrm{pH} 5.5$ did not adequately separate iron contamination due to an overlap of uranium and iron precipitations at that condition.

Carbonate extraction of the uranium from the SDU required an extended (3-4 hours) digestion at $40^{\circ} \mathrm{C}$ and $\mathrm{pH} 7-8$ to complete. Sodium bicarbonate was found to be

the preferred extractant because of its lower $\mathrm{pH}$, which helped drop the $\mathrm{pH}$ of the reaction solution and allow for continued uranyl carbonate formation. During the second and fifth test series, the carbonate extraction was proven to successfully separate the iron contamination from the uranium, since the iron remained in solid precipitate form after the uranium had been converted into a liquid uranyl carbonate solution.

Potassium-based chemistry did produce a potassium diuranate (KDU) analogue to SDU, but the subsequent carbonate extraction using either potassium bicarbonate or 
potassium carbonate could not be completed fully. More research will need to be done to find out exactly why this reaction did not work, but the potassium carbonate and bicarbonate simply could not strip the uranium from the KDU and form a uranyl carbonate complex solution. The potassium testing was terminated at this step.

The uranyl peroxide precipitation was found to operate best at $\mathrm{pH} 3.5-4.0$, at room temperature, and required an extended digestion period of $8-10$ hours. The reaction was nearly complete at those conditions, and ICP-MS analysis showed a filtrate residual ranging from 2.4 to $36.8 \mathrm{ppmU}$, with an average of $17.625 \mathrm{ppmU}$. The uranyl peroxide itself was very pure, with impurity averages at a very low $0.8 \mathrm{ppmNa}$ and 0.004 ppmFe. ASTM maximum levels are $20 \mathrm{ppmNa}$ and $150 \mathrm{ppmFe}$, so the uranyl peroxide produced met and exceeded those standards, and could be reintroduced to the nuclear fuel cycle if all other standards were met, as they were assumed to be throughout experimentation. Drying and calcination of the $\mathrm{UO}_{4} \cdot \mathrm{nH}_{2} \mathrm{O}$ showed that $81-85 \%$ of the uranium present in the simulated wash solution was recovered by the process.

Fluoride removal from the $\mathrm{NaF}$ solution that was a product of the SDU precipitation step required multiple passes of the solution through a calcite bed. Each pass required acid addition to adjust the $\mathrm{pH}$ back down to below 6 and heating to $70^{\circ} \mathrm{C}$ before each pass to allow the removal reaction to proceed. This result was a modification of a single pass technique that was initially hypothesized and attempted due to the apparent shutdown of the $\mathrm{NaF} /$ calcite reaction at a $\mathrm{pH}$ above about 10 .

Conclusions drawn from the testing were that the results demonstrated a workable and effective series of processing steps. The process successfully removes the uranium and iron from cylinder wash solution through a co-precipitation of $\mathrm{SDU}$ and $\mathrm{Fe}(\mathrm{OH})_{3}$. It 
then separates out the iron contaminants during uranyl carbonate extraction with sodium bicarbonate. Highly pure, solid uranyl peroxide can be precipitated from the uranyl carbonate complex solution, nearly completely recovering the initial amount of uranium. Techniques developed from the tests will make uranium recovery viable when transferred to a commercial process design. 


\section{REFERENCES}

1. "Uranium hexafluoride" Wikipedia: The Free Encyclopedia. Wikipedia, n.d. Web. Accessed 31 Oct. 2013. 〈http://en.wikipedia.org/wiki/Uranium_hexafluoride>

2. Figure from "Depleted $\mathrm{UF}_{6}$ Production and Handling Slide Presentation, Slide 22: $\mathrm{UF}_{6}$ Phase Diagram." Depleted UF 6 Management Information Network. Argonne National Laboratory (for the U.S. DOE Office of Environmental Management). Web. Accessed 31 Oct. 2013. <web.ead.anl.gov/uranium/guide/prodhand/sld022.cfm>

3. "Uranium Hexafluoride (UF6)." URENCO. URENCO Limited, n.d. Web. 31 Oct. 2013. <http://www.urenco.com/page/58/Uranium-Hexafluoride-UF6.aspx>

4. Figure from "Depleted $\mathrm{UF}_{6}$ Production and Handling Slide Presentation, Slide 19: $\mathrm{UF}_{6} . "$ Depleted UF 6 Management Information Network. Argonne National Laboratory (for the U.S. DOE Office of Environmental Management). Web. Accessed 31 Oct. 2013. <web.ead.anl.gov/uranium/guide/prodhand/sld019.cfm>

5. "Transport." URENCO. URENCO Limited, n.d. Web. Accessed 31 Oct. 2013. <http://www.urenco.com/page/21/Transport.aspx>

6. Packaging of Uranium Hexafluoride for Transport. ANSI Standard N14.1-2001 Table 1. Accessed 31 Oct. 2013. $<$ http://archive.org/stream/gov.law.ansi.n14.1.2001/ansi.n14.1.2001\#page/n13/mod e/2up>

7. Figure from "Uranium Hexafluoride (UF6) Monitoring Needs, Slide 1." Presentation by Eccleston, George, and Ed Wonder. Presented at NMMSS Users Group Meeting, Las Vegas, NV, 18 May 2010. <http://nnsa.energy.gov/sites/default/files/nnsa/inlinefiles/Monitoring_UF6_Cylind ers.ppt>

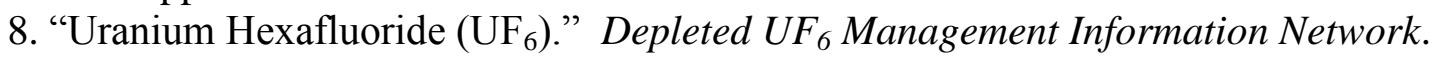
Argonne National Laboratory (for the U.S. DOE Office of Environmental Management). Web. Accessed 31 Oct. 2013. <http://web.ead.anl.gov/uranium/guide/uf6/>

9. OECD Nuclear Energy Agency. Uranium 2011: Resources, Production and Demand. OECD Nuclear Energy Agency, 2011. Online PDF Copy. < http://www.oecdnea.org/ndd/pubs/2012/7059-uranium-2011.pdf>

10. Eccleston, George, and Ed Wonder. "Uranium Hexafluoride (UF6) Monitoring Needs, Slide 6: Illustrative Worldwide Cylinder Numbers and Flows." Presented at NMMSS Users Group Meeting, Las Vegas, NV, 18 May 2010. <http://nnsa.energy.gov/sites/default/files/nnsa/inlinefiles/Monitoring_UF6_Cylind ers.ppt>

11. Packaging of Uranium Hexafluoride for Transport. ANSI Standard N14.1-2001, Section 6.3.2 "Periodic Inspections and Tests." Accessed 31 Oct. 2013. 
<http://archive.org/stream/gov.law.ansi.n14.1.2001/ansi.n14.1.2001\#page/n15/mod e/2up>

12. "Uranium hexafluoride (fissile, fissile excepted and non-fissile)." Title 49 Code of Federal Regulations, Pt. 173.420. 2013 ed.

13. Packaging of Uranium Hexafluoride for Transport. ANSI Standard N14.1-2001, Section 8.1.2 "Empty Cylinders." Accessed 31 Oct. 2013. <http://archive.org/stream/gov.law.ansi.n14.1.2001/ansi.n14.1.2001\#page/n43/mod e/2up>

14. Walters, Marten, Thomas Baroody, and Wes Berry. Technologies for Uranium Recovery from Phosphoric Acid. Presented at AIChE Central Florida Section 2008 Clearwater Convention. 7 June 2008. < http://www.aichecf.org/Clearwater/2008/Paper1/8.1.4.pdf >

15. "Depleted $\mathrm{UF}_{6}$ Production and Handling Slide Presentation, Slide 6: Conversion of Yellow Cake to UF 6 ." Depleted UF 6 Management Information Network. Argonne National Laboratory (for the U.S. DOE Office of Environmental Management).

Web. Accessed 31 Oct. 2013. <web.ead.anl.gov/uranium/guide/prodhand/sld006.cfm>

16. Hardwick, Thomas J. (1982). U.S. Patent No. 4,428,911. Washington, DC: U.S. Patent and Trademark Office.

17. Murty, B. Narasimha, et al. "Influence of temperature of precipitation on agglomeration and other powder characteristics of ammonium diuranate." Powder Technology 115 (2001): 167-183. Print.

18. Manna, Subhankar, Saswati B. Roy and Jyeshtharaj B. Joshi. "Study of crystallization and morphology of ammonium diuranate and uranium oxide." Journal of Nuclear Materials 424 (2012): 94-100. Print.

19. Bonini, A., et al. Nuclear Fuel Cycle Head-Enriched Uranium Purification and Conversion Into Metal. Presented at The 1998 International Reduced Enrichment for Test Reactor Conference, Sao Paulo, Brazil. 18-23 October 1998. Web. <http://www.rertr.anl.gov/Fuels98/Bonini.pdf>

20. Standard Specification for Blended Uranium Oxides with ${ }^{235} U$ Content of Less Than 5\% for Direct Hydrogen Reduction to Nuclear Grade Uranium Dioxide. ASTM C1348-01 (2008). Table 1.

21. "Overview of Chemicals Available to Treat AMD (Active)." LEO EnviroSci Inquiry. Lehigh Environmental Initiative at Lehigh University, n.d. Web. Accessed 8 Nov. 2013. 〈http://www.ei.lehigh.edu/envirosci/enviroissue/amd/links/chem1.html>

22. Slama, Elshafeea H. Y. Abow, Etemad Ebraheem, and Adam K. Sam. Precipitation and purification of uranium from rock phosphate. Sudan Atomic Energy Commission, n.d. Web. Accessed 8 Nov 2013. $<$ http://indico.cern.ch/getFile.py/access? contribId=189\&sessionId=3\&resId=0\&mat erialId=poster\& confId=117934>

23. Schnell, Henry. "The Trekkopje Project, Slide 25: MINI - SDU Precipitation." Presented at the IAEA Technical Meeting on Low Grade Uranium Ore. By Areva. 29-31 March, 2010. Web. Accessed 8 Nov. 2013 <http://www.iaea.org/OurWork/ST/NE/NEFW/documents/RawMaterials/TM_LGU O/4b_Sch.pdf> 
24. Ikeda, Atsushi, et al. "Comparative Study of Uranyl(VI) and -(V) Carbonato Complexes in an Aqueous Solution." Inorganic Chemistry 46 (2007): 4212-4219. Print.

25. Morais, C. A., et al. "Uranium stripping from tertiary amine by sulfuric acid solution and its precipitation as uranium peroxide." Minerals Engineering 18 (2005): 13311333. Print. 